\title{
ADSORÇÃO DE CÁDMIO EM LATOSSOLOS ÁCRICOS PAULISTAS
}

\author{
NIVEA MARIA PICCOLOMINI DIAS
}

Engenheira Agrônoma

Orientador: Prof. Dr. LUÍS REYNALDO FERRACCIÚ ALLEONI

Dissertação apresentada à Escola Superior de Agricultura "Luiz de Queiroz", Universidade de São Paulo, para obtenção do título de Mestre em Agronomia, Área de Concentração: Solos e Nutrição de Plantas.

PIRACICABA

Estado de São Paulo - Brasil

Dezembro - 1999 
Dados Internacionais de Catalogação na Publicação (CIP) DIVISÃo DE BIBLIOTECA E DOCUMENTAÇĀO - Campus "Luiz de Queiroz"/USP

Dias, Nivea Maria Piccolomini

Adsorção de cádmio em latossolos ácricos paulistas / Nivea Maria Piccolomini Dias. - Piracicaba, 1999.

$100 \mathrm{p}$.

Dissertação (mestrado) - - Escola Superior de Agricultura Luiz de Queiroz, 1999.

Bibliografia

1. Adsorção 2. Cádmio 3. Latossolo roxo 4. Quimica do solo 5. Terra roxa I. Título

CDD 631.44 


\section{ERRATA}

p. 19: Ítem 2.5: onde se lê " $\Delta \mathrm{G}_{\mathrm{o}}=$ energia livre ( $\mathrm{mol} / \mathrm{L}, \mathrm{R}=8,30 \mathrm{~J}$ oules $/ \mathrm{mol}$ " $\mathrm{K}$ ", leia-se " $\Delta \mathrm{G}_{\mathrm{o}}=$ energia livre $\left(\mathrm{J} \mathrm{mol}^{-1}\right), \mathrm{R}=8,30 \mathrm{~J} \mathrm{~mol}^{-1} \mathrm{~kg}^{-1}$ ".

p. 27: onde se lê "ClCs", leia-se "CsCl"

p.69: Figura 16. Eixo das ordenadas: onde se lê " $\left(\mathrm{J} \mathrm{mol} \mathrm{dm}^{-3}\right)$, leia-se $\left(\mathrm{J} \mathrm{mol}^{-1}\right)$. 
Aos meus pais, Irineu e Regina, pelo apoio, compreensão e lição de vida;

DEDICO

À Deus, pela minha vida, humildemente 


\section{AGRADECIMENTOS}

Ao Dr. Luís Reynaldo Ferracciú Alleoni, pela orientação, amizade, apoio e confiança;

Ao Dr. José Carlos Casagrande (Universidade Federal de São CarlosUFSCar-Araras) pelos incentivos, ensinamentos e por sempre ter acreditado em minha capacidade;

À Coordenação do Curso de Pós-Graduação em Solos e Nutrição de Plantas, pela oportunidade de realizar o curso;

À Fundação de Amparo à Pesquisa do Estado de São Paulo (FAPESP) pela concessão da Bolsa de estudo;

Aos pesquisadores do Instituto Agronômico de Campinas: Dr. Otávio A. de Camargo pelas sugestões e à Dra. Mônica F. de Abreu pelo auxílio na determinação do cádmio;

Aos professores da Universidade Federal de São Carlos- UFSCar- Araras: Maria Tereza M. R. Borges pela paciência por ter sido minha primeira orientadora e Norberto Lavorenti pelo auxílio nas análises estatísticas;

Aos funcionários do Departamento de Solos e Nutrição de Plantas, Márcia, Bete, Luciano, Flávia e Luís Silva pelo apoio técnico e amizade;

Às minhas amigas e irmãs, Glauce, Elaine, Audria, Cris, Luciana e Lú pelo apoio e carinho, e em especial aos meus amigos Marcelo, pelo auxílio nas análises estatísticas e à Soraia pela paciência e ajuda nos momentos difíceis;

A todos que direta ou indiretamente, contribuíram para a execução deste trabalho. 


\section{SUMÁRIO}

\section{Página}

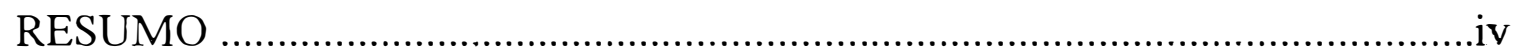

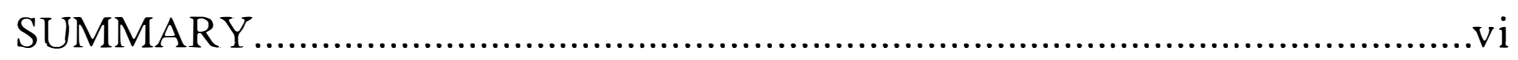

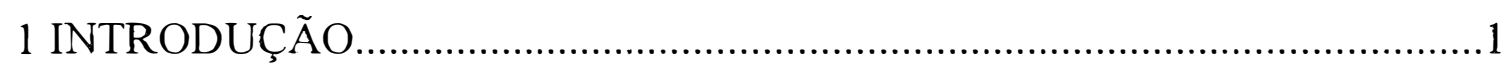

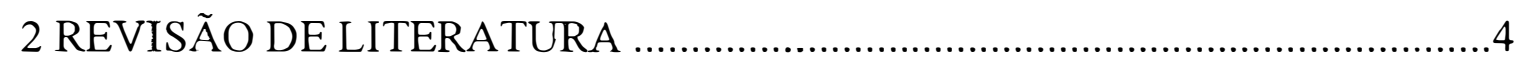

2.1 Geoquímica e formas de ocorrência do cádmio.............................................

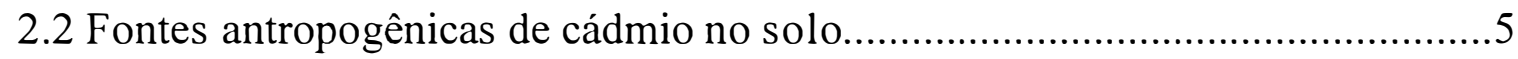

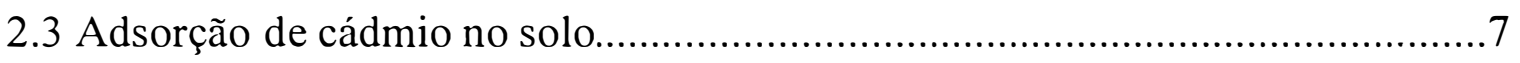

2.3.1 Adsorção de cádmio em óxidos e hidróxidos de $\mathrm{Fe}$ e $\mathrm{Al}$................................8

2.3.2 Efeito do pH na adsorção de cádmio..........................................................11

2.3.3 Influência da matéria orgânica sobre a adsorção de cádmio.........................15

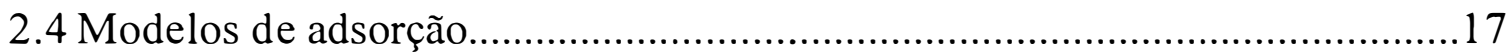

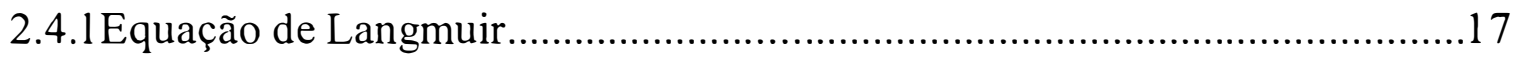

2.4.2 Equação de Freundlich.........................................................................18

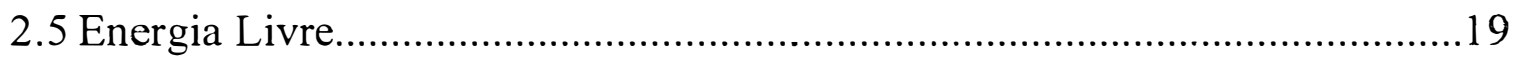

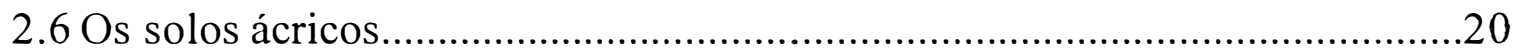

2.6.1 Atributos químicos, físicos e mineralógicos............................................21

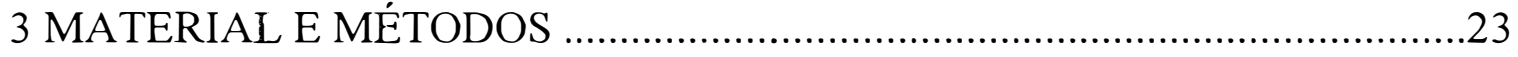

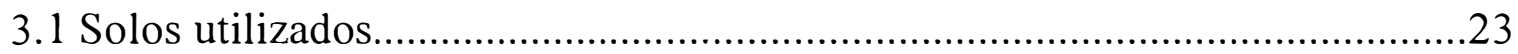

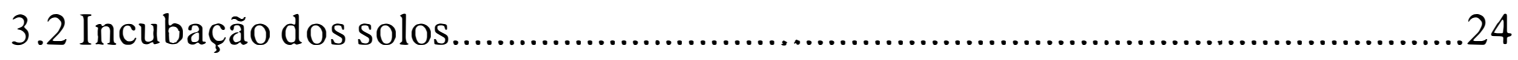

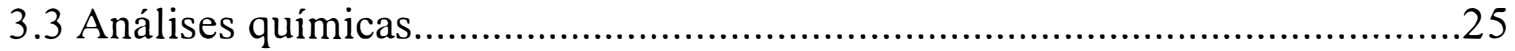

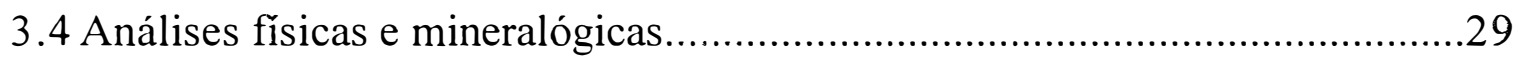

3.5 Adsorção de cádmio.................................................................................. 31

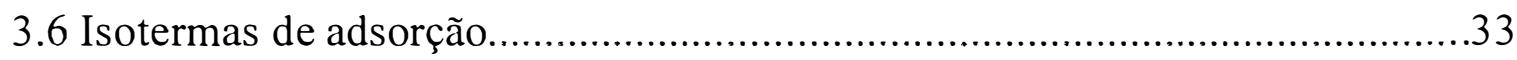

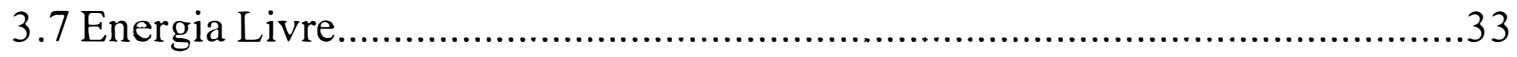




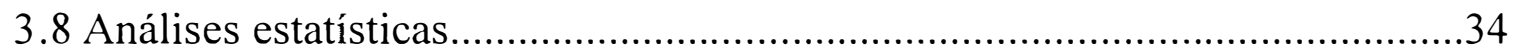

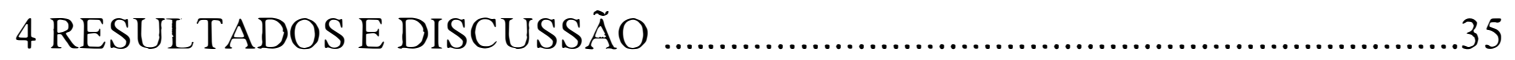

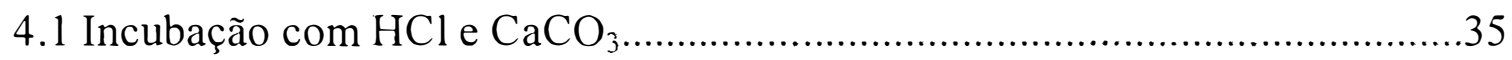

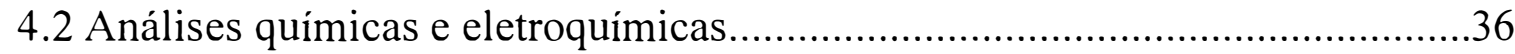

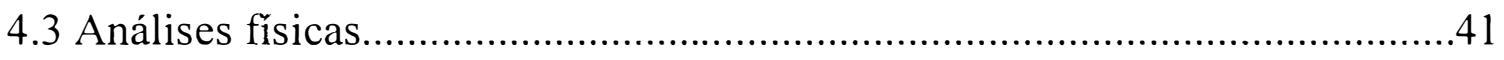

4.4 Análises mineralógica qualitativa e quantitativa..........................................42

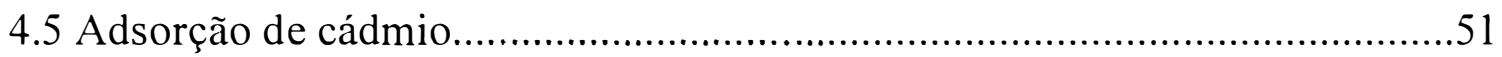

4.5.1 Efeito do pH na adsorção de cádmio.........................................................52

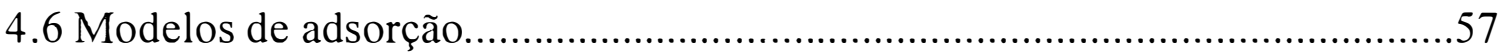

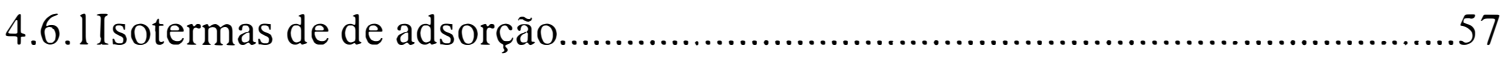

4.6.2 Os parâmetros de Langmuir e de Freundlich...........................................62

4.6.3 Correlações entre os parâmetros dos modelos de Langmuir e de Freundlich

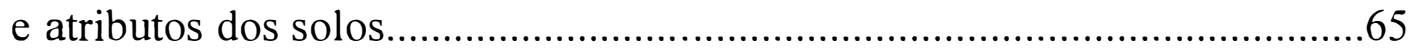

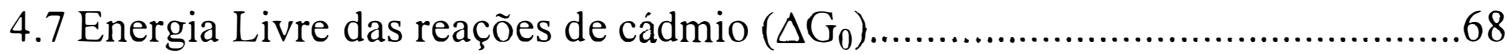

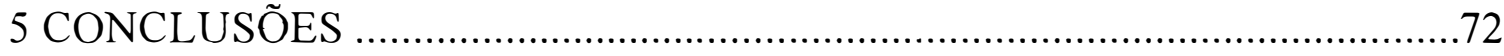

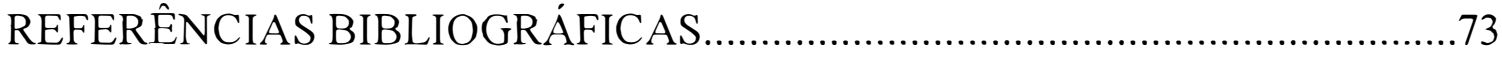

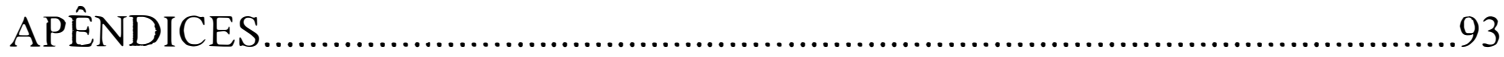

Al - Resultados de cádmio adsorvido e estimado pelas equações de Langmuir e de Freundlich, que originaram as isotermas de adsorção...............................94

A2 - Coeficientes de correlação simples entre os parâmetros das equações de Langmuir e de Freundlich e os atributos dos solos.....................................97

A3 - Coeficientes de correlação simples entre a CTC e alguns atributos dos

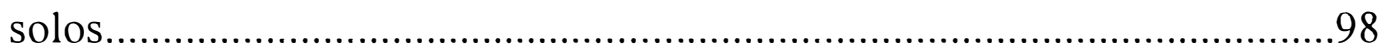

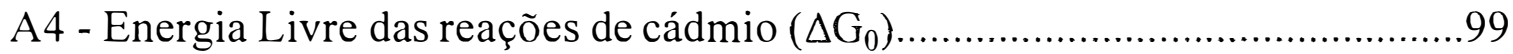

A5 - Quadro de análise de varância com aplicação do Teste $F$, obtido no estudo de Adsorção de cádmio.........................................................100 


\title{
ADSORÇÃO DE CÁDMIO EM LATOSSOLOS ÁCRICOS PAULISTAS
}

\author{
Autor: NIVEA MARIA PICCOLOMINI DIAS \\ Orientador: Prof. Dr. LUÍS REYNALDO FERRACCIÚ ALLEONI
}

\section{RESUMO}

O cádmio pode ser adicionado ao solo através de resíduos de pneus, óleos combustíveis, restos de metais fundidos com zinco, lixo urbano ou industrial, lodo de esgoto e fertilizantes fosfatados. Embora não seja essencial ao desenvolvimento vegetal, este metal é facilmente absorvido e translocado nas plantas e tem potencial de entrar na cadeia alimentar humana. A persistência e a mobilidade, conseqüentemente, a disponibilidade do cádmio é determinada pela extensão de adsorção pelas partículas do solo. Em vista disso, é importante determinar quais os atributos do solo, como $\mathrm{pH}$, matéria orgânica, argila e óxidos e hidróxidos de $\mathrm{Fe}$ e de $\mathrm{Al}$, afetam a adsorção, para predizer o impacto ambiental que pode ser causado pela adição antropogênica do elemento no solo.

Alguns pesquisadores brasileiros desenvolveram estudos sobre 0 comportamento de cádmio no solo, mas pouco se sabe a respeito de seu comportamento em solos tropicais altamente intemperizados, como os ácricos que podem apresentar balanço positivo de cargas em profundidade e que representam o extremo na escala de intemperismo. Os objetivos deste estudo foram obter valores de cádmio adsorvido, em diferentes valores de $\mathrm{pH}$, em camadas superficiais $(0-0,20 \mathrm{~m})$ e subsuperficiais (horizonte $B$ ) de dois solos com diferentes texturas: Latossolo Roxo ácrico (LR) e Latossolo Una ácrico (LU) e compará-los com os valores adsorvidos na Terra Roxa Estruturada, cujo comportamento eletroquímico é diferente, por apresentar balanço negativo de carga ao longo de todo o perfil, obter valores de adsorção máxima e K, a partir 
das equação de Langmuir e os parâmetros "K" e " $n$ " da equação de Freundlich, ao $\mathrm{pH}$ natural para cada solo e correlacioná-los com atributos físicos, químicos e mineralógicos dos solos. As amostras de solo foram incubadas com carbonato de cálcio ou ácido clorídrico para se obterem valores de $\mathrm{pH}$, abrangendo a faixa de 4 a 7, as amostras foram suspensas em $20 \mathrm{~mL}$ de solução $0,0025 \mathrm{~mol} \mathrm{~L}^{-1}$ de $\mathrm{Ca}\left(\mathrm{NO}_{3}\right)$ contendo $2 \mathrm{mg} \mathrm{dm}^{-3}$ de cádmio, como $\mathrm{Cd}\left(\mathrm{NO}_{3}\right)_{2}$. Após agitação por 24 horas foi feita a determinação de cádmio no extrato por espectrometria de absorção atômica. Para a construção das curvas de adsorção e obtenção dos parâmetros das equações de Langmuir e de Freundlich, foram adicionadas soluções com concentrações variando de 5 a $200 \mathrm{mg} \mathrm{dm}^{-3}$ de cádmio, e seguiu-se o mesmo procedimento descrito na primeira etapa. A adsorção de cádmio dos solos estudados mostrou-se fortemente dependente do $\mathrm{pH}$. Com a elevação do $\mathrm{pH}$, houve expressivo aumento na adsorção em todos os solos, tanto nas camadas superficiais como nas subsuperficiais. Nos valores de pH entre 6,0 e 7,0 não houve diferenças na adsorção de cádmio entre os solos, sendo que para todos os solos ocorreu quase $100 \%$ de adsorção do cádmio inicialmente adicionado. Os horizontes superficiais adsorveram maiores quantidades de cádmio em relação aos horizontes subsuperficiais, devido ao maior teor de matéria orgânica nesta camada. A TE adsorveu maiores quantidades de cádmio em relação aos Latossolos, por apresentar cargas negativas em todo o perfil. Os parâmetros $\mathrm{K}$ e b de Langmuir e $\mathrm{K}$ de Freundlich foram positivamente correlacionados com carbono orgânico, capacidade de troca de cátions (CTC), retenção de cátions (RC), superfície específica (SE), argila, cargas negativas variáveis e cargas negativas permanentes. A CTC foi o atributo do solo selecionado por meio de regressão múltipla que teve maior efeito sobre a adsorção de cádmio. A capacidade de troca de cátions e o pH mostraram-se fatores preponderantes, no controle da adsorção de cádmio nos solos estudados. 


\title{
CADMIUM ADSORPTION ON ACRIC OXISOLS FROM THE STATE OF SÃO PAULO
}

\author{
Author: NIVEA MARIA PICCOLOMINI DIAS \\ Adviser: Prof. Dr. LUÍS REYNALDO FERRACCIÚ ALLEONI
}

\section{SUMMARY}

Cadmium can be added to the soils through tyre residues, oils, disposal of city wastes, sewage sludge and phosphatic fertilisers. Although it is not essential to plant nutrition, cadmium is easily adsorbed and translocated by plants and has a great potencial to enter the human food chain. The persistence and mobility of cadmium in soils and, consequently, its bioavailability is largely determined by the extent of adsorption by soils particles. So it is important to determine how adsorption is affected by soil attributes such as $\mathrm{pH}$, organic matter, clays, and iron and aluminium oxides, for predicting the environmental impact that can be caused by the addition of antropogenic cadmium to soils.

Some Brazilian researchers studied the behavior of cadmium in soils, but little is known with respect to its behavior in highly weathered tropical soils, as the acric soils, that represent the extreme conditions in the scale of weathering and can exhibit a positive charge balance in deep layers.

The objectives of this study were to obtain the amounts of adsorbed cadmium at different $\mathrm{pH}$ values in the surface $(0-0,20 \mathrm{~m})$ and subsurface horizons (B horizon) of two soils with different textures: Anionic "Rhodic" Acrudox (RA) and Anionic "Xanthic" Acrudox (XA) and compare them with the amount adsorbed Cd in a Rhodic Kandiudalf (RK), whose electrochemical behavior is the opposite, as it exhibited negative charge balance all along the profile, the maximum adsorption and the constant of Langmuir's equation and " $\mathrm{K}$ " and " $\mathrm{n}$ "of 
Freundlich's equation were obtained in natural $\mathrm{pH}$ and correlated with the chemical, physical and mineralogical soil attributes. The samples were incubated with either calcium carbonate or chloridric acid with a $\mathrm{pH}$ ranging from 4.0 to 7,0 , samples were suspended in $20 \mathrm{~mL}$ of $\mathrm{Ca}\left(\mathrm{NO}_{3}\right)_{2} 0,0025 \mathrm{~mol} \mathrm{~L}^{-1}$ solution, containing cadmium $\mathrm{Cd}\left(\mathrm{NO}_{3}\right)_{2}$ at $2 \mathrm{mg} \mathrm{dm}^{-3}$. After 24-hours, cadmium was determined in the extract, using an atomic absorption spectrophotometer. With the objective of obtaining adsorption isotherms and Langmuir and Freundlich parameters, Cd was added to the soil in concentrations ranging from 5 to $200 \mathrm{mg}$ $\mathrm{dm}^{-3}$, and the same procedure as described in the first stage was performed. Cadmium adsorption on the soils studied appeared strongly $\mathrm{pH}$ dependent. Its adsorption increases with an increase in $\mathrm{pH}$, either in surface or subsurface layers. When the $\mathrm{pH}$ values ranged between 6,0 and 7,0, the amounts of adsorbed Cd were similar for all soils, with almost $100 \%$ adsorption. Surface horizons adsorbed greater amounts of cadmium in relation to the subsurface horizons, reinforcing the influence of organic matter. RK adsorbed greater amounts of cadmium, due to the negative net charge along the profile. Organic carbon, cation exchange capacity (CEC), cation retention (CR), specific surface (SS), clay content, variable negative charge and permanent negative charge were positively correlated to Langmuir's K and b parameters and Freundlich's K. The CEC were the main soil attributes that exhibited a greater effect on cadmium adsorption through multiple regression analysis. It was also observed that $\mathrm{CEC}$ and $\mathrm{pH}$ controlled adsorption of cadmium on the studied soils. 


\section{INTRODUÇÃO}

A concentração de grandes populações urbanas tem gerado uma elevada produção de resíduos domiciliares e industriais, que, via de regra, tem causado deterioração da qualidade do ambiente. O uso inadequado de fertilizantes, inseticidas, fungicidas e herbicidas também são agravantes desse quadro, já que os impactos desses agentes poluidores são sentidos na atmosfera, nos cursos d'água e nos solos. Para o solo, embora esta poluição ocorra a longo prazo, há necessidade de se conhecer com detalhe o comportamento dos metais presentes nos resíduos, a fim de se subsidiar ações eficientes de controle, para evitar que os danos se tornem irreversíveis.

A expressão "metal pesado", definida a partir de densidades atômicas (> 6 $\mathrm{g} \mathrm{cm}^{-3}$ ), imprópria ou não, vem sendo, amplamente utilizada na literatura científica. Esse termo engloba um grupo de metais, semi-metais e até não metais (selênio) que, normalmente, se encontram associados à poluição e toxicidade, e inclui, também, alguns elementos essenciais aos seres vivos $(\mathrm{Cu}, \mathrm{Zn}, \mathrm{Mn}, \mathrm{Co}$, $\mathrm{Mo}$ ) e não essenciais (Cd e outros como $\mathrm{Pb}, \mathrm{Hg}, \mathrm{As}, \mathrm{Ti}, \mathrm{V}$ ).

O cádmio é amplamente utilizado para revestimento de materiais, em pigmentos de tintas e na indústria plástica. Pode ser adicionado ao solo por meio de restos de metais fundidos com zinco, resíduos de pneus, óleos combustiveis, fertilizantes, lodo de esgoto e lixo urbano. A ocorrência de cádmio em óleo de motor e pneus explica seu relativo acúmulo em solos próximos às rodovias. Embora também presente nos adubos fosfatados, as maiores fontes de 
contaminação dos solos com esse elemento são o lodo de esgoto e os resíduos industriais.

Embora não seja essencial ao desenvolvimento vegetal, o cádmio é facilmente absorvido e translocado nas plantas, tem efeito cumulativo no organismo animal/humano, podendo levar a sérios problemas de saúde.

A persistência e a mobilidade, conseqüentemente, a disponibilidade do cádmio é determinada pela extensão de adsorção pelas partículas do solo. Em vista disso, é importante determinar quais os atributos do solo, como $\mathrm{pH}$, matéria orgânica, argila e óxidos e hidróxidos de $\mathrm{Fe}$ e de $\mathrm{Al}$, afetam a adsorção, para predizer o impacto ambiental que pode ser causado pela adição antropogênica de Cd no solo.

Alguns pesquisadores desenvolveram estudos à respeito do comportamento de cádmio em solos brasileiros, mas o conhecimento sobre os fatores de nossos solos que influenciam e determinam seu comportamento ainda é restrito, principalmente em solos altamente intemperizados, como os ácricos, que representam o extremo na escala de intemperismo.

No horizonte B de solos ácricos, o valor de PCZ em muitos casos supera o de $\mathrm{pH}$, conferindo um balanço positivo de carga ao solo, que passa a atuar predominantemente como trocador de ânions. O fenômeno de reversão de carga ocorre quase sempre em profundidades maiores que $50 \mathrm{~cm}$, pois, nessa condição, a matéria orgânica, cujo PCZ é bastante baixo $(=2,0)$, praticamente não atua.

Os estudos com metais pesados, como o cádmio, comumente concentram-se na camada arável dos solos (0-0,20m). Entretanto, é importante se conhecer também o comportamento dos elementos nas camadas mais profundas, principalmente quando o horizonte apresenta atributos eletroquímicos diferentes do horizonte A, como é o caso dos solos ácricos.

Os objetivos deste trabalho foram: obter valores de cádmio adsorvido em camadas superficiais e subsuperficiais de Latossolos ácricos em diferentes valores 
de $\mathrm{pH}$ e compará-los com os valores adsorvidos na Terra Roxa Estruturada e obter valores de adsorção máxima e afinidade do solo ao íon cádmio $\left(\mathrm{Cd}^{2+}\right)$ a partir da equação de Langmuir e dos parâmetros "K" e " $n$ " da equação de Freundlich, ao $\mathrm{pH}$ natural para cada solo e correlacioná-los com os atributos físicos, químicos e mineralógicos dos solos.

As hipóteses testadas foram:

- A adsorção de cádmio deverá ser maior em superfície do que em subsuperfície, devido ao maior teor de matéria orgânica nas camadas superficiais em todos os solos;

- A Terra Roxa Estruturada deverá adsorver maior quantidade de cádmio em relação aos Latossolos, por apresentar maior quantidade de cargas negativas em todo o perfil;

- Com o aumento do pH, deverá ocorrer maior adsorção de cádmio em todos os solos, tanto nas camadas superficiais como nas camadas subsuperficiais;

- Deverá ocorrer boa adequação das equações de Langmuir e de Freundlich aos dados de adsorção de cádmio e correlação positiva do cádmio adsorvido principalmente com matéria orgânica, argila, óxidos e hidróxidos de ferro e de alumínio. 


\section{REVISÃO DE LITERATURA}

\subsection{Geoquímica e formas de ocorrência do cádmio}

O cádmio é um metal de transição com número atômico 48, peso atômico 112,4 e densidade $8,642 \mathrm{~g} \mathrm{~cm}^{-3}$. Relativamente raro, não é encontrado em estado puro na natureza e não há minérios e nem minas exploradas para a sua produção. Muito relacionado com o zinco, é encontrado principalmente em minérios de $\mathrm{Zn}$, $\mathrm{Pb}-\mathrm{Zn}$ e $\mathrm{Pb}-\mathrm{Cu}-\mathrm{Zn}$. De um modo geral, o teor de $\mathrm{Cd}$ nesses minérios é diretamente proporcional ao de zinco (Malavolta, 1994).

A concentração média na crosta terrestre é $0,1 \mathrm{mg} \mathrm{kg}^{-1}$, com teores médios de 0,15 nas rochas ígneas, variando de 0,01 a 0,6 nos basaltos e de 0,01 a 1,6 mg $\mathrm{kg}^{-1}$ nos granitos. As rochas sedimentares apresentam as mais altas concentrações de cádmio, encontradas nas rochas fosfatadas, nas quais os teores estão entre $10 \mathrm{e}$ $980 \mathrm{mg} \mathrm{kg}^{-1}$. Nas metamórficas, os teores variam entre $0,04 \mathrm{mg} \mathrm{kg}^{-1}$ nos gnaisses e $0,02 \mathrm{mg} \mathrm{kg}^{-1}$ nos xistos (Alloway,1990).

A concentração de cádmio em solos não contaminados por fontes antropogênicas é governada pelo teor na rocha de origem. Os solos derivados de rochas ígneas deveriam conter entre 0,1 e $0,3 \mathrm{mg} \mathrm{kg}^{-1}$ de $\mathrm{Cd}$, os oriundos de rochas metamórficas entre $0,1 \mathrm{e} 1 \mathrm{mg} \mathrm{kg}^{-1}$, enquanto nos provenientes das sedimentares o teor estaria perto de $11 \mathrm{mg} \mathrm{kg}^{-1}$. Nas proximidades da minas de zinco, os teores de cádmio poderiam ser muito mais altos, até centenas de $\mathrm{mg} \mathrm{kg}^{-1}$ (Kabata \& Pendias, 1984). 


\subsection{Fontes antropogênicas de cádmio no solo}

Além da rocha mãe, várias outras fontes podem contribuir para o $\mathrm{Cd}$ no solo. De acordo com Kabata \& Pedias (1984) e Alloway (1990), o aumento anormal das concentrações de cádmio e outros metais pesados nos solos das regiões de agricultura altamente tecnificada resultou da deposição atmosférica, da aplicação de agrotóxicos, de resíduos orgânicos, de fertilizantes, de corretivos e de água de irrigação.

Tiller (1989) considerou que essas fontes de contaminação poderiam ser primárias, isto é, metais pesados adicionados ao solo devido às práticas agrícolas ou secundárias principalmente pela deposição atmosférica.

O nível crítico de cádmio no solo, que corresponde à faixa da concentração total acima da qual a toxicidade foi considerada possível, esteve entre 3 e $8 \mathrm{mg} \mathrm{kg}^{-1}$ Kabata \& Pedias (1984) e o nível comum, considerado como concentrações típicas em solos agriculturáveis foi de $0,25 \mathrm{mg} \mathrm{kg}^{-1}$ (Alloway, 1990).

Alguns metais pesados, considerados micronutrientes, são frequentemente, adicionados ao solo na forma de adubação complementar à de macronutrientes, os adubos que contém esses elementos essenciais apresentam apreciáveis teores de impurezas derivadas das matérias-primas utilizadas, sendo que entre essas impurezas se encontram metais pesados tóxicos, como o cádmio. De um modo geral, os produtos mais estudados e discutidos do ponto de vista de adição de cádmio ao solo foram os adubos fosfatados (Mulla et al., 1980; Mortvedt,1987; Amaral Sobrinho et al., 1992 e Hamon et al., 1998). Os níveis de cádmio

adicionados ao solo por adubos fofatados estão entre 0,1 e $190 \mathrm{mg} \mathrm{kg}^{-1}$ (Fergusson, 1990). 
Com o aumento do custo de fertilizantes comerciais e a dificuldade na utilização de áreas de sacrifício para despejo dos resíduos industriais e urbanos, o uso desses materiais nas culturas tornou-se uma alternativa atrativa, tanto do ponto de vista econômico, quanto do ponto de vista de reciclagem de nutrientes. A aplicação desses resíduos em áreas agrícolas tem trazido preocupações em função da presença de metais pesados nesses materiais. Os metais pesados presentes em lodo de esgoto que aparecem em maior concentração são o Cd, o $\mathrm{Cu}$, o $\mathrm{Cr}$, o $\mathrm{Mn}$, o $\mathrm{Ni}$, o $\mathrm{Pb}$ e o $\mathrm{Zn}$. Esses metais, juntamente com o $\mathrm{Hg}$, tem recebido maior atenção com respeito a acumulação em solos, absorção pelas plantas e contaminação de águas subterrâneas. Os níveis de cádmio adicionados ao solo pela aplicação de lodo de esgoto estão entre 3 e $3000 \mathrm{mg} \mathrm{kg}^{-1}$ (Fergusson, 1990).

A utilização do composto de lixo, como agente capaz de melhorar as propriedades do solo (Mazur et al., 1983), subprodutos industriais usados como fonte de zinco (Mortvedt, 1985) e a utilização de resíduos industriais, como resíduo siderúrgico alcalino, utilizado como corretivo de acidez do solo (Amaral Sobrinho et al., 1995), podem também levar à contaminação do solo por metais pesados.

Dentre as fontes antropogênicas primárias de contaminação com metais pesados do solo, a irrigação pode constituir fonte significativa, principalmente, quando a água utilizada é proveniente de rios que recebem grande carga poluidora (Tiller, 1989). De acordo com Nriagu \& Pacyna (1988) as adições anuais de Cd, provenientes de água de irrigação foram de $0,1 \mathrm{mg} \mathrm{dm}^{-3}$.

A atmosfera é um importante meio de transporte de metais de diversas origens. Os solos são geralmente contaminados a vários quilômetros do local de emissão (Fergusson, 1990). A deposição atmosférica do cádmio se dá pela queima de carvão nos fornos industriais, lixo urbano e papel, óleos dos motores 
de carros e desgaste de pneus, já que esse elemento entra na sua fabricação no processo de vulcanização.

\subsection{Adsorção de cádmio no solo}

A persistência, a mobilidade e a disponibilidade de cádmio às plantas são determinadas pela extensão da adsorção pelas partículas do solo. A adsorção pode ser definida como acumulação de uma substância ou material na interface entre a superfície sólida e uma solução, podendo ocorrer por atração eletrostática ou adsorção específica, forças químicas e físicas estão envolvidas no processo de adsorção de solutos. As forças físicas incluem a força de van der Waals, formando complexos de esfera externa (troca de íons) e as forças químicas de interação que incluem mecanismo de troca de ligantes e ligação covalente com o hidrogênio, formando complexos de esfera interna (Sparks, 1995).

A adsorção de íons é consequência direta da superfície de carga do solo, principalmente em solos altamente intemperizados, que devido à sua composição mineralógica apresentam cargas variáveis (propriedades anfóteras), podendo adsorver cátions e ânions ( Ji \& Li, 1997).

O equilíbrio dinâmico entre o cádmio na solução do solo e o adsorvido na fase sólida depende da contribuição dos atributos do solo, além da competição com outros metais pelos sítios de adsorção e quelatação, controlando a solubilidade, mobilidade e retenção de cádmio no solo (Lindsay, 1979).

A influência dos atributos do solo, tais como matéria orgânica, óxidos de Fe e de Al, capacidade de troca de cátions, $\mathrm{pH}$, superfície específica e mineralogia, na capacidade de adsorção de metais aos solos, foi estudada por meio de modelos de regressão múltipla (Kort et al., 1976; Amoozegar-Fard et al., 1984; Tiller et al., 1984ab e King, 1988). Os atributos do solo com melhor 
correlação foram o pH, havendo maior adsorção com a elevação do pH (GarciaMiragaya \& Page, 1978 e King, 1988), matéria orgânica e CTC (Singh, 1979 e Petruzzelli et al., 1985), superfície específica (Kort et al., 1976) e força iônica da solução, cuja elevação causou redução da adsorção (Garcia-Miragaya \& Page, 1976; Petruzzelli et al., 1985 e Matos, 1995).

\subsubsection{Adsorção de cádmio em óxidos e hidróxidos de Fe e de Al}

Os óxidos e hidróxidos de $\mathrm{Fe}$ e de $\mathrm{Al}$ são considerados importantes constituintes no solo, apresentando em suas superfícies sítios de maiores energias de ligação para a adsorção de metais pesados (Anderson \& Christensen, 1988), o que tem levado a numerosos estudos de adsorção de metais nesses materiais (Forbes et al., 1976; Garcia-Miragaya \& Page, 1978; McKenzie, 1980; Anderson \& Christensen, 1988 e Martin \& Kaplan, 1998).

O desenvolvimento de cargas elétricas na superfície dos óxidos pode ser considerado um processo em duas etapas: hidratação superficial, com formação do hidróxido de superfície e dissociação-associação de prótons dos grupos $\mathrm{OH}^{-}$ expostos (Figura 1). A segunda etapa é responsável pela formação de cargas superficiais, os principais íons determinantes de potenciais na solução do solo são os íons $\mathrm{H}^{+}$e $\mathrm{OH}^{-}$, quando um íon determinador de potencial passa da solução para a fase sólida, ele carrega uma carga com ele, portanto, uma carga positiva deve-se à adsorção de um $\mathrm{H}^{+}$, enquanto uma carga negativa origina-se da dissociação de uma hidroxila da superfície, dependendo d o pH do meio (Raij, 1986). 


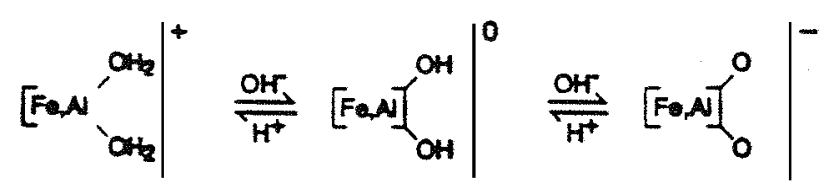

Figura 1 - Geração de cargas positivas e negativas na superficie de óxidos de ferro.

A adsorção de cádmio pelos óxidos pode ocorrer por adsorção específica (complexação) dentro dos óxidos ou não específica (trocável) na superfície dos óxidos (Bolton \& Evans, 1996).

Os grupamentos hidroxila que aparecem na superfície dos óxidos podem estar ligados a um, a dois ou até a três metais na estrutura do mineral, podendo formar complexos monodentado, bidentado e tridentado com o cádmio (Figura 2) (Fontes, 1996).

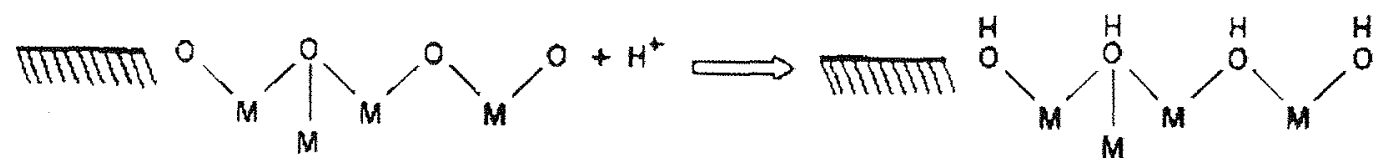

Figura 2 - Grupamentos de hidroxila na superficie dos óxidos e possíveis ligações com metais.

Ao mesmo tempo, as cargas negativas da superfície dos óxidos podem atrair cátions eletrostaticamente, sendo estas em menores quantidades, porque nos valores de $\mathrm{pH}$ normalmente encontrados em solos tropicais (entre 4,0 e 6,5), a superfície dos óxidos apresenta cargas positivas, por apresentar PCZ (ponto de 
carga zero) em torno do pH 8,0. Assim, o fenômeno de adsorção não pode ser explicado simplesmente por forças eletrostáticas. Desta forma a adsorção de metais pesados em óxidos e hidróxidos é governada por ligação covalente e específica (Forbes et al., 1976 e Lothenbach et al., 1997). As reações de troca entre Cd são importantes nos valores de $\mathrm{pH}$ menores que 6,5 (Cowan et al., 1992), enquanto as formas adsorvidas por complexação aumentam com a elevação do pH (Zachara \& Smith, 1994 e Filius et al., 1998).

Em baixas concentrações, o cádmio se encontra adsorvido especificamente (Garcia-Miragaya \& Page, 1977 e Tiller et al., 1979). Já em altas concentrações, é esperada adsorção não específica, porque depois da saturação dos sítios de alta afinidade, a concentração residual do metal é elevada em relação aos outros cátions, o metal é capaz de competir pelos sítios de baixa afinidade (Tiller et al., 1984 a,b).

Em estudos de adsorção de $\mathrm{Cd}$ em óxidos de $\mathrm{Fe}$ e de $\mathrm{Al}$ cristalino, McKenzie (1972); Anderson et al.(1973); Burns (1976); Harter (1984); Kou (1986); Amacher et al.(1986) e Bruemmer et al. (1988) demonstraram que a adsorção ocorre em dois passos: uma rápida adsorção na superfície de troca, seguida por uma lenta reação, sendo esta caracterizada como substituição do íon na matriz, penetração do íon dentro da fase sólida por um processo de recristalização e difusão dentro dos poros.

Ainsworth et al. (1994), em estudos de adsorção-desorção de cobalto, cádmio e chumbo em hidróxidos de ferro, verificaram que a adsorção de chumbo foi completamente reversível, não havendo indicação de que o chumbo foi incorporado dentro da fase sólida dos óxidos. O contrário foi observado para o cobalto e o cádmio, os autores sugeriram que os elementos foram incorporados dentro das estruturas dos óxidos via recristalização. Em amostras contendo altas quantidades de óxidos de ferro, de alumínio e de manganes, o cádmio foi adsorvido irreversivelmente (Backes et al., 1995). 
Com aumento do tempo de contato do metal com o solo, houve menor dessorção do metal (Padmanabham, 1983; Lehmann \& Harter, 1984; McLaren et al., 1986; Hogg et al., 1993; Ainsworth et al., 1994; Backes et al.,1995 e Fischer et al., 1996), provavelmente devido à difusão do íon metálico dentro da estrutura do mineral, especialmente em óxidos (Tiller et al, 1984b; Bruemmer et al., 1988 e Ainsworth et al., 1994). Fischer et al. (1996) examinaram partículas de goetita em microtopografia, encontraram numerosos microporos, sugeriram que possivelmente a difusão ocorreu em pequenos poros, que podiam ter afetado a adsorção e dessorção de metais pesados. Filius et al. (1998), estudaram a adsorção-dessorção de cádmio em solos, também comentaram que a pequena dessorção deve ter sido devida a oclusão do metal pelos óxidos de ferro.

Os metais pesados podem exibir diferentes afinidades para os sítios de superfície. A ordem de afinidade pela superfície dos óxidos é dada conforme a tendência de formarem íons metálicos hidratados em solução aquosa (Forbes et al.,1976; Kinniburgh et al., 1976; Benjamin \& Leckie, 1981 e Naidu et al., 1994). Gadde \& Laitinen (1974) verificaram adsorção específica de $\mathrm{Pb}^{2+}, \mathrm{Zn}^{2+} \mathrm{e} \mathrm{Cd}^{2+} \mathrm{em}$ óxido de manganês e de ferro, a ordem de adsorção foi $\mathrm{Pb}^{2+}>\mathrm{Zn}^{2+}+\mathrm{Cd}^{2+}$. Forbes et al. (1976) calcularam a ordem de afinidade na superfície da goetita e encontraram a seguinte ordem: $\mathrm{Cu}>\mathrm{Pb}>\mathrm{Zn}>\mathrm{Co}>\mathrm{Cd}$. Tiller et al. (1984b), estudando a adsorção de $\mathrm{Cd}, \mathrm{Ni}$, e $\mathrm{Zn}$ encontraram a seguinte ordem de afinidade $\mathrm{Zn}>\mathrm{Ni} \geq \mathrm{Cd}$ em um solo dominado por óxidos de Fe e em goetita sintética a ordem de afinidade foi $\mathrm{Zn}>>\mathrm{Ni}>\mathrm{Cd}$.

\subsubsection{Efeito do $\mathrm{pH}$ na adsorção de cádmio}

O efeito do $\mathrm{pH}$ na adsorção de cádmio tem sido extensivamente estudado em minerais puros e em solos (Tiller et al., 1984b; Naidu et al., 1994; Lee et al., 
1996; Hooda \& Alloway, 1997; Gray et al., 1998; Barrow \& Whelan, 1998 e Filius et al., 1998). O pH tem marcante influência na adsorção de cádmio, sendo sempre observado aumento da adsorção com a elevação do pH. Esse aumento se deve à formação de novos sítios de adsorção, junto com a diminuição da competição entre $\mathrm{H}^{+}$e o cádmio por estes sítios (Garcia-Miragaya \& Page, 1978 e Christensen, 1984 a,b).

Chumbo e cobre tendem a ser adsorvidos a valores de $\mathrm{pH}$ menores que cádmio, zinco e cobalto (Kinniburgh et al., 1976 e Benjamin \& Leckie, 1981). Christensen (1984a) e Gray et al.(1998) verificaram que a adsorção de cádmio foi máxima ao redor do $\mathrm{pH} 6,0$.

Num intervalo de $\mathrm{pH}$ de 4,0 a 7,7, Christensen (1984a) encontrou que a capacidade de adsorção dos solos aumentou três vezes para cada aumento de uma unidade no pH. Yuan \& Lavkulich (1997) e Filius et al.(1998) relataram que a variação de uma unidade no $\mathrm{pH}$ ocasionou uma grande diferença na adsorção de cádmio. Lee et al. (1996) estudaram a adsorção de cádmio no intervalo de $\mathrm{pH}$ entre 3,0 e 10,0, verificaram que aumentando de 2 a 3 unidades no valor do $\mathrm{pH}$, a porcentagem do metal adsorvido aumentou de 0 para $100 \%$, sendo que a adsorção chegou próxima de $100 \%$ no pH 6,0 em um solo com altos teores de argila e matéria orgânica e no pH 9,0 em um solo com baixos teores, demonstrando que a transição de 0 para $100 \%$ de cádmio adsorvido não ocorreu nos mesmos valores de $\mathrm{pH}$ para todos os tipos de solo.

A dessorção de cádmio também é muito sensitiva pelo $\mathrm{pH}$, sendo reduzida com a elevação do pH (Jarvis \& Jones, 1980; Christensen, 1984b e Tiller et al., 1984a). Esta redução tem sido encontrada em estudos envolvendo outros cátions, como Cu (Padmanabham, 1983 e Hogg et al., 1993) e Zn (Stahl \& James, 1991 e Pardo \& Guadalix, 1995).

Padmanabham (1983) sugeriu a existência de sítios de alta e de baixa afinidade. sendo estes sítios fortemente dependentes do pH (Tiller et al., 1984b). 
Em baixos valores de $\mathrm{pH}$, observaram-se grandes quantidades de cádmio dessorvido, correspondendo ao cádmio ligado nos sítios de baixa afinidade, em contraste aos valores de $\mathrm{pH}$ elevado, nos quais pequenas quantidades de cádmio são dessorvidos, indicando grande número de sítios de forte ou alta afinidade (Gray et al., 1998). Filius et al. (1998) também relataram que a elevação do pH, aumentou a quantidade de sítios ocupados pelo cádmio por adsorção específica, e nesses valores de $\mathrm{pH}$ os sítios não específicos (trocável) tornaram-se menos pronunciados.

O efeito do aumento do $\mathrm{pH}$ na adsorção de cádmio pode ser pela:

(i) diminuição da competição do cádmio com o próton $\mathrm{H}^{+}$pelo mesmo sítio de adsorção, sendo importante fator que controla a adsorção de cádmio (Garcia-Miragaya \& Page, 1978 e Christensen, 1984a);

(ii) formação de espécies hidroxiladas do metal. A principal espécie adsorvida é a espécie monohidroxilada $\left(\mathrm{CdOH}^{+}\right)($James \& Healy, 1972; Davis \& Leckie, 1979; Bleam \& McBride, 1986 e Barrow, 1987b). Apesar de existirem muitas controvérsias com relação à precisa natureza da espécie do metal adsorvido pelo solo. Naidu et al. (1994), usaram cálculos para indentificar a especiação de cádmio, encontraram que a concentração de $\left(\mathrm{CdOH}^{+}\right)$foi negligenciável em relação a forma $\mathrm{Cd}^{2+}$ e concluíram que a espécie hidroxilada do metal apresenta alta afinidade com a superfície do solo, dirigindo a reação (2) de hidrólise do metal para a direita:

$$
\begin{aligned}
& \mathrm{M}^{2+}+\mathrm{H}_{2} \mathrm{O} \leftrightarrow \mathrm{MOH}^{+}+\mathrm{H}^{+} \\
& \mathrm{MOH}^{+}+\text {Solo } \leftrightarrow \text { Solo-MOH }
\end{aligned}
$$

Mais pesquisas precisam ser realizadas para determinar a precisa natureza da interação do metal com o solo ( Naidu et al., 1997) e 
(iii) a influência da elevação do $\mathrm{pH}$ pode se dar também pelo aumento da afinidade da superfície, pela mudança da superfície de carga e do potencial eletrostático no plano de adsorção, na qual o potencial eletrostático diminui com a elevação do $\mathrm{pH}$, tornando a superfície mais negativa.

Em solos altamente intemperizados, o efeito do $\mathrm{pH}$ se manifesta pela mudança da densidade de carga da superfície dos minerais de cargas variáveis (Sposito, 1984 e Naidu et al., 1994). A magnitude da carga gerada é normalmente em função da superfície específica do material. Muitos materiais tem superfície específica elevadas, variando de 5 a $40 \mathrm{~m}^{2} \mathrm{~g}^{-1}$ para caulinita, 60 a $200 \mathrm{~m}^{2} \mathrm{~g}^{-1}$ para goetita e $1000 \mathrm{~m}^{2} \mathrm{~g}{ }^{-1}$ para alofanas. A superfície específica de um determinado material é constante. Assim, a geração de carga vai resultar em um aumento na densidade de carga da superficie (Naidu et al., 1997).

$\mathrm{O}$ efeito do $\mathrm{pH}$ na afinidade da superfície depende da natureza dos constituintes do solo, sendo que a carga elétrica da superfície dos óxidos em altos valores de $\mathrm{pH}$ são mais negativas e mais hábeis em reter cátions por complexação, no caso de coloides inorgânicos a carga positiva é desenvolvida em valores de $\mathrm{pH}$ menores que o PCZ e cargas negativas acima deste valor. GarciaMiragaya \& Page (1978) verificaram que entre pH 6 e 7, solos com altos teores de matéria orgânica e óxidos de ferro e alumínio adsorveram mais cádmio do que solos dominados com argilas 2:1 que possuem maiores valores de CTC. Essa constatação foi consistente com Bolton \& Evans (1996), que relataram que óxidos e hidróxidos de ferro somente se tornam importantes superficies adsorvedoras em $\mathrm{pH}$ maiores que 7,0. 


\subsubsection{Influência da matéria orgânica na adsorção de cádmio}

A matéria orgânica do solo tem sido particularmente estudada devido ao significante efeito na capacidade de troca de cátions e principalmente pela tendência dos metais formarem complexos estáveis com ligantes orgânicos (Elliott et al., 1986 e Anderson \& Christensen, 1988). A forma livre do metal parece ser a forma mais tóxica, quando comparada com estáveis complexos orgânicos e inorgânicos encontrados no solo. Assim a formação de complexos estáveis da matéria orgânica com o cátion metálico reduz o efeito tóxico às plantas (Neal \& Sposito, 1986).

A matéria orgânica apresenta alta densidade de carga negativa, proveniente da dissociação dos grupos carboxílicos e fenólicos. Em valores de $\mathrm{pH}$ normalmente encontrados em solos tropicais, a matéria orgânica é capaz de gerar somente cargas negativas, por apresentar um PCZ baixo $(=2,0)$ e a geração de carga se dá pela seguinte equação:

$$
\mathrm{R}-\mathrm{COOH} \underset{\mathrm{H}^{+}}{\stackrel{\mathrm{OH}^{-}}{\rightleftarrows}} \mathrm{RCOO}^{-}+\mathrm{H}_{2} \mathrm{O}
$$

A matéria orgânica, juntamente com o pH tem grande importância na adsorção de cádmio (Pombo, 1995), sendo positivamente correlacionada com adsorção de cádmio no solo (Bolton \& Evans, 1996; Lee et al., 1996; Hooda \& Alloway, 1997; Gray et al.,1998 e Singh \& Pandeya, 1998).

Uma redução do carbono orgânico do solo de 46,0 para 40,9 $\mathrm{g} \mathrm{kg}^{-1}$, que equivale a uma perda de $11 \%$ da matéria orgânica original, a qual é normal em regiões úmidas em uma escala de 10 anos (Goldin \& Lavkulich, 1990), acarretou uma redução de $62 \%$ na capacidade de adsorção de cádmio (Yuan \& Lavkulich, 1997). 
A interação das substâncias húmicas e o metal com as matrizes inorgânicas o solo foi estudada em vários trabalhos (Neal \& Sposito, 1986 e Pandeya, 1991). A reação do cátion metálico organicamente complexado, provavelmente, deve ser diferente em relação ao inorganicamente complexado, pelo fato de que a complexação pelas substâncias húmicas, neutralizam a carga positiva do cátion metálico (Singh \& Pandeya, 1998). Há divergências na literatura com relação a importância e a precisa natureza da associação do cádmio com a matéria orgânica do solo. Davis (1984) e Elliot et al.(1986) sugeriram que o cádmio forma complexos fracos com a matéria orgânica, e que o aumento da adsorção ocorre pela geração de cargas negativas provenientes da matéria orgânica presente na superfície das partículas do solo. Neal \& Sposito (1986) mostraram que a remoção de material orgânico solúvel de solos aumentou a adsorção de Cd. Com a retirada da matéria orgânica, a associação do cádmio com o ligante orgânico é reduzida, favorecendo a adsorção do $\mathrm{Cd}$ pelos outros constituíntes do solo. Apesar de ser difícil determinar a precisa forma da relação do complexo orgânico na superfície do solo, Singh \& Pandeya (1998) e Naidu \& Harter (1998) sugeriram que a fração argila provavelmente possua sítios para adsorção do metal complexado organicamente, e que a adsorção poderia ocorrer de duas formas: pela complexação do metal na matéria orgânica adsorvida no solo ou pela formação de complexo metal-ligante orgânico na solução e este é adsorvido no solo (Figura 3). 

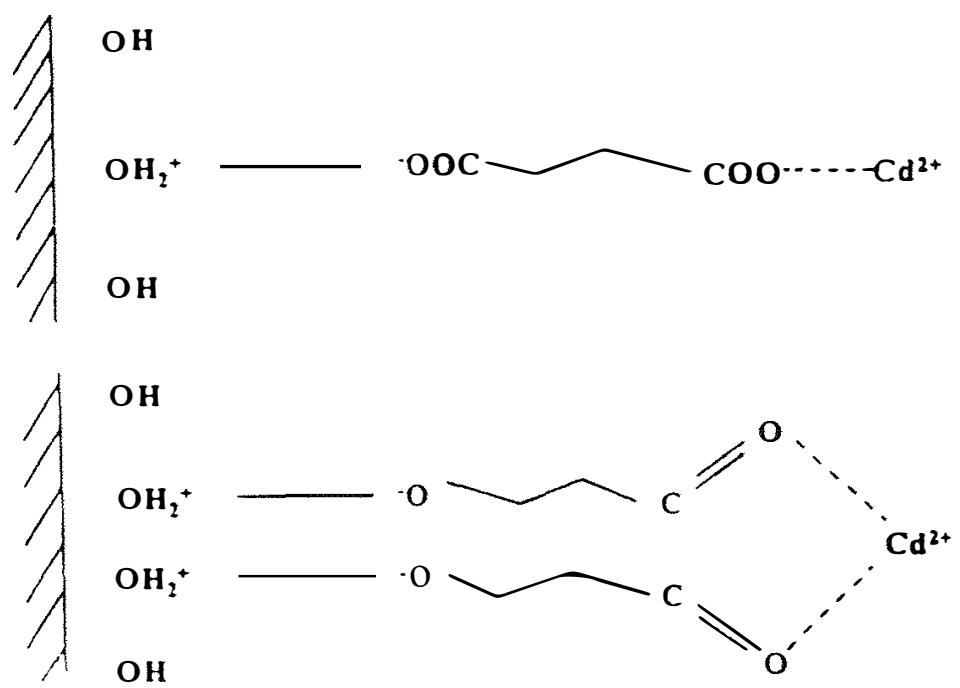

Figura 3 - Possíveis ligações entre o metal e a matéria orgânica do solo

O efeito da matéria orgânica se dá pelo recobrimento da superfície dos óxidos, aumentando as cargas negativas, aumentando a CTC e consequentemente a adsorção de cádmio (Singh \& Pandeya, 1998 e Naidu \& Harter, 1998).

\subsection{Modelos de adsorção}

\subsubsection{Equação de Langmuir}

Olsen \& Watanabe (1957) foram os primeiros pesquisadores a utilizarem a equação de Langmuir para descrever a adsorção de fosfato em solos. A partir daí, passou a ser amplamente utilizada para inúmeros cátions e ânions.

A equação é assim representada (Barrow, 1978):

$x=\frac{\mathrm{Kbc}}{1+\mathrm{Kc}}$ 
Em que $\mathrm{x}=$ quantidade de cádmio adsorvido por unidade de massa de solo; $\mathrm{c}=$ concentração de cádmio na solução de equilíbrio; $\mathrm{K}=$ termo de afinidade, refletindo a taxa relativa de adsorção e dessorção no equilíbrio; $b=$ adsorção máxima.

A forma linear, mais comumente utilizada em estudos de solo é representada por:

$$
\frac{\mathrm{c}}{\mathrm{x}}=\frac{1}{\mathrm{~Kb}}+\frac{\mathrm{c}}{\mathrm{b}}
$$

Pombo (1995) verificou que a adsorção de cádmio para solos do Rio Grande do Sul, em dois valores de pH, ajustou-se às equações de Langmuir. A adsorção variou com o pH, matéria orgânica, argila e capacidade de troca de cátions. Cavallaro \& McBride (1978) e Omae (1984) também obtiveram bons ajustes da equação de Langmuir aos dados de adsorção de cádmio.

\subsubsection{Equação de Freundlich}

Esta equação tem sido, freqüentemente, utilizada, para descrever a adsorção de diferentes elementos químicos pelo solo. A equação pode ser assim representada (Barrow, 1978).

$$
\mathrm{x}=\mathrm{K} \mathrm{C^{ \textrm {n } }}
$$


na qual $\mathrm{x}=$ quantidade de cádmio adsorvido por unidade de massa do solo: $\mathrm{C}=$ concentração de cádmio na solução de equilíbrio; $\mathrm{K}$ e $\mathrm{n}$ = parâmetros; ou, na forma linear:

$\log \mathrm{x}=\log \mathrm{K}+\mathrm{n} \log \mathrm{c}$

Os trabalhos de (Garcia-Miragaya \& Page,1978; Petruzzelli et al., 1985 e Pombo,1995) são exemplos de bom ajustes para adsorção de cádmio a esse modelo.

\subsection{Energia Livre}

De posse dos resultados obtidos em curvas de adsorção, pode-se calcular a energia livre molar do sistema. As mudanças que ocorrem quando um elemento é adsorvido podem servir como medida da extensão ou da força que guia determinada reação (Singh, 1971). A equação termodinâmica usada por Singh (1971) e recentemente por Alleoni \& Camargo (1998), estudando a adsorção de boro foi:

$$
\left.\Delta \mathrm{G}_{0}=\mathrm{R} T \text { (ln B equilíbrio }-\ln \mathrm{B} \text { adicionado }\right)
$$

em que $\Delta \mathrm{G}_{0}=$ energia livre $\left(\mathrm{mol} / \mathrm{L}, \mathrm{R}=8,30\right.$ Joules $/ \mathrm{mol}^{0} \mathrm{~K}$ e $\mathrm{T}=298{ }^{0} \mathrm{~K}$.

Os valores de $\Delta \mathrm{G}_{0}$ indicam quão distante do equilíbrio está o estado inicial do sistema. Seu sinal negativo indica que a reação é espontânea e exergônica. Por outro lado, valores positivos indicam que a reação é endergônica, não espontânea e quanto maior seu valor, maior será a força de determinada reação. 


\subsection{Os solos ácricos}

A palavra ácrico vem do grego akros, que significa "na ponta" ou "no fim". Uehara (1988) fez uma abordagem interessante a respeito dos chamados quatro extremos taxonômicos, nos quais o material ácrico, que representa o máximo acúmulo de minerais oxídicos, ocupa uma das posições. As outras três posições são ocupadas pelos materiais hísticos (acúmulo de material orgânico), ândico (acúmulo de material amorfo ou microcristalino) e vértico (acúmulo de material com argilas expansíveis), como ilustra a Figura 4.

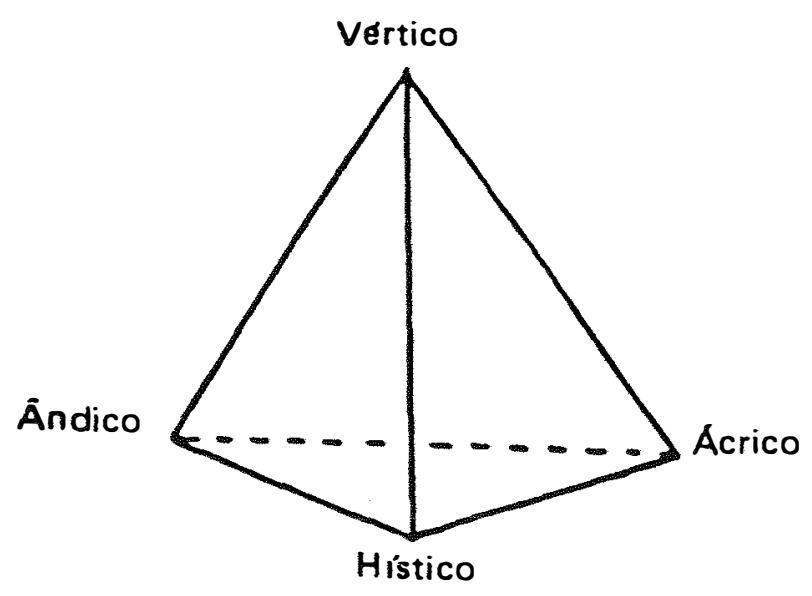

Figura 4 - Representação dos quatro extremos taxonômicos (Uehara, 1988).

Os solos ácricos representam o extremo na escala de intemperismo, sendo mais freqüentes em regiões próximas ao Equador, e dominam vasta região do norte paulista, onde são intensamente cultivados (Alleoni \& Camargo, 1994). Oliveira \& Prado (1987) contabilizaram $74.264,5$ ha ou $26 \%$ do total da quadrícula de Ribeirão Preto como solos ácricos (sozinhos ou associados), predominando Latossolos Roxos e Latossolos Vermelho-Escuros. Na região de 
Guaíra, foram registrados 95.200 ha de solos ácricos, correspondendo a Latossolos Roxos e variação Una (Oliveira \& Prado, 1991).

Segundo critério derivado da FAO (1989), o termo ácrico refere-se a materiais de solos que apresentam CTC efetiva igual ou menor que $15 \mathrm{mmol}_{\mathrm{c}} \mathrm{kg}^{-1}$ de argila, $\mathrm{pH}\left(\mathrm{KCl} 1 \mathrm{~mol} \mathrm{~L}^{-1}\right)$ maior ou igual a 5,0 ou $\Delta \mathrm{pH}\left(\mathrm{pH} \mathrm{KCl}-\mathrm{pH} \mathrm{H} \mathrm{H}_{2} \mathrm{O}\right)$ positivo ou nulo em uma profundidade de $125 \mathrm{~cm}$ (Embrapa, 1999).

Os estudos com metais pesados, como o cádmio, comumente concentramse na camada arável dos solos $(0-0,20 \mathrm{~m})$. Entretanto, é importante se conhecer também o comportamento dos elementos nas camadas mais profundas (Lune \& Zwart, 1997), principalmente quando o horizonte apresenta atributos eletroquímicos diferentes do horizonte $\mathrm{A}$, como é o caso dos solos ácricos.

\subsubsection{Atributos químicos, físicos e mineralógicos}

Os solos ácricos são normalmente profundos, variando de argilo-arenosos a muito argilosos, sendo bastante friáveis e com fraco desenvolvimento de macroestrutura no horizonte B (Alleoni \& Camargo, 1995). Apresenta forte microagregação, resultado da ação cimentante dos óxidos de ferro nas argilas, como consequência prática, a infiltração e a percolação de água são livres no perfil do solo. A quantidade de argila dispersa em água (ADA) é baixa, principalmente nos horizontes subsuperficiais, devido a proximidade dos valores de $\mathrm{pH}$ e do ponto de carga zero (PCZ). Esta proximidade é acompanhada de uma redução na carga superficial líquida, provocando a floculação dos colóides, fruto da diminuição na repulsão entre as duplas camadas elétricas das partículas de argila (Raij, 1972). Os valores de superfície específica são baixos, variando de 40

a $100 \mathrm{~m}^{2} \mathrm{~g}^{-1}$ no horizonte $\mathrm{B}$, conseqüência da predominância de minerais 
cauliníticos e oxídicos na fração argila e do baixo teor de matéria orgânica em profundidade (Alleoni \& Camargo, 1995).

Quimicamente, a principal característica dos solos ácricos é a baixa retenção de cátions, baixos valores de alumínio trocável e proximidade entre o $\mathrm{pH}$ do solo e seu PCZ no horizonte B. A proximidade desses valores acontece porque os óxidos que se acumulam após a intensa dessilicatização, apresentam altos índices de PCZ, entre 7,5 e 9,0 (Bell \& Gillman, 1978). Em muitos casos, o valor de PCZ supera o de $\mathrm{pH}$, conferindo um balanço positivo de carga ao solo, que passa a atuar predominantemente como trocador de ânions. $O$ fenômeno de reversão de carga ocorre quase sempre em profundidades maiores que $50 \mathrm{~cm}$, pois, nessa condição, a matéria orgânica, cujo PCZ é bastante baixo $(=2,0)$, praticamente não atua (Uehara, 1988). Os valores de potencial elétrico superficial são reduzidos, devido a proximidade do $\mathrm{pH}$ do solo de seu PCZ. Para solos com cargas variáveis, os íons $\mathrm{H}^{+}$e $\mathrm{OH}^{-}$são considerados determinadores de potencial elétrico superficial $\left(\psi \psi_{0}\right)$, assim considera-se que o $\psi_{0}$ também varia com o $\mathrm{pH}$ da solução de equilíbrio (Alleoni \& Camargo, 1994). Em relação à mineralogia da fração argila deferrificada, tem-se altas porcentagens de caulinita (argila do tipo 1:1) e gibbsita (hidróxido de alumínio). 


\section{MATERIAL E MÉTODOS}

As análises químicas, físicas e mineralógicas foram realizados nos Laboratórios do Departamento de Solos e Nutrição de Plantas, da Escola Superior de Agricultura "Luiz de Queiroz" e no Centro de Solos e Recursos Agroambientais do Instituto Agronômico de Campinas.

\subsection{Solos utilizados}

As amostras de solos foram coletadas nos municípios de Ribeirão Preto e Guaíra, região Norte do Estado de São Paulo, na camada superficial (0-0,20 m) e em profundidade, na maior expressão do horizonte diagnóstico, de acordo com levantamentos pedológicos realizados por (Oliveira \& Menk, 1984 e Oliveira \& Prado, 1987). Os solos foram os seguintes:

1. Latossolo Roxo ácrico- LR - Ribeirão Preto (Latossolo Vermelho acriférrico- LVwf);

2. Latossolo variação Una ácrico - LU - textura argilo arenosa - Guaíra (Latossolo Amarelo ácrico- LAw);

3. Terra Roxa Estruturada- TE - Ribeirão Preto (Nitossolo Vermelho eutroférrico- NVef). Os nomes entre parênteses correspondem a denominação pelo novo Sistema Brasileiro de Classificação de Solos (Embrapa, 1999). 
A Terra Roxa, cujo comportamento eletroquímico é diferente daquele dos Latossolos ácricos, por apresentar carga elétrica negativa ao longo de todo o perfil, foi utilizada como comparativo.

\subsection{Incubação dos solos}

A incubação dos solos foi realizada em maio/98, tendo como base a metodologia empregada por Barrow (1984). As amostras de solos coletadas foram passadas em peneiras de $2 \mathrm{~mm}$, colocadas em sacos plásticos e armazenadas no laboratório. Foram tomadas sete porções de $1,0 \mathrm{~kg}$ de terra fina seca ao ar (TFSA) de cada amostra dos solos estudados. Três porções receberam doses de carbonato de cálcio puro, correspondentes a 2, 8 e $16 \mathrm{tha}^{-1}$. Outras três porções receberam doses de ácido clorídrico nas mesmas proporções dos equivalentes de carbonato de cálcio adicionados. Uma das porções não recebeu nem ácido nem carbonato. As quantidades de $\mathrm{CaCO}_{3}$ (Merck) e $\mathrm{HCl}$ em solução (Merck - 1 mol dm ${ }^{-3}$ ), para cada $1,0 \mathrm{~kg}$ de solo estão descritas na Tabela 1 .

A cada dois dias foi adicionada água às amostras, sendo a primeira de $300 \mathrm{~g}$ de água (30\% em relação à massa de TFSA), e as subseqüentes foram controladas por pesagens, até completarem esse valor. A incubação foi conduzida até $\mathrm{pH}$ constante. A seguir, as amostras foram secas ao ar, passadas em peneira $2 \mathrm{~mm}$ e acondiconadas em sacos plásticos.

Das sete porções inicialmente tratadas com ácido ou com carbonato, foram selecionadas quatro porções de cada amostra dos solos estudados, com valores de $\mathrm{pH}$ próximos de 4,0, 5,0 6,0 e 7,0, abrangendo-se, assim a faixa de $\mathrm{pH}$ mais comumente encontrada nos solos do Estado de São Paulo. 
Tabela 1. Quantidades de $\mathrm{CaCO}_{3}$ e $\mathrm{HCl}$ aplicadas para cada $1,0 \mathrm{~kg}$ de terra das quatro porções selecionadas, abrangendo-se a faixa de $\mathrm{pH}$ desejada de cada amostra dos solos estudados.

\begin{tabular}{cccc}
\hline Solo & Horizonte & $\mathrm{HCl} 1 \mathrm{~mol} \mathrm{dm}^{-5}$ & $\mathrm{CaCO}_{3}$ \\
\hline TE & A & $80 ; 160$ & $\mathrm{~g}$ \\
& B & $80 ; 160$ & $2 ; 8$ \\
& & & 4 \\
LR & A & - & $2 ; 8 ; 16$ \\
& B & 80 & $2 ; 8$ \\
& A & 80 & $2 ; 8$ \\
LU & B & $80 ; 160$ & 4 \\
\hline
\end{tabular}

\subsection{Análises químicas}

Foram realizadas algumas análises químicas e eletroquímicas dos solos estudados que será descrita a seguir com algum detalhe, sendo que a metodologia utilizada encontra-se em Camargo et al. (1986).

a) Carbono orgânico: obtido pela oxidação da matéria orgânica do solo com solução de dicromato de potássio em presença de ácido sulfúrico e titulação do excesso de dicromato com sulfato ferroso amoniacal. O carbono ocorre no solo na forma tanto orgânica como inorgânica. O teor de matéria orgânica (M.O.) foi considerado como a quantidade de carbono orgânico (C) pela fórmula: $\%$ M.O. $=\%$ C X 1,725 . 
b) Cátions trocáveis $(\mathrm{Ca}, \mathrm{Mg}, \mathrm{K}$ e $\mathrm{Na})$ : extração dos elementos trocáveis com solução normal de acetato de amônio pH 7,0 e determinação de seus teores no extrato;

c) Ferro e alumínio livres $\left(\mathrm{Fe}_{\mathrm{d}}\right.$ e $\left.\mathrm{Al}_{\mathrm{d}}\right)$ : em meio tamponado com

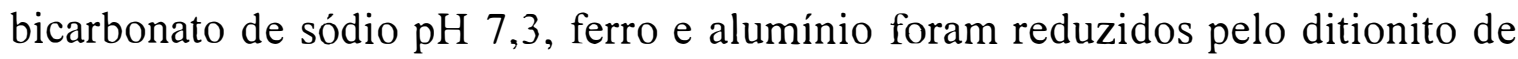
sódio e complexados pelo citrato de sódio, permanecendo em solução;

d) Ferro e alumínio amorfos $\left(\mathrm{Fe}_{0}\right.$ e $\left.\mathrm{Al}_{0}\right)$ : obtidos por solubilização do ferro/alumínio amorfos em ácido oxálico e seu sal de amônio;

e) Teores totais de óxidos $\left(\mathrm{SiO}_{2}\right.$ e $\left.\mathrm{Fe}_{2} \mathrm{O}_{3}, \mathrm{Al}_{2} \mathrm{O}_{3}, \mathrm{TiO}_{2}\right)$ : obtidos após ataque com ácido sulfúrico;

f) $\mathrm{pH}$ em $\mathrm{H}_{2} \mathrm{O}$ e em $\mathrm{KCl}$ mol dm${ }^{-3}$ : relação solo-solução 1:2,5 e obtenção dos valores pela medida da variação do potencial em um eletrodo de vidro com a variação da atividade hidrogeniônica da solução em que ele está mergulhado, usando um eletrodo de referência;

g) Ponto de efeito salino nulo (PESN): foi utilizado o método da titulação da amostra com $\mathrm{H}^{+}$e $\mathrm{OH}^{-}$, a três diferentes concentrações de eletrólito $(\mathrm{KCl})$, sendo o PESN o valor de pH no ponto em que ocorrerá intersecção das curvas de titulação, ou seja, o ponto em que independentemente das três concentrações do sal há somente um valor de $\mathrm{pH}$. Foram utilizadas soluções de $\mathrm{NaOH}(0,002$ e $\left.0,004 \mathrm{~mol} \mathrm{dm}^{-3}\right)$ e $\mathrm{HCl}\left(0,002 ; 0,004 ; 0,006 ; 0,0012 \mathrm{~mol} \mathrm{dm}^{-3}\right)$ em três diferentes concentrações do eletrólito suporte, ou seja, $\mathrm{KCl}\left(0,001 ; 0,01\right.$ e $\left.0,1 \mathrm{~mol} \mathrm{dm}^{-3}\right)$. O cloreto de potássio foi o sal escolhido, pois é um eletrólito do tipo indiferente, cujos íons tem raios hidratados semelhantes, capazes de serem adsorvidos de forma não específica (Sposito,1981). Foram utilizadas o equivalente a $4 \mathrm{~g}$ de terra fina seca em estufa em recipiente para determinação de pH e $20 \mathrm{~mL}$ de cada uma das soluções com concentrações de $\mathrm{KCl} 0,1 ; 0,01 ; 0,001 \mathrm{~mol} \mathrm{dm}^{-3}$ e as diferentes concentrações de ácido ou base. Deixou-se equilibrar por 24 horas. agitando ocasionalmente, procedendo a última agitação 30 minutos antes da leitura de $\mathrm{pH}$. 
$\mathrm{O}$ pH foi medido em potenciômetro digital. As determinações foram feitas em triplicata. A quantidade de $\mathrm{H}^{+} \mathrm{e} \mathrm{OH}^{-}$adsorvida pela amostra de terra, num dado valor de $\mathrm{pH}$, foi considerada igual à quantidade de milimols de $\mathrm{HCl}$ ou $\mathrm{NaOH}$ adicionada à suspensão menos a quantidade exigida de ácido ou base para trazer o mesmo volume e à mesma concentração de $\mathrm{HCl}$, sem a amostra de terra, ao mesmo valor de pH. O PESN foi considerado o ponto de intersecção das curvas de titulação obtidas na presença das três concentrações de $\mathrm{KCl}$.

h) Medidas de densidade de carga acessível: densidade de carga negativa permanente $\left(\sigma_{0}\right)$ e variável $\left(\sigma_{H}\right)$. O método utilizado para a quantificação das cargas permanentes e variáveis foi segundo Anderson \& Sposito (1991). O método utiliza apenas medidas de adsorção de um cátion na superfície dos colóides e é baseado na maior seletividade do $\mathrm{Cs}^{+}$nas cavidades siloxanas dos argilominerais 2:1 do que nas superfícies ionizáveis (Peixoto, 1995). Foram colocadas $3,5 \mathrm{~g}$ de solo em tubos de centrífuga de $50 \mathrm{~mL}$ e adicionadas soluções de $\mathrm{ClCs}$ com diferentes concentrações para promover a saturação do solo com ClCs, após a saturação, foi realizada a lavagem com etanol para reduzir a concentração de $\mathrm{Cs}^{+}$"entranhado" (não adsorvido). Posteriormente iniciou-se a extração do $\mathrm{Cs}^{+}$, primeiramente dos sítios de baixa seletividade $\left(\sigma_{\mathrm{H}}\right)$, com a utilização de solução de $\mathrm{LiCl} 0,01 \mathrm{~mol} \mathrm{dm}^{-3}$ (pH 6,0), e posteriormente realizouse a extração do $\mathrm{Cs}^{+}$dos sítios de alta seletividade $\left(\sigma_{0}\right)$, adicionando-se solução de $\mathrm{NH}_{4} \mathrm{Ac}$ 1,0 mol dm${ }^{-3}$. As concentrações de $\mathrm{Cs}^{+}$nos extratos de $\mathrm{LiCl}$ e $\mathrm{NH}_{4} \mathrm{Ac}$ foram determinadas por espectrometria de absorção atômica. A carga estrutural acessível da superfície, carga variável $\left(\sigma_{\mathrm{H}}\right)$, foi calculada como o excesso de $\mathrm{Cs}^{+}$ retido na superfície seguindo a troca $\mathrm{Cs}^{+}$pelo $\mathrm{Li}^{+}$e as cargas de superfície permanente efetiva $\left(\sigma_{0}\right)$ foi calculada como o excesso de $\mathrm{Cs}^{+}$retido na carga de superfície específica relativa seguindo a troca de $\mathrm{Cs}^{+}$pelo $\mathrm{Li}^{+}$. 
Após as determinações citadas, obtiveram-se os seguintes valores:

- Soma de bases $(\mathrm{SB})=\mathrm{Ca}+\mathrm{Mg}+\mathrm{K}+\mathrm{Na}$

- Capacidade de troca de cátions efetiva $\left(\mathrm{CTC}_{\mathrm{e}}\right)=\mathrm{SB}+\mathrm{Al}$

- Capacidade de troca de cátions total $\left(\mathrm{CTC}_{\mathrm{t}}\right)=\mathrm{SB}+(\mathrm{H}+\mathrm{Al})$

- Porcentagem de saturação por bases $(\mathrm{V} \%)=\mathrm{SB} \times 100 / \mathrm{CTC}_{\mathrm{t}}$

- $\Delta \mathrm{pH}=\mathrm{pH} \mathrm{KCl}-\mathrm{pH} \mathrm{H} \mathrm{H}_{2} \mathrm{O}$

- Porcentagem de saturação por alumínio $(\mathrm{m} \%)=100 \mathrm{Al} / \mathrm{SB}+\mathrm{Al}$

- Índice ki (índice de intemperização) $=\left(\mathrm{SiO}_{2} / 60\right) /\left(\mathrm{Al}_{2} \mathrm{O}_{3} / 102\right)$

- Índice $\mathrm{kr}=\left(\mathrm{SiO}_{2} / 60\right) /\left[\left(\mathrm{Al}_{2} \mathrm{O}_{3} / 102\right)+\left(\mathrm{Fe}_{2} \mathrm{O}_{3} / 160\right)\right]$

- Retenção de cátions $(\mathrm{RC})=\mathrm{CTC}_{\mathrm{e}} \times 100 /$ teor de argila

- Potencial superficial de carga $\left(\psi_{0}\right)$ : Foi utilizanda a equação de Nernst.

$\psi_{0}=59,1(\mathrm{PCZ}-\mathrm{pH})$

sendo que $\mathrm{PCZ}=$ ponto de carga zero, corresponde ao valor de $\mathrm{pH}$ no qual o somatório de cargas positivas se iguala ao somatório de cargas negativas. Porém, para o cálculo do potencial elétrico superficial foi considerado o valor do PESN, devido a proximidade dos valores de PCZ e PESN em solos com carga variável; - Carga elétrica líquida: foi determinada a partir do gráfico do PESN. O PESN teve seu ponto coincidido com o ponto zero de titulação (PZT), na qual obteve-se um valor de concentração de ácido, que foi descontado dos valores na região ácida ou alcalina e somados aos valores básicos da curva de titulação;

- Densidade superficial de carga $(\sigma)$ : Com os valores de SE (superficie específica) e da carga elétrica líquida. calculou-se a densidade de carga $(\sigma)$ a partir da relação:

$\sigma=$ Carga elétrica líquida / SE 


\subsection{Análises físicas e mineralógicas}

Foram realizadas algumas análises químicas e eletroquímicas dos solos estudados que será descrita a seguir com algum detalhe, sendo que a metodologia utilizada encontra-se em Camargo et al. (1986).

a) Análise granulométrica: realizada pelo método do densímetro. Foram tomados $20 \mathrm{~g}$ de terra e adicionadas $100 \mathrm{~mL}$ da solução dispersante. Para elaboração da solução dispersante, dissolveram-se $20 \mathrm{~g}$ de hidróxido de sódio em 5 litros de água destilada e adicinaram-se $50 \mathrm{~g}$ de hexametafosfato de sódio. A suspensão solo-dispersante foi agitada por $16 \mathrm{~h}$ em agitador rotatório a $30 \mathrm{rpm}$. Trasferiu-se a suspensão para uma proveta, e completou-se o volume de $1 \mathrm{~L}$ com água destilada. A amostra foi agitada com agitador manual por 40 segundos e, em seguida, iniciou-se a contagem do tempo de sedimentação. Após 40 segundos, introduziu-se o densimetro na suspensão e realizou-se a primeira leitura, correspondente às frações argila + silte. Após 2 h, realizou-se a segunda leitura, correspondente à fração argila. Por diferença, calcularam-se as quantidades de silte e areia;

b) Argila dispersa em $\mathrm{H}_{2} \mathrm{O}(\mathrm{ADA})$ : agitação de $10 \mathrm{~g}$ de terra fina (seca ao ar) com água destilada, durante dezesseis horas em agitador rotativo a $30 \mathrm{rpm}$, com determinação do tempo de sedimentação e obtenção de alíquotas, de maneira semelhante àquela utilizada para análise granulométrica;

c) Umidade na Capacidade de Campo: obtida por meio da aplicação de tensão de $0,3 \mathrm{MPa}$ às amostras deformadas de terra, previamente saturadas com água. Essa determinação teve como objetivo calcular a quantidade de água a ser adicionada no ensaio de incubação do solo com carbonato de cálcio e ácido clorídrico; 
d) Superfície específica (SE): empregou-se o método utilizado por Cihacek \& Bremner (1979), baseado na técnica da retenção de éter monoetílico do etilenoglicol (EMEG), proposto por Heilman et al. (1965). Em lugar do prétratamento das amostras com pentóxido de fósforo $\left(\mathrm{P}_{2} \mathrm{O}_{5}\right)$, para retirada de água, foi feita secagem das amostras em estufa por $24 \mathrm{~h}$ a $110^{\circ} \mathrm{C}$, conforme RatnerZohar et al. (1983). Para a retenção do EMGE, amostras com o equivalente a 0,5g de terra fina seca em estufa foram dispostas em dessecador contendo $\mathrm{CaCl}_{2}$ e mantidas por trinta minutos. A seguir foi adicionado lentamente $1 \mathrm{~mL}$ de EMEG em cada amostra, que era novamente colocada no dessecador ligado a uma bomba de vácuo, onde era aplicada pressão de $0,25 \mathrm{MPa}$ por 45 minutos. Foram efetuadas pesagens de quatro em quatro horas, intercaladas pela aplicação de vácuo, até que a massa ficasse constante (diferença inferior a $0,002 \mathrm{~g}$ ). As determinações foram feitas em triplicata. A superfície específica da amostra de terra, foi calculada da seguinte forma:

$\mathrm{SE}\left(\mathrm{m}^{2} \mathrm{~g}^{-1}\right)=(\mathrm{g}$ EMEG $/ \mathrm{g}$ terra $\left.) / 0,000286\right)$

e) Análise mineralógica qualitativa: realizada em amostras de argila previamente tratadas para eliminação da matéria orgânica e dos óxidos de ferro, com auxílio da difração de raios $\mathrm{X}$ nas amostras saturadas com $\mathrm{Mg}^{2+}$, glicoladas, e nas saturadas com $\mathrm{K}^{+}$e submetidas às temperaturas de 25,350 e $550^{\circ} \mathrm{C}$;

f) Análise mineralógica quantitativa: Caulinita e gibbsita foram quantificadas por meio da Análise Térmica Diferencial (ATD) na fração argila deferrificada (duas extrações com ditionito-citrato-bicarbonato de sódio). As amostras de argila deferrificada, isentas de matéria orgânica e saturadas com $\mathrm{Mg}$, foram misturadas com $\mathrm{Al}_{2} \mathrm{O}_{3}$ calcinado na proporção de 1:3. 


\subsection{Adsorção de cádmio}

No presente estudo foram utilizadas as amostras de solo incubadas com ácido e/ou com carbonato de cálcio e avaliou-se o efeito do pH na adsorção de cádmio. Foram tomadas amostras de $2,000 \mathrm{~g}$ de solo, com quatro repetições, colocadas em tubos de centrífuga de $50 \mathrm{~mL}$ e suspensas em $20 \mathrm{~mL}$ de solução $0,0025 \mathrm{~mol} \mathrm{dm}^{-3} \mathrm{de} \mathrm{Ca}\left(\mathrm{NO}_{3}\right)_{2}$ contendo $2 \mathrm{mg} \mathrm{dm}^{-3}$ de cádmio, como $\mathrm{Cd}\left(\mathrm{NO}_{3}\right)_{2}$. A dose foi escolhida de acordo com o trabalho de Gray et al. (1998), no qual os autores consideraram essa quantidade como a mais encontrada em solos contaminados por cádmio. Optou-se pela utilização do nitrato de cádmio $\left(\mathrm{Cd}\left(\mathrm{NO}_{3}\right)_{2}\right)$ e nitrato de cálcio $\left(\mathrm{Ca}\left(\mathrm{NO}_{3}\right)_{2}\right)$ ao invés de cloreto de cádmio $\left(\mathrm{CdCl}_{2}\right)$ e cloreto de cálcio $\left(\mathrm{CaCl}_{2}\right)$, devido à possibilidade de o cádmio formar clorocomplexos $\left(\mathrm{Cd}_{2}-\mathrm{Cl}^{-}\right)$altamente estáveis (Garcia-Miragaya \& Page, 1976 e Doner, 1978). A solução foi agitada em agitador horizontal (120 oscilações/minuto) por 24 horas. Após a agitação, o pH foi determinado e, em seguida, as soluções foram centrifugadas, sendo feita a determinação de cádmio no extrato por espectrofotometria de absorção atômica (PERKIN ELMER Modelo 5100 PC), no Centro de Solos e Recursos Agroambientais do Instituto Agronômico de Campinas. Para a determinação do cádmio nas amostras foi construída uma curva padrão obtida a partir das seguintes soluções: $0 ; 0,5 ; 1,0$; 1,$5 ; 2,0 \mathrm{mg} \mathrm{dm}^{-3}$ de cádmio. Para se ter segurança de que os resultados obtidos seriam confiáveis, sendo representativo da realidade, calculou-se o limite de deteç̧ão, que é definido como a concentração de um elemento que produz um sinal analítico distinguível do ruído (Skoog \& Leary, 1992 e Beaty \& Kerber,1993). Para uma boa precisão é necessário que as concentrações analisadas estejam acima do limite de deteç̧ão do aparelho.

O limite de deteç̧ão foi calculado efetuando-se um grande número de leituras do branco (23 leituras). Calculou-se o desvio padrão (s) das 
determinações, tomou-se como ruído um valor igual a $\mathrm{S}$, multiplicando-se por $\mathrm{k} \mathrm{o}$ valor do desvio padrão $(S=k$. $s)$, na qual $\mathrm{k}=3$, considerando-se $99 \%$ de probabilidade. Em seguida, com o valor do coeficiente angular da curva de calibração, calculou-se o limite de detecção (L.D.), dado em $\mathrm{mg} \mathrm{dm}^{-3}$, por meio da seguinte relação:

L. D. $=3 \mathrm{~s}$ ou S / Coeficiente angular

A quantidade de cádmio adsorvida pelo solo foi estimada subtraindo-se o valor determinado da quantidade inicialmente presente na solução de equilíbrio.

Em vista de não ter sido possível a obtenção dos mesmos valores de $\mathrm{pH}$ para cada amostra dos solos estudados, estimaram-se os valores de adsorção de cádmio para cada repetição, nos pH iguais a 4,5; 5,0; 5,5; 6,0; 6,5 e 7,0 por meio de interpolação dos pontos, procedimento disponível no programa Origin (Origin, 1999), e realizaram-se às comparações entre os solos e profundidades. Este procedimento de interpolação de pontos foi realizado seguindo-se os seguintes passos: os dados de adsorção obtidos em laboratório, referentes a cada repetição para cada amostra de solo e para cada $\mathrm{pH}$, foram digitalizados, e posteriormente as curvas foram plotadas, por meio da união dos pontos. Posteriormente foram estimados 500 valores de $\mathrm{pH}$ na faixa de 4,0 a 7,0 e correspondentes valores de adsorção de cádmio, utilizando-se dos dados originais. Com estes valores de $\mathrm{pH}$ e correspondentes quantidades de cádmio adsorvida, foram selecionados seis valores de $\mathrm{pH}$, espaçados de 0,5 unidade, entre 4,5 e 7,0, que correspondem aos mais comumente encontrados em solos do Estado de São Paulo. 


\subsection{Isotermas de adsorção}

À semelhança de (Pombo,1995 e Petruzzelli et al.,1985), foram tomadas amostras de 2,000 g de solo, em duplicata, colocando-as em tubos de centrífuga de $50 \mathrm{~mL}$ e suspensas em $20 \mathrm{~mL}$ de solução $0,0025 \mathrm{~mol} \mathrm{dm}^{-3}$ de $\mathrm{Ca}\left(\mathrm{NO}_{3}\right)_{2}$ contendo cádmio como $\mathrm{Cd}\left(\mathrm{NO}_{3}\right)_{2}$, nas concentrações de $0,5,10,15,25,50,75$,

$100,125,150,175,200 \mathrm{mg} \mathrm{dm}^{-3}$ de cádmio. A solução foi agitada em agitador horizontal (120 oscilações/minuto) por 24 horas. Após a agitação, o pH foi medido e, em seguida, as soluções foram centrifugadas, sendo feita a determinação de cádmio no extrato por espectrometria de absorção atômica. A curva padrão utilizada foi a mesma do item 3.5, sendo necessárias diluições quando os resultados estavam fora da faixa linear da curva. Para construção das curvas e obtenção das constantes de Langmuir (adsorção máxima e afinidade), e também os parâmetros K e n da equação de Freundlich, foi utilizado o programa "Fitfun.bas" (Barrow, 1987a), que ajusta equações não lineares aos dados de adsorção, seguindo a metodologia dos "mínimos quadrados" (Shani et al., 1992).

\subsection{Energia Livre}

De posse dos resultados obtidos em curvas de adsorção, calculou-se a energia livre molar do sistema. A equação termodinâmica usada foi a mesma utilizada por Singh (1971) e Alleoni \& Camargo (1998):

$\Delta \mathrm{G}_{\mathrm{o}}=\mathrm{R} T$ (ln Cádmio em equilíbrio - ln Cádmio adicionado)

sendo que $\Delta \mathrm{G}_{\mathrm{o}}=$ energia livre $\left(\mathrm{J} \mathrm{mol}^{-1}\right), \mathrm{R}=8,30 \mathrm{~J} \mathrm{~mol}^{-1} \mathrm{~kg}^{-1}$ e $\mathrm{T}=298^{\circ} \mathrm{K}$ 


\subsection{Análises estatísticas}

O delineamemnto foi inteiramente casualizado em esquema fatorial $3 \times 2 \times 6$, sendo 3 tipos de solo (TE, LR e LU), dois horizontes (A e B) e 6 valores de $\mathrm{pH}(4,5 ; 5,0 ; 5,5 ; 6,0 ; 6,5 ; \mathrm{e} 7,0)$ com quatro repetições.

A partir dos dados coletados em laboratório foi realizada a análise de variância e posterior aplicação do teste $\mathrm{F}$ para todos os fatores estudados e interações. Quando o teste F foi significativo, aplicou-se o teste de comparação múltiplas ( teste de Tukey) ao nível de 5\%.

Foi também realizada analises de regressão e correlação linear simples entre as constantes obtidas pelas equação de Langmuir e de Freundlich e os atributos químicos, físicos e mineralógicos dos solos. O tratamento estatístico dos dados foi efetuado utilizando o programa SAS (Statistical Analysis System) (SAS Institute, 1988). 


\section{RESULTADOS E DISCUSSÃO}

\subsection{Incubação com $\mathrm{HCl}$ e $\mathrm{CaCO}_{3}$}

Os valores de $\mathrm{pH}$ obtidos em $\mathrm{CaCl}_{2} 0,01 \mathrm{~mol} \mathrm{dm}^{-3}$, das amostras selecionadas para cada solo, abrangendo-se a faixa de $\mathrm{pH}$ geralmente encontrada em solos do Estado de São Paulo pela incubação com $\mathrm{HCl}$ e $\mathrm{CaCO}_{3}$ estão apresentados na Tabela 2. Os valores de $\mathrm{pH}$ obtidos pela incubação estão dentro da faixa desejada, porém não se conseguiram valores iguais para todos os solos.

Tabela 2. Valores de $\mathrm{pH}$ das amostras selecionadas abrangendo-se a faixa de $\mathrm{pH}$ de 4,0 a 7,3 obtidos pela incubação dos solos com $\mathrm{HCl}$ e $\mathrm{CaCO}_{3}$

\begin{tabular}{ccccccccc}
\hline Solo & \multicolumn{3}{c}{ Superfície } & \multicolumn{5}{c}{ Profundidade } \\
\hline TE & 4,0 & 4,7 & $5,6^{*}$ & 7,3 & 3,2 & 3,6 & $5,6^{*}$ & 7,3 \\
& & & & & & & & \\
LR & $4,3^{*}$ & 5,6 & 7,3 & 7,3 & 3,3 & $4,9^{*}$ & 6,6 & 7,3 \\
& & & & & & & & \\
LU & 3,2 & $4,3^{*}$ & 5,5 & 7,1 & 3,2 & 3,7 & $5,9^{*}$ & 7,3 \\
\hline
\end{tabular}

* Correspondem ao pH natural dos solos (testemunhas). 


\subsection{Análises químicas e eletroquímicas}

Os resultados das análises químicas estão apresentados nas Tabelas 3, 4, 5 e 6. O Latossolo Roxo e o Latossolo variação Una em subsuperfície possuem baixos teores de cátions, devido ao grau de intemperismo avançado, com consequente lixiviação de cátions (Tabela 3). Estes solos apresentam baixa CTC e baixa retenção de cátions (RC), característica de solos ácricos, que possuem $\mathrm{RC}<$ $15 \mathrm{mmol}_{\mathrm{c}} \mathrm{kg}^{-1}$. A Terra Roxa Estruturada, utilizada como comparativo, apresentou resultados contrastantes, com altos teores de cátions, CTC e alta RC, tanto em superfície, como em profundidade.

$\mathrm{O}$ índice ki teve seus maiores valores na TE do que nos Latossolos, devido ao menor grau de intemperismo (Tabela 4). Segundo Resende \& Santana (1988), os solos podem ser classificados de acordo com seus valores de ki e $\mathrm{kr}$ como: caulinítico não sesquioxídico ( $\mathrm{ki}>0,75$ e kr $>0,75$ ); gibbsítico sesquioxídico ( $\mathrm{ki}$ $\leq 0,75$ e $\mathrm{kr} \leq 0,75)$ e caulinítico sesquioxídico $(\mathrm{ki}>0,75$ e $\mathrm{kr} \leq 0,75)$. Utilizandose desta classificação e observando-se os valores de ki e $\mathrm{kr}$ dos três solos estudados (Tabela 4), a Terra Roxa Estruturada, o Latossolo Roxo ácrico e o Latossolo variação Una ácrico podem ser classificados como: caulinítico não sesquioxídico, gibbsítico sesquioxídico e caulinítico sesquioxídico respectivamente.

Os teores totais de óxidos de ferro e de alumínio foram superiores no Latossolo Roxo (Tabela 4). As quantidades de óxidos de ferro mal cristalizados foram pequenas nos solos estudados. Em média, 50\% do óxido de ferro total estava na forma livre e no LU em superfície, a forma livre correspondeu a quase $80 \%$ do ferro total. Já a porcentagem de óxido de alumínio livre correspondeu. em média, a $10 \%$ do total na TE e no $L R$, porém no LU esse valor foi próximo de $20 \%$. 


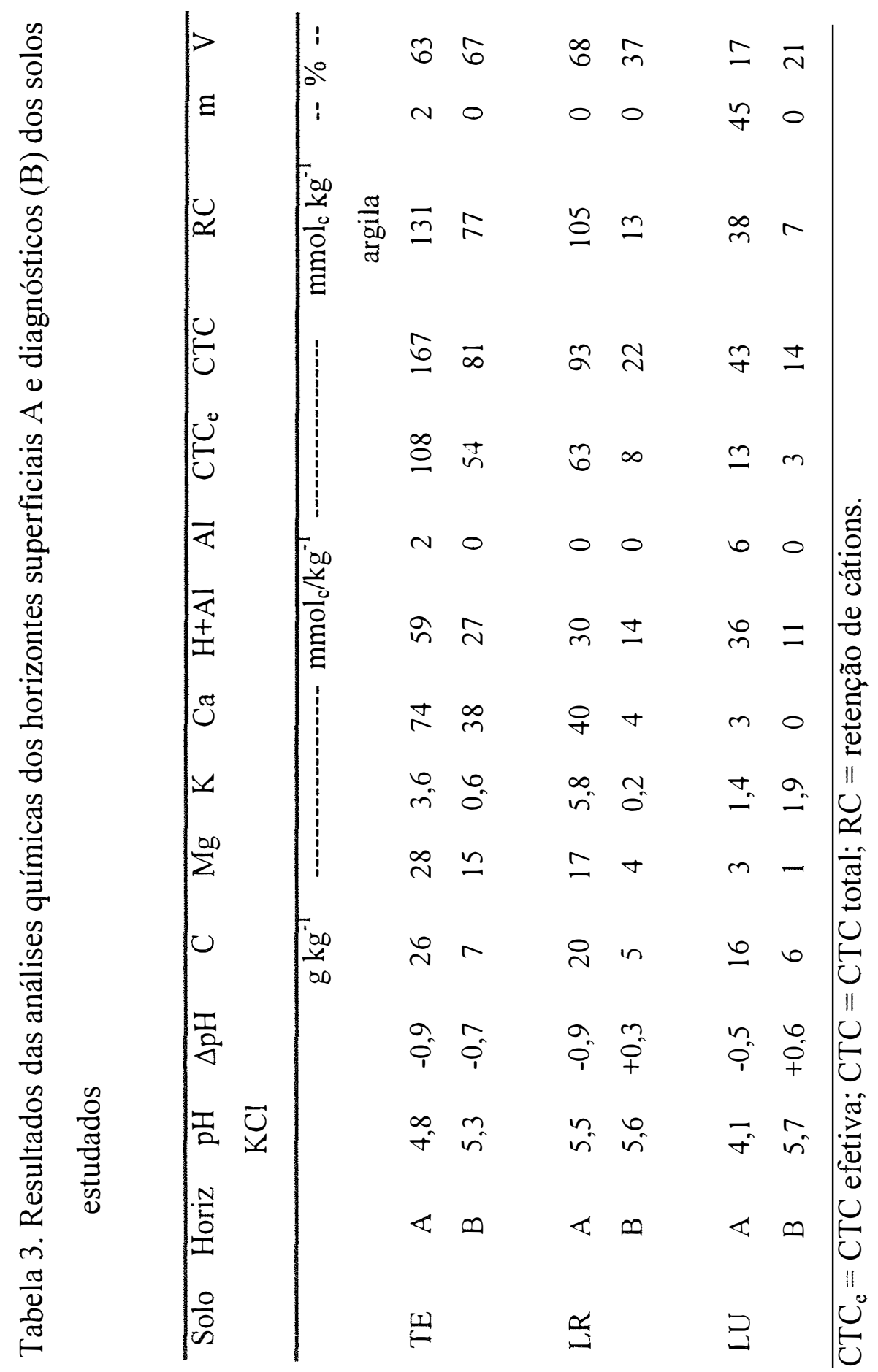


Com relação aos atributos eletroquímicos, os valores de $\Delta \mathrm{pH}$ (Tabela 3), nos horizontes superficiais dos três solos estudados foram negativos, provavelmente pela contribuição da matéria orgânica. Porém. em subsuperfície, o Latossolo Roxo e o Latossolo variação Una apresentaram potenciais elétricos superficiais $\left(\psi_{0}\right)$ positivos. Essa reversão de carga pode ocorrer em solos ácricos nas camadas subsuperficiais, devido à predominância de óxidos e hidróxidos de ferro e alumínio e baixos teores de matéria orgânica (Tabela 4).

Tabela 4. Teores de óxidos de silício, de titânio, de ferro e de alumínio totais, livres $\left(\mathrm{Fe}_{\mathrm{d}}\right.$ e $\left.\mathrm{Al}_{\mathrm{d}}\right)$ e mal cristalizados $\left(\mathrm{Fe}_{\mathrm{o}}\right.$ e $\left.\mathrm{Al} \mathrm{o}_{\mathrm{o}}\right)$, índices ki e $\mathrm{kr}$ dos horizontes superficiais (A) e diagnóstico (B) dos solos estudados.

\begin{tabular}{lccccccccccc}
\hline Solo & Horiz. & $\mathrm{SiO}_{2}$ & $\mathrm{Fe}_{2} \mathrm{O}_{3}$ & $\mathrm{Al}_{2} \mathrm{O}_{3}$ & $\mathrm{TiO}_{2}$ & $\mathrm{Fe}_{\mathrm{d}}$ & $\mathrm{Al}_{\mathrm{d}}$ & $\mathrm{Fe}_{\mathrm{o}}$ & $\mathrm{Al}_{\mathrm{o}}$ & $\mathrm{ki}$ & $\mathrm{kr}$ \\
\hline \multirow{2}{*}{$\mathrm{TE}$} & $\mathrm{A}$ & 153 & 298 & 183 & 77 & 139 & 23 & 22 & 8 & 1,42 & 0,70 \\
& $\mathrm{~B}$ & 227 & 273 & 237 & 71 & 138 & 21 & 27 & 7 & 1,62 & 0,94 \\
& & & & & & & & & & & \\
$\mathrm{LR}$ & $\mathrm{A}$ & 112 & 321 & 248 & 108 & 131 & 26 & 22 & 10 & 0,77 & 0,42 \\
& $\mathrm{~B}$ & 114 & 338 & 257 & 106 & 158 & 21 & 31 & 7 & 0,75 & 0,41 \\
& & & & & & & & & & & \\
$\mathrm{LU}$ & $\mathrm{A}$ & 52 & 59 & 113 & 27 & 44 & 22 & 2,1 & 6 & 0,78 & 0,59 \\
& $\mathrm{~B}$ & 80 & 134 & 172 & 40 & 72 & 31 & 1,4 & 8 & 0,79 & 0,52 \\
\hline
\end{tabular}

Os resultados do ponto de efeito salino nulo (PESN) confirmam os resultados comentados anteriormente, pois os Latossolos ácricos em profundidade apresentaram altos valores de PESN (Tabela 5), estando acima do $\mathrm{pH}$ do solo, devido à predominância de óxidos de ferro e alumínio, que possuem valores de PESN próximos de 8,0. Nestas condições, os potenciais elétricos superficiais $\left(\psi_{\mathrm{o}}\right)$ 
(Tabela 5) passam de valores negativos no horizonte A para valores positivos no horizonte $\mathrm{B}$, apresentando assim carga líquida positiva nessa camada. Em superfície a matéria orgânica, foi responsável pelos baixos valores de PESN encontrados nos três solos estudados, por apresentar PESN próximo de 2,0 (Sparks, 1995).

Tabela 5. Pontos de Efeito Salino Nulo (PESN), Potencial Elétrico, carga elétrica líquida e densidade de cargas para os solos estudados.

\begin{tabular}{cccccc}
\hline Solo & Horizontes & PESN & $\begin{array}{c}\text { Potencial Elétrico } \\
\left(\Psi_{0}\right)\end{array}$ & Carga líquida & $\begin{array}{c}\text { Densidade de } \\
\text { cargas }\end{array}$ \\
\hline \multirow{2}{*}{ TE } & A & 3,6 & $-121,2$ & -25 & $-1,86$ \\
& B & 3,6 & $-141,8$ & -35 & $-2,31$ \\
& & & & & \\
\multirow{2}{*}{ LR } & A & 3,6 & $-165,5$ & -14 & $-2,16$ \\
& B & 5,6 & 20,7 & +2 & $+0,26$ \\
& & & & & -12 \\
\multirow{2}{*}{ LU } & A & 3,4 & $-70,9$ & -12 & $-1,85$ \\
& B & 6,0 & 56,2 & +6 & $+1,12$ \\
\hline
\end{tabular}

A Terra Roxa Estruturada apresentou PESN inferior ao $\mathrm{pH}$ do solo nos horizontes superficiais e subsuperficiais, devido à constituição mineralógica da fração argila ser predominantemente caulinítica. Nesse solo, os valores de cargas negativas variáveis $\left(\sigma_{\mathrm{H}}\right)$ e permanentes $\left(\sigma_{0}\right)$ (Tabela 6) foram os mais altos. tanto em superfície como em profundidade, conferindo potenciais elétricos negativos em todo perfil (Tabela 5). Esses valores de PESN explicam os baixos valores de RC (retenção de cátions) (Tabela 3 ) encontrados nos horizontes subsuperficiais 
dos Latossolos ácricos. Consequentemente, a capacidade de troca de ânions é maior que a capacidade troca de cátions nesses horizontes. Em superfície, os valores de densidade de carga foram semelhantes para os três solos, enquanto que em profundidade os Latossolos ácricos apresentaram menores valores devido aos baixos valores de carga líquida, como mostra a proximidade do $\mathrm{pH}$ em relação ao PESN.

Tabela 6. Medidas da densidade de carga negativa variável $\left(\sigma_{H}\right)$ e permanente $\left(\sigma_{0}\right)$ dos três solos estudados

\begin{tabular}{|c|c|c|c|}
\hline \multirow[t]{2}{*}{ Solo } & \multirow[t]{2}{*}{ Horizonte } & \multicolumn{2}{|c|}{ Densidade de carga negativa } \\
\hline & & variável $\left(\sigma_{\mathrm{H}}\right)$ & permanente $\left(\sigma_{0}\right)$ \\
\hline & & $\mathrm{m}$ & $\mathrm{kg}^{-1}$ \\
\hline \multirow[t]{2}{*}{ TE } & A & 63,1 & 30,2 \\
\hline & B & 35,4 & 30,9 \\
\hline \multirow[t]{2}{*}{ LR } & A & 39,9 & 8,2 \\
\hline & B & 16.1 & 4,7 \\
\hline \multirow[t]{2}{*}{$\mathrm{LU}$} & A & 32,3 & 8,4 \\
\hline & B & 18,4 & 1,3 \\
\hline
\end{tabular}

Os valores representativos de carga negativa variável $\left(\sigma_{H}\right)$ encontradas nos solos eram esperadas, pois em solos tropicais os principais materiais responsáveis pela geração de cargas são a matéria orgânica. a caulinita e os óxidos e os hidróxidos de $\mathrm{Fe}$ e de Al, que possuem cargas variáveis (Smith \& Emerson. 1976 e Brady, 1983). Verifica-se também que as medidas de carga negativa variável 
$\left(\sigma_{\mathrm{H}}\right)$ diminuíram em profundidade, o que pode ser atribuído ao menor teor de matéria orgânica, que é a principal geradora de cargas nos solos.

A presença de carga elétrica negativa permanente, embora pequena, pode ser explicada pela presença de argilominerais 2:1 nos solos. Fontes \& Sposito (1995), analisando carga estrutural acessivel ao $\mathrm{Cs}^{+}$em três solos brasileiros, verificaram que a carga permanente medida foi consistente com a mineralogia detectada pela difração de raios $\mathrm{X}$ em dois dos três solos estudados, sendo que o terceiro solo, apesar de não mostrar pico distintivo de minerais $2: 1$, apresentou alta carga permanente. Os autores sugeriram que provavelmente este solo apresenta algum mineral 2:1 não detectado pela análise de raios $\mathrm{X}$.

As medidas de carga elétrica negativa permanentes $\left(\sigma_{0}\right)$ foram maiores na Terra Roxa Estruturada em relação ao Latossolos ácricos, provavelmente devido ao seu menor grau de intemperização, apresentando em sua constituição mineralógica minerais do tipo 2:1 além de minerais $1: 1$, como a caulinita.

\subsection{Análises físicas}

Os resultados obtidos nas análises físicas encontram-se na Tabela 7. Quanto à textura, a TE e o LR são classificados como argilosos, enquanto o LU se enquadra na classe franco-argiloso (Brady, 1989).

Os valores de argila dispersa em água (ADA) foram menores nos Latossolos ácricos, sendo estes resultados semelhantes aos encontrados por Alleoni \& Camargo (1994), os quais sugeriram que a redução da ADA em latossolos ácricos é devida principalmente ao balanço de cargas, potencial elétrico e $\triangle \mathrm{pH}$. A proximidade do valor do $\mathrm{pH}$ com o PESN é acompanhado de uma redução na carga superficial líquida e, devido à menor repulsão entre as duplas 
camadas elétricas as partículas de argila, estas passam a interagir livremente, atraindo-se por forças de van der Walls, floculando-se (Raij, 1972).

Tabela 7. Resultados das análises físicas dos horizontes $\mathrm{A}$ e $\mathrm{B}$ dos solos estudados

\begin{tabular}{lccccccc}
\hline Amostra & Horiz. & Areia & Silte & Argila & ADA & Ucc & S.E. \\
\hline \multirow{2}{*}{ TE } & A & 60 & 120 & 820 & 420 & 30 & 134 \\
& B & 80 & 220 & 700 & 90 & 31 & 151 \\
& & & & & & & \\
LR & A & 170 & 230 & 600 & 340 & 25 & 65 \\
& B & 130 & 230 & 640 & 20 & 27 & 76 \\
& & & & & & & \\
LU & A & 610 & 40 & 350 & 180 & 13 & 65 \\
& B & 510 & 40 & 450 & 0 & 19 & 53
\end{tabular}

$\mathrm{ADA}=$ argila dispersa em água; Ucc $=$ umidade na capacidade de campo; S.E. $=$ superfície específica.

Os baixos valores de SE (superfície específica) encontradas nos Latossolos ácricos (Tabela 7) estão relacionados à predominância de caulinita e de óxidos e hidróxidos de ferro e de alumínio, na fração argila desses solos (Alleoni \& Camargo, 1994).

\subsection{Análises mineralógicas qualitativa e quantitativa}

Os resultados obtidos na análise mineralógica quantitativa das amostras superficiais e subsuperficiais, por meio de análise termodiferencial, encontram-se 
na Tabela 8 e na Figura 5. Verifica-se que a presença de gibbsita (hidróxido de alumínio) foi maior nos Latossolos ácricos, sendo mais acentuada no Latossolo Roxo. Já na Terra Roxa Estruturada a caulinita predominou. Esses resultados estão coerentes com a classificação de Resende \& Santana (1988), mencionada anteriormente.

Tabela 8. Composição mineralógica quantitativa dos horizontes superficiais (A) e diagnósticos (B) dos solos estudados.

\begin{tabular}{lcccc}
\hline Amostras & \multicolumn{2}{c}{ Caulinita } & \multicolumn{2}{c}{ Gibbsita } \\
\hline & Superfície & Profundidade & Superficie & Profundidade \\
& -149 & 263 & 59 & 80 \\
TE & 172 & 216 & 375 & 431 \\
LR & 248 & 196 & 200 & 189 \\
LU & & & \\
\hline
\end{tabular}

Nas Figuras 6, 7, 8, 9, 10 e 11 são apresentados os difratogramas de raios $\mathrm{X}$ da fração argila deferrificada dos horizontes superfíciais e subsuperficiais dos solos. A caulinita, com picos a $0,7 \mathrm{~nm}$ e $0,43 \mathrm{~nm}$. foi o mineral dominante, aparecendo em todos os solos, seguida pela gibbsita, com picos a $0,49 \mathrm{~nm}$ e 0 , $43 \mathrm{~nm}$. Indícios de mica apareceram somente no horizonte A do LU, sendo este mineral identificado em picos de $1,0 \mathrm{~nm}$ e $0,33 \mathrm{~nm}$. A TE em superfície apresentou mais de um tipo de mineral $2: 1$, clorita com vermiculita intraestratificada $(\mathrm{CI} / \mathrm{V}) \mathrm{e}$ indícios de vermiculita $(\mathrm{V})$, com picos de $1,4 \mathrm{~nm}$ para $\mathrm{Cl} / \mathrm{V}$ e $1,2 \mathrm{~nm}$ e $0,98 \mathrm{~nm}$ para a vermiculita. O quartzo não apareceu no LU. estando presente no LR no horizonte A e B e na TE superfície, em 0,34nm e 0,33nm. 

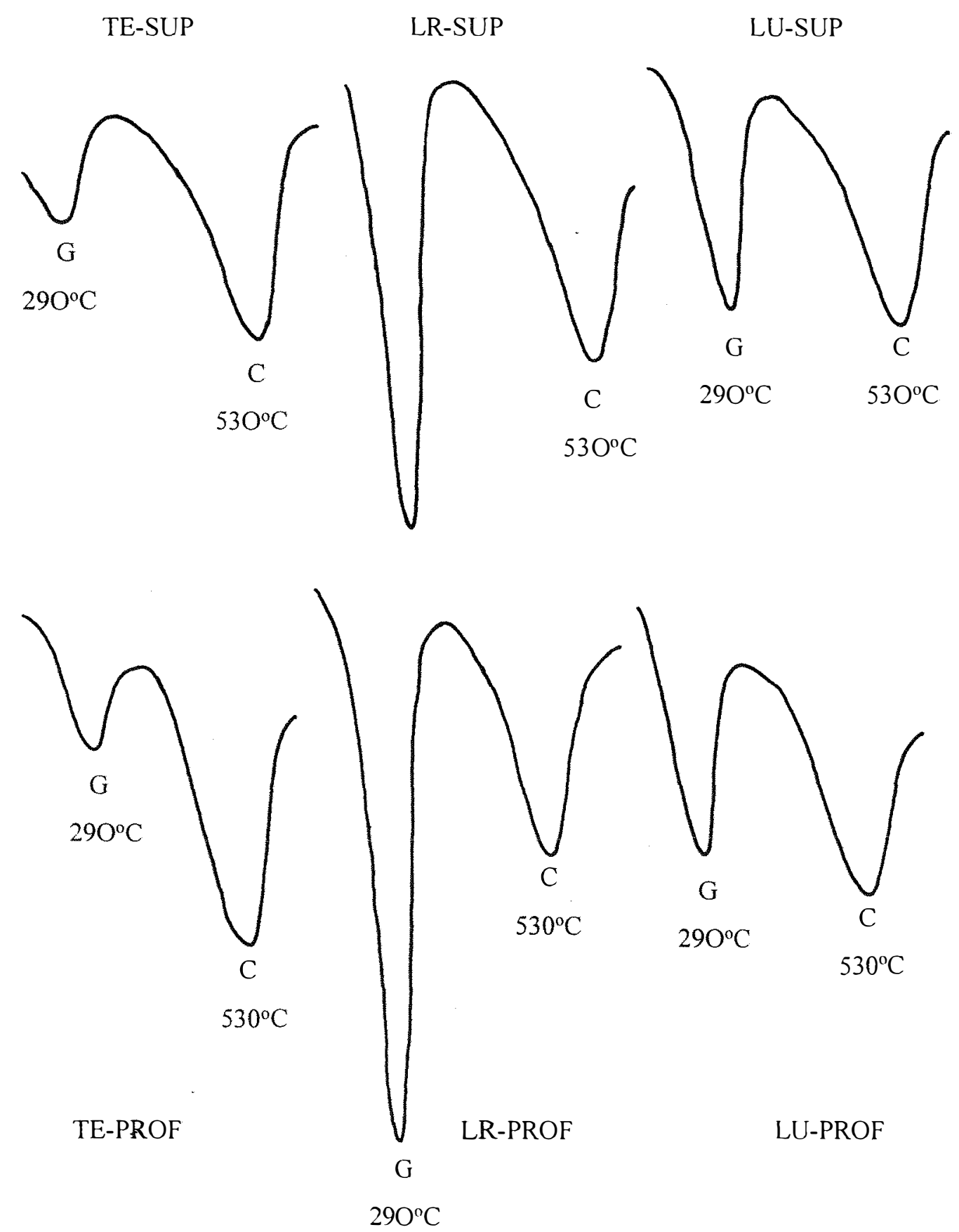

Figura 5 - Curvas de análise térmica diferencial das frações argilas, livre de ferro e saturadas com $\mathrm{Mg}$, dos horizontes A e B dos solos estudados ( $\mathrm{C}=$ caulinita e $\mathrm{G}=$ gibbsita) 


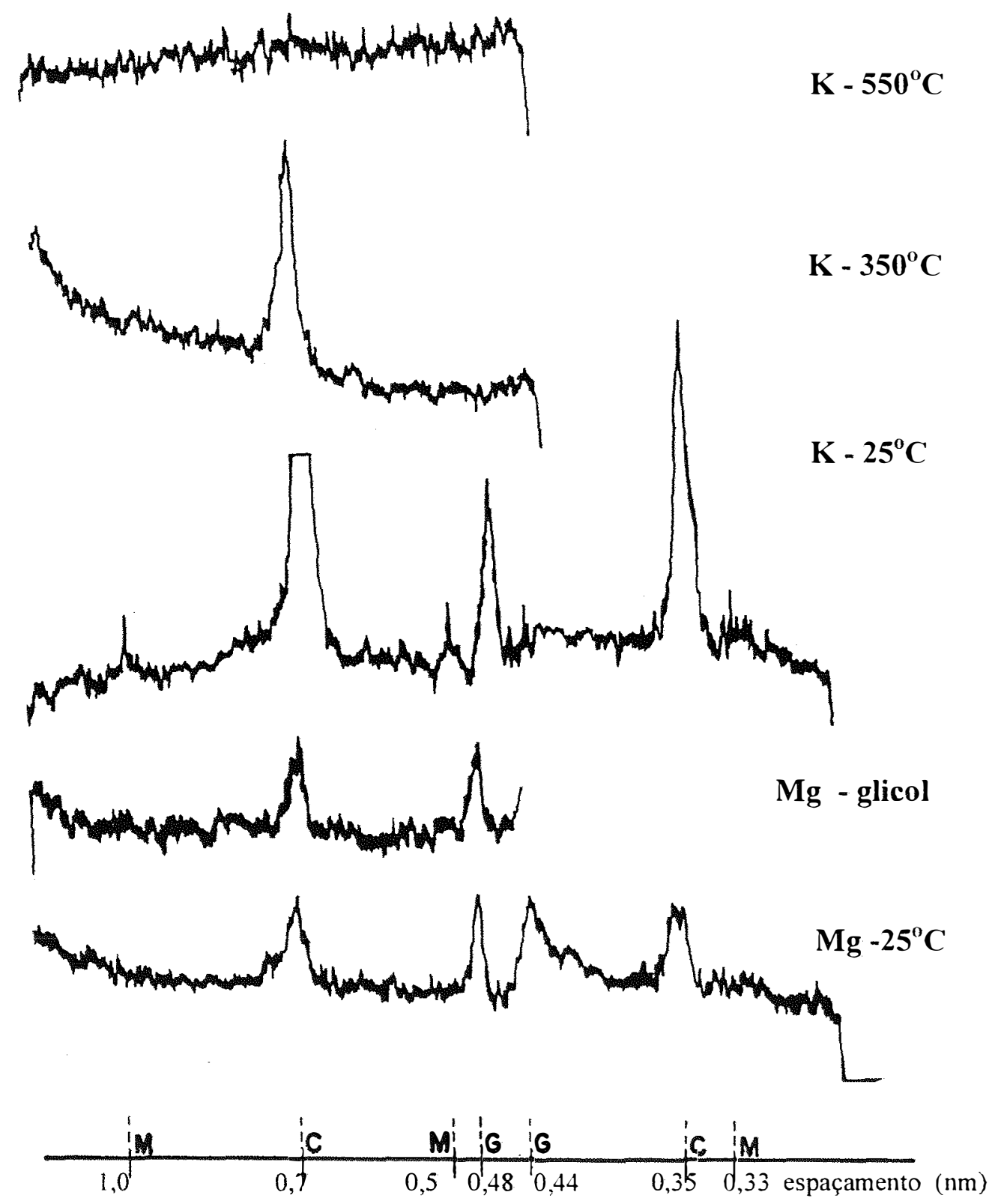

Figura 6 - Difratogramas de raio-X da fração argila deferrificada do horizonte $\mathrm{A}$ do Latossolo variação Una ácrico ( $\mathrm{C}=$ caulinita; $\mathrm{G}=$ gibbsita; $\mathrm{M}=$ indícios de mica) 


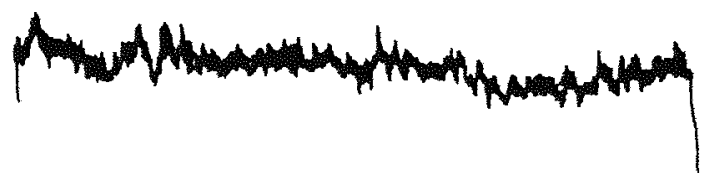

$$
\mathrm{K}-\mathbf{5 5 0}^{\circ} \mathrm{C}
$$

$\int_{1}$

$\mathrm{K}-350^{\circ} \mathrm{C}$
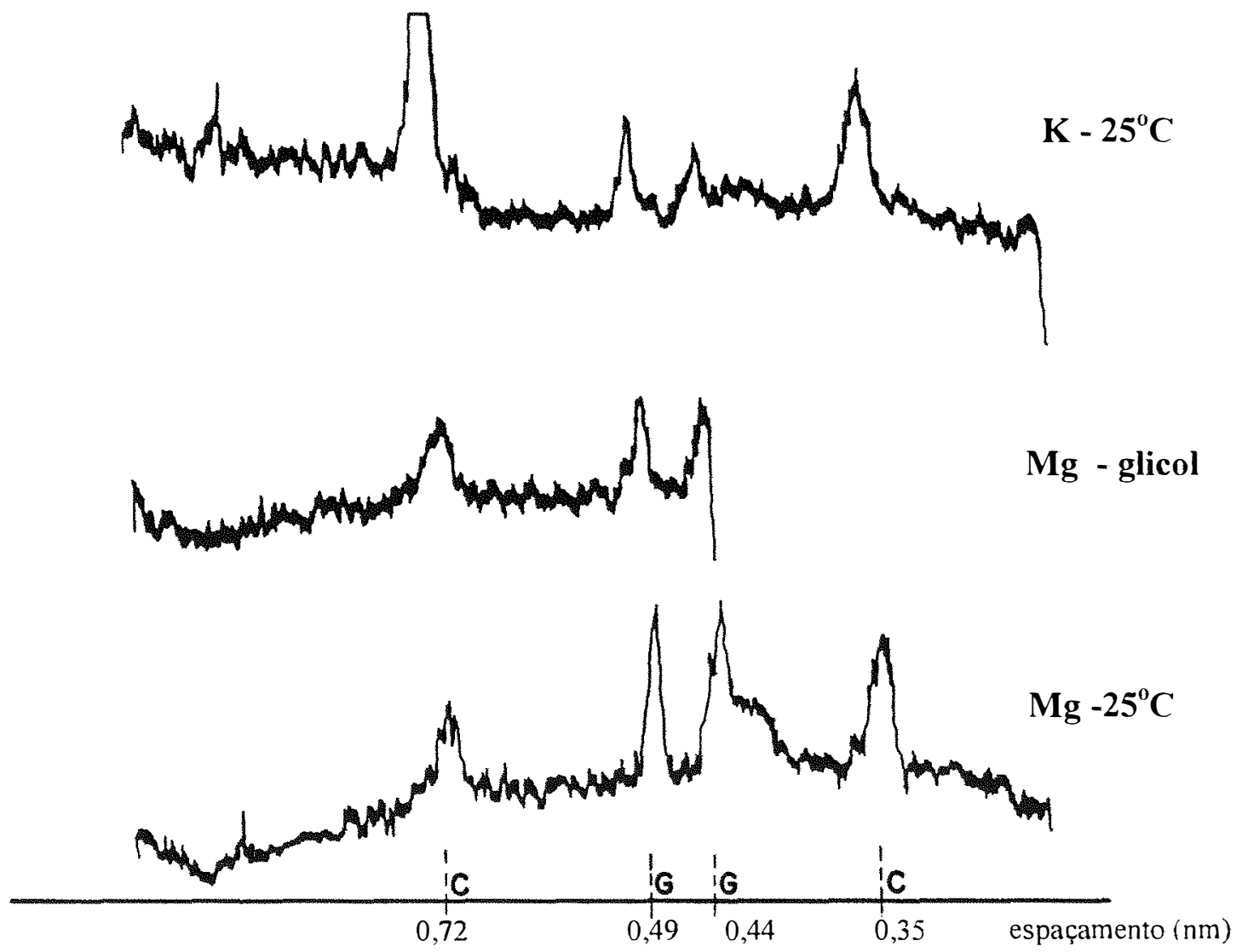

Figura 7 - Difratogramas de raio-X da fração argila deferrificada do horizonte $B$ do Latossolo variação Una ácrico ( $\mathrm{C}=$ caulinita; $\mathrm{G}=$ gibbsita) 


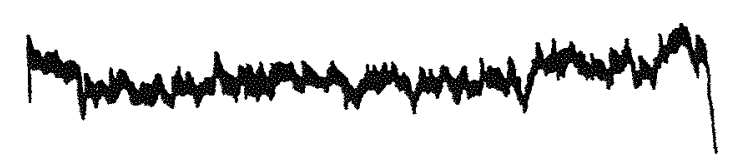

$K-550^{\circ} \mathrm{C}$ (1)
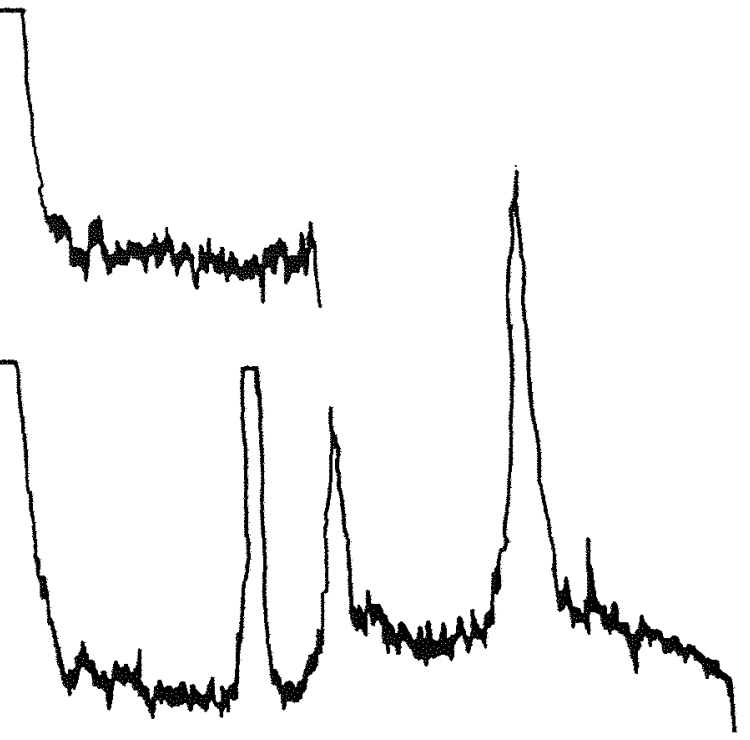

$K-350^{\circ} \mathrm{C}$
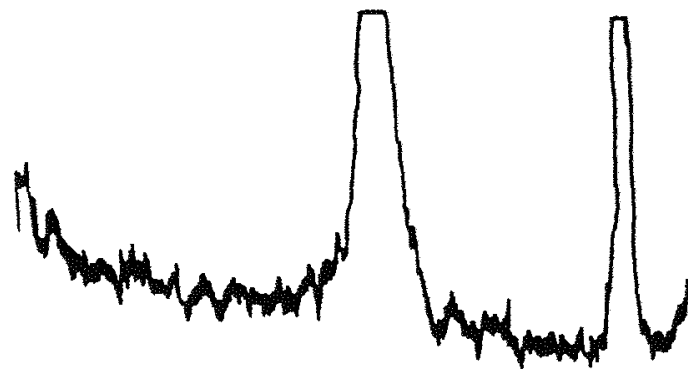

$\mathrm{K}-25^{\circ} \mathrm{C}$
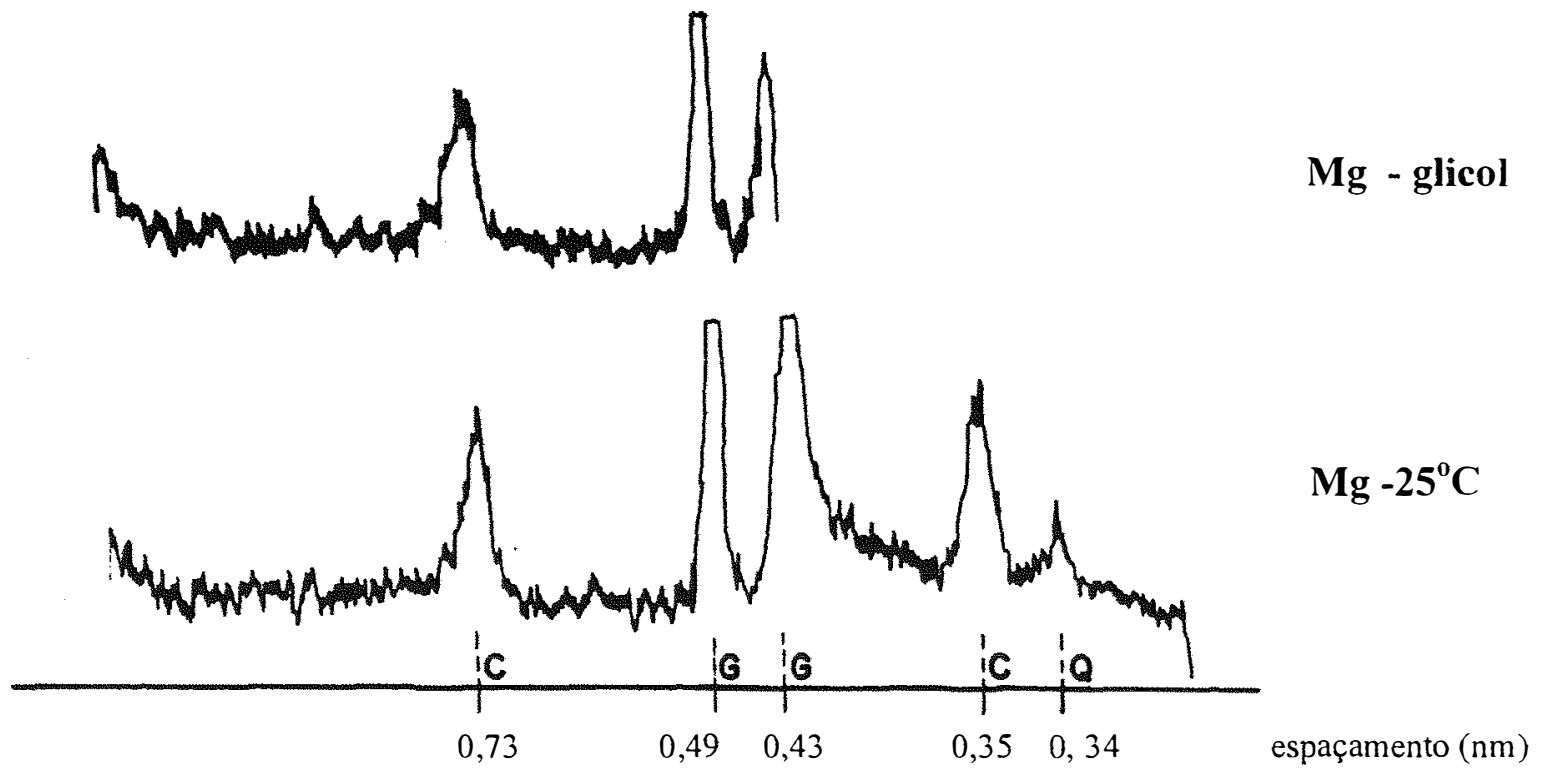

Figura 8 - Difratogramas de raio-X da fração argila deferrificada do horizonte $A$ do Latossolo Roxo ácrico ( $\mathrm{C}$ = caulinita; $\mathrm{G}=$ gibbsita; $\mathrm{Q}=$ quartzo) 


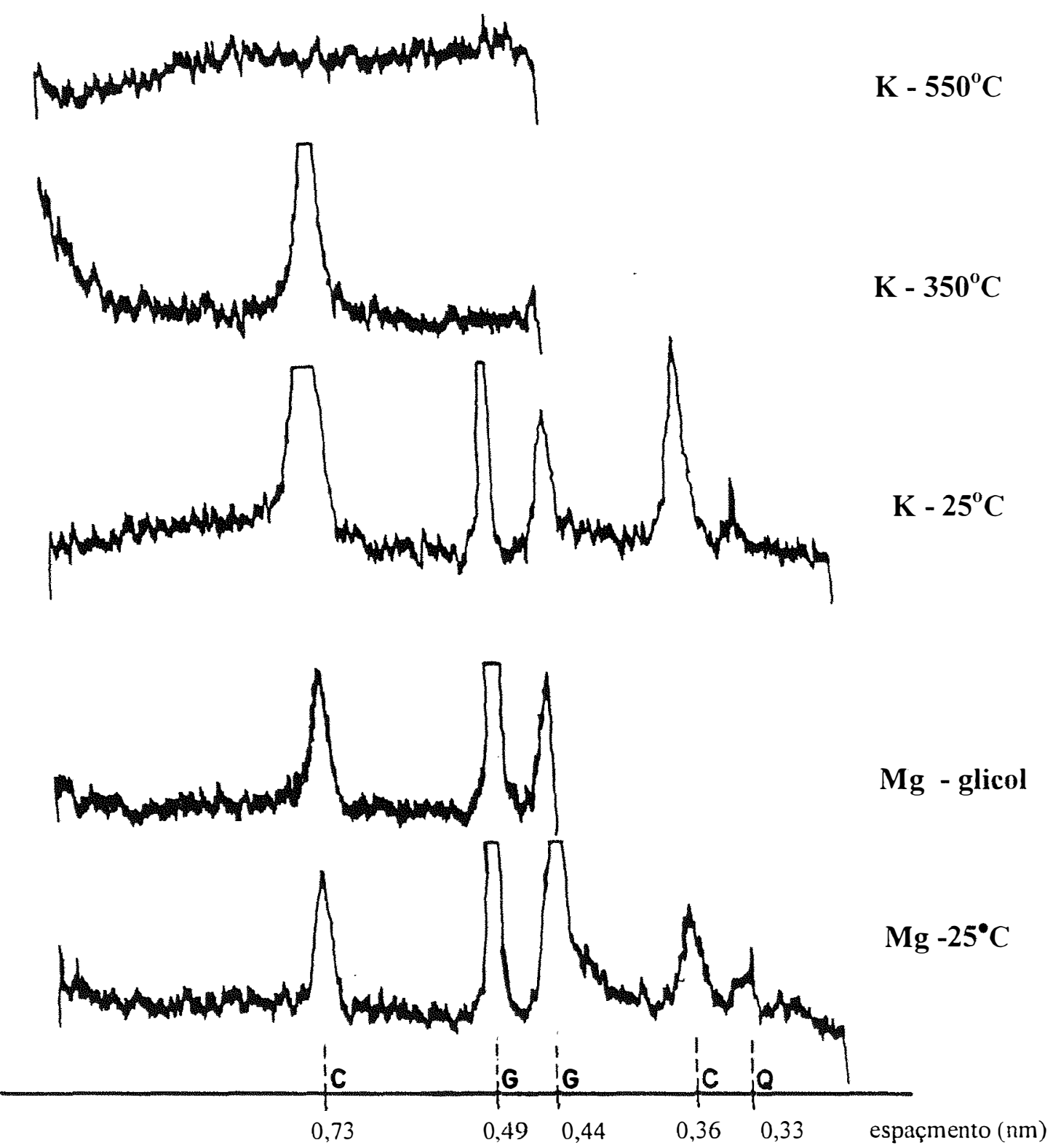

Figura 9 - Difratogramas de raio-X da fração argila deferrificada do horizonte $B$ do Latossolo Roxo ácrico ( $\mathrm{C}$ = caulinita; $\mathrm{G}=$ gibbsita: $\mathrm{Q}=$ quartzo) 

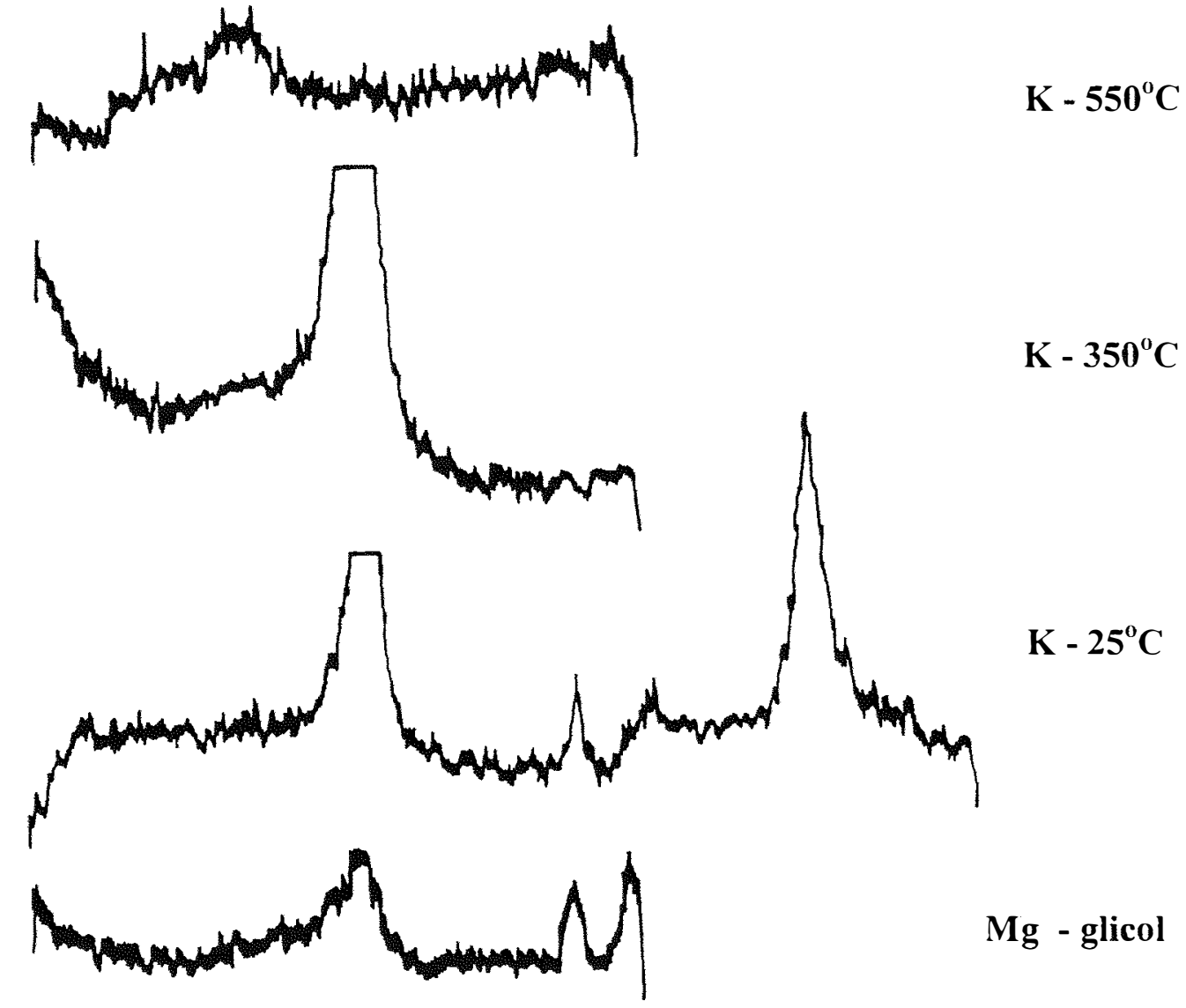

Mg - glicol

$\mathrm{K}-350^{\circ} \mathrm{C}$

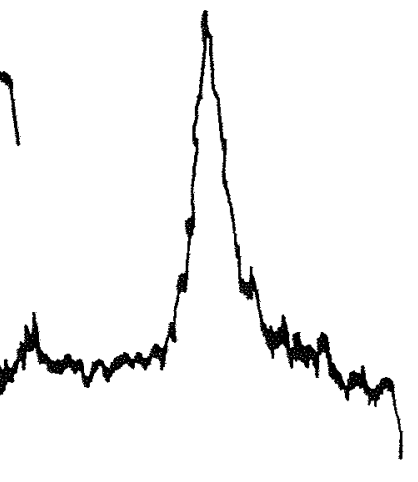

$\mathrm{K}-25^{\circ} \mathrm{C}$
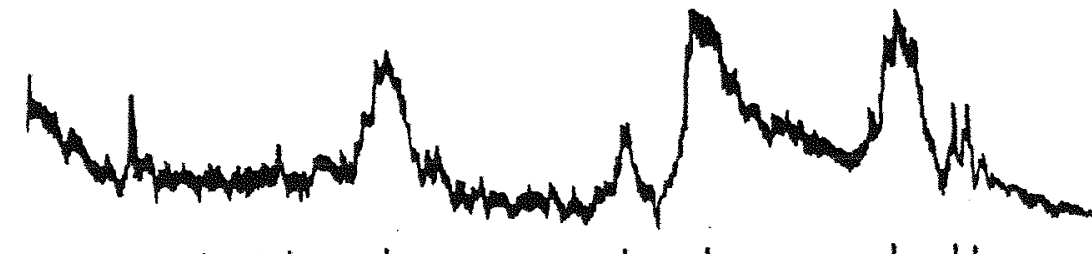

$\operatorname{Mg}-25^{\circ} \mathrm{C}$

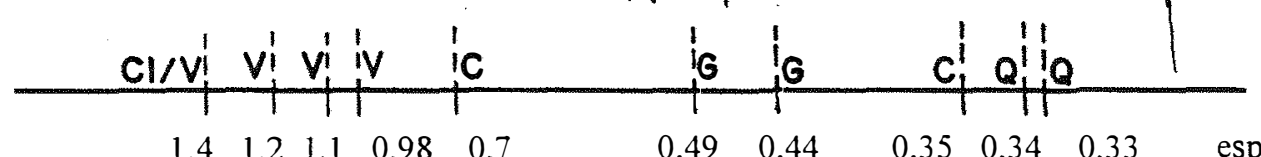

$\begin{array}{lllll}1,4 & 1,2 & 1,1 & 0,98 & 0,7\end{array}$

$0,49 \quad 0,44$

$0,35 \quad 0,34 \quad 0,33$

espaçamento $(\mathrm{nm})$

Figura 10 - Difratogramas de raio-X da fração argila deferrificada do horizonte $\mathrm{A}$ da Terra Roxa Estruturada ( $\mathrm{C}$ = caulinita; $\mathrm{G}=$ gibbsita; $\mathrm{Q}=$ quartzo; $\mathrm{Cl} / \mathrm{V}=$ Clorita /vermiculita intraestratificada; $\mathrm{V}=$ indícios de vermiculita) 


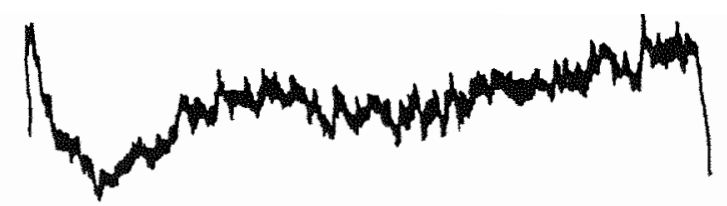

$$
K-550^{\circ} \mathrm{C}
$$

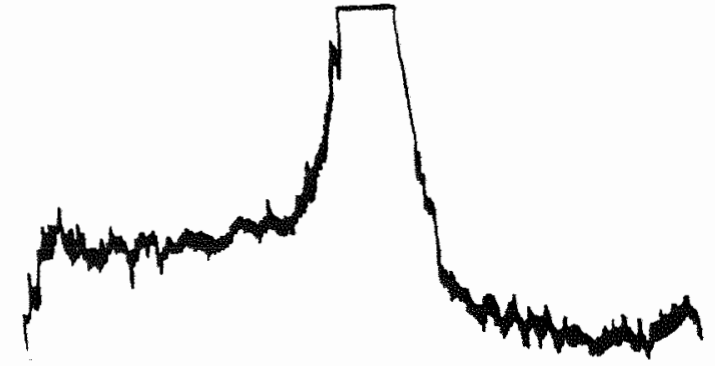

$$
\mathrm{K}-350^{\circ} \mathrm{C}
$$
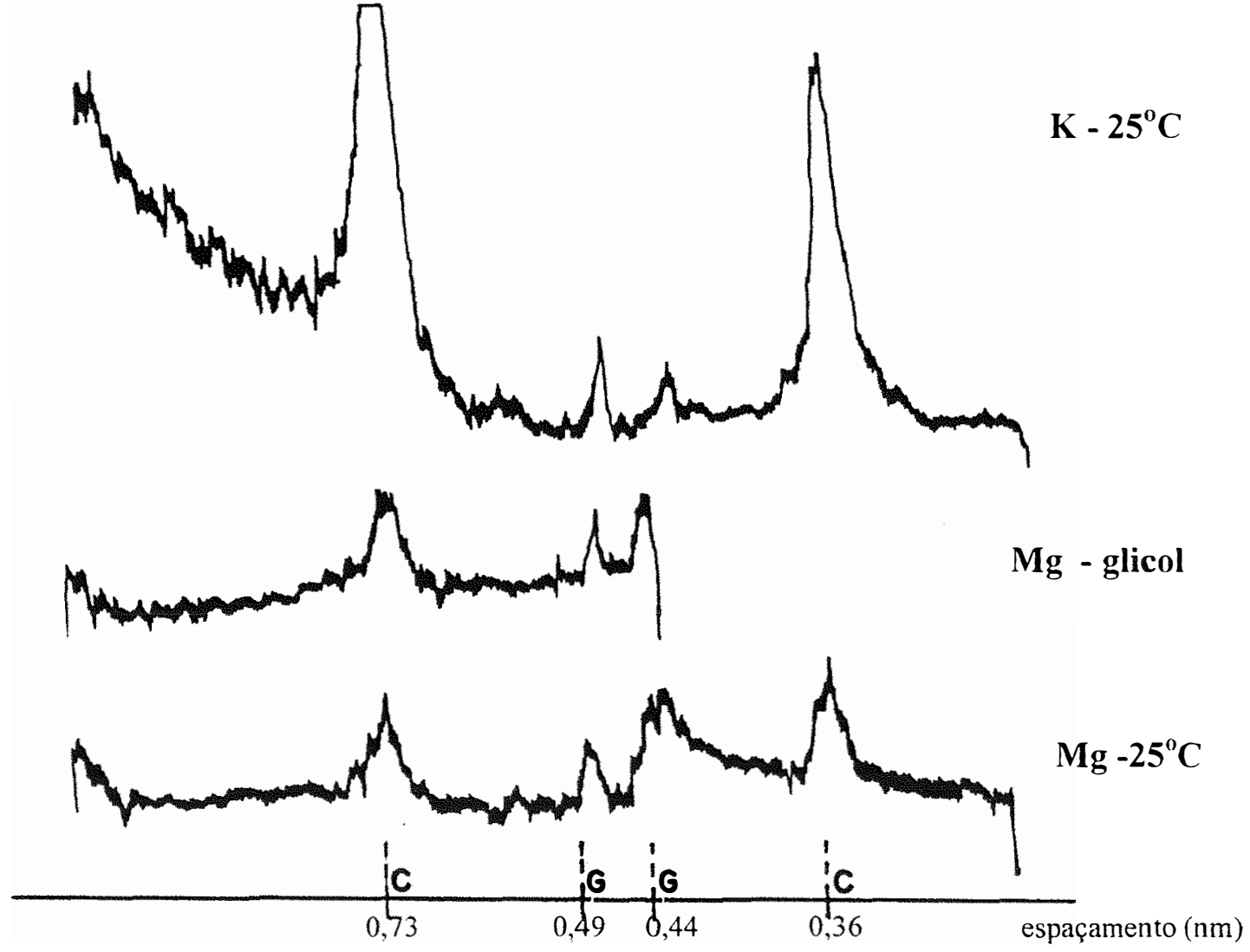

Figura 11- Difratogramas de raio-X da fração argila deferrificada do horizonte $\mathrm{B}$ da Terra Roxa Estruturada ( $\mathrm{C}=$ caulinita; $\mathrm{G}=$ gibbsita) 


\subsection{Adsorção de cádmio}

Quando se trabalha com cádmio, o principal limitante dos métodos analíticos é o limite de detecção, pois os extratos normalmente não apresentam a concentração mínima necessária do metal para leitura. Assim, para se ter segurança de que os resultados apresentados neste trabalho são confiáveis, será apresentada a curva padrão e seu respectivo limite de detecção (Figura 12).

Observa-se um ótimo ajuste da curva analítica de cádmio. O limite de detecção calculado foi $0,01951 \mathrm{mg} \mathrm{dm}^{-3}$. Os resultados encontrados estão precisos, pois a menor leitura encontrada foi de $0,05 \mathrm{mg} \mathrm{dm}^{-3}$ e se encontra acima do limite de detecção do aparelho (Beaty \& Kerber, 1993).

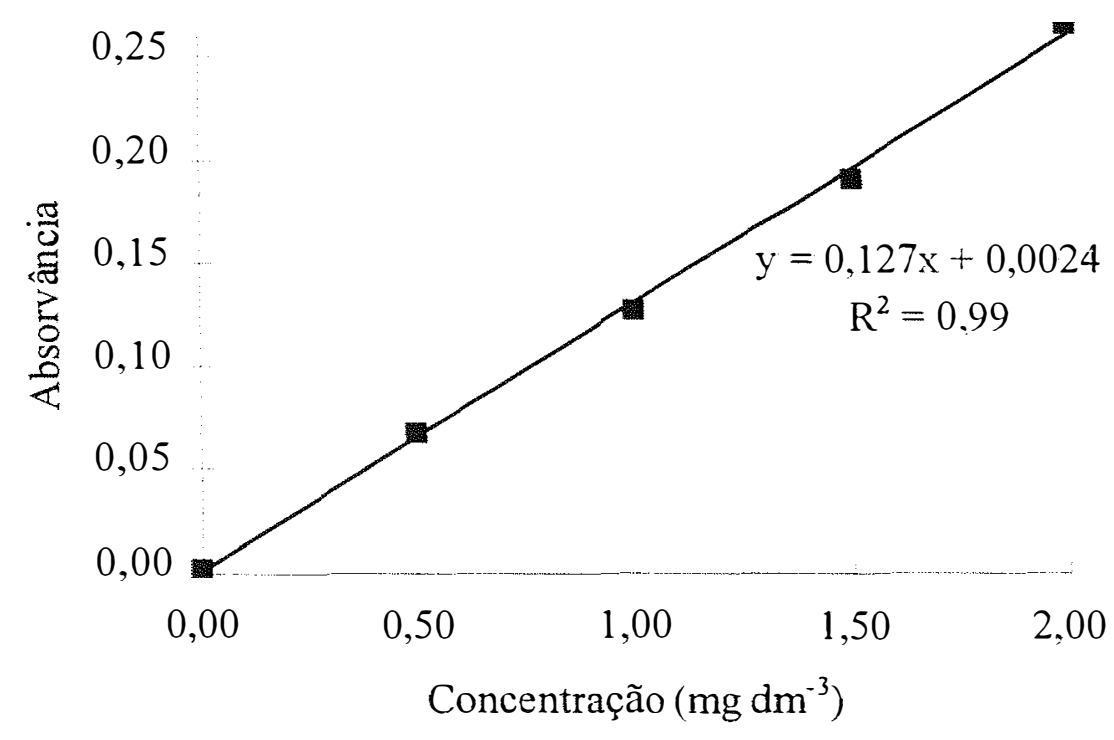

Figura 12 - Curva analítica utilizada para a determinação do cádmio por espectrofotometria de absorção atômica. 


\subsubsection{Efeito do pH na adsorção de cádmio}

No estudo de adsorção de cádmio, foram adicionados $2 \mathrm{mg} \mathrm{dm}^{-3}$ do elemento, para avaliar o efeito da elevação do $\mathrm{pH}$ na adsorção do metal. A concentração do $\mathrm{Cl}^{-}$presente neste experimento nas amostras incubadas com $\mathrm{HCl}$, não deve ter possibilitado a formação de clorocomplexos $\left(\mathrm{Cd}_{2}-\mathrm{Cl}^{-}\right)$, pois segundo Lindsay (1979) são necessárias concentrações de $\mathrm{Cl}^{-}$superiores a $1 \mathrm{~mol} \mathrm{dm}^{-3}$ para a formação destes complexos. A formação de clorocomplexos de cádmio levaria a interpretação errada dos resultados, pois reduziria a adsorção do cádmio pela possível formação de espécie neutras ou carregadas negativamente, assim o cádmio complexado não seria adsorvido pelo solo (Petruzzelli et al., 1985). Garcia-Miragaya \& Page (1976) obtiveram menores valores de adsorção de cádmio por montmorilonita em soluções de cloreto.

Os resultados obtidos encontram-se na Tabelas 9 e 10 e são as médias de quatro repetições. A análise de variância entre os três fatores (solo, profundidade e $\mathrm{pH}$ ) mostrou que a interação tripla foi significativa e então procedeu-se o desdobramento desta interação, estudando-se cada fator na presença dos demais.

A adsorção de cádmio dos solos estudados mostrou-se fortemente dependente do $\mathrm{pH}$. Com a elevação do $\mathrm{pH}$, os valores de cádmio adsorvido aumentaram (Tabela 9) em todos os solos estudados, tanto em superfície como em profundidade, o que é consistente com estudos anteriores (Pombo, 1995; Gray et al.,1998 e Filius et al.,1998).

$\mathrm{O}$ efeito do $\mathrm{pH}$ na adsorção de cátions metálicos em solos altamente intemperizados se manifesta pela mudança da densidade de carga na superfície dos minerais com cargas variáveis. Com a elevação do pH, há aumento das cargas negativas, diminuindo a competição entre o cádmio e o íon hidrogênio pelo mesmo sítio de troca, aumentando sua adsorção (Garcia-Miragaya \& Page, 1978 e Christensen, 1984a,b). 
Tabela 9. Adsorção de cádmio nos horizontes superficiais (A) e diagnósticos (B) da Terra Roxa Estruturada (TE), Latossolo Roxo ácrico (LR) e Latossolo Una ácrico (LU), após a adição de $2 \mathrm{mg} \mathrm{dm}^{-3}$ do elemento Análise dentro de cada solo.

\begin{tabular}{|c|c|c|c|c|c|c|c|}
\hline \multirow[t]{2}{*}{$\mathrm{pH}$} & \multicolumn{2}{|r|}{ TE } & \multicolumn{3}{|c|}{ LR } & \multicolumn{2}{|c|}{$\mathrm{LU}$} \\
\hline & A & B & A & & B & A & B \\
\hline & & & - & $\mathrm{mg}$ & 8 & & 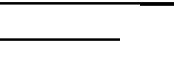 \\
\hline 4,5 & $17,5 \mathrm{C} \quad \mathrm{a}$ & $14,0 \mathrm{D} \quad \mathrm{b}$ & $15,6 \mathrm{D}$ & $\mathrm{a}$ & $9,6 \mathrm{E} \mathrm{b}$ & $16,5 \mathrm{C} \mathrm{a}$ & $9,6 \mathrm{E} \quad \mathrm{b}$ \\
\hline 5,0 & $18,7 \mathrm{~B} \quad \mathrm{a}$ & $16,3 \mathrm{C} \quad \mathrm{b}$ & $16,8 \mathrm{C}$ & $\mathrm{a}$ & $12,2 \mathrm{D} \quad \mathrm{b}$ & $17,9 \mathrm{~B} \mathrm{a}$ & $12,1 \mathrm{D}$ \\
\hline 5,5 & $19,3 \mathrm{AB}$ a & $18,6 \mathrm{~B} \quad \mathrm{~b}$ & $18,0 \mathrm{~B}$ & $\mathrm{a}$ & $14,3 \mathrm{C} \mathrm{b}$ & $18,8 \mathrm{~A} \mathrm{a}$ & $14,6 \mathrm{C} \mathrm{b}$ \\
\hline 6,0 & $19,4 \mathrm{~A} \quad \mathrm{a}$ & $19,1 \mathrm{AB} a$ & $18,4 \mathrm{AB}$ & $\mathrm{a}$ & $16,4 \mathrm{~B} \mathrm{~b}$ & $19,0 \mathrm{~A} \mathrm{a}$ & $16,8 \mathrm{~B}$ \\
\hline 6,5 & $19,5 \mathrm{~A} \quad \mathrm{a}$ & $19,2 \mathrm{AB}$ a & $18,7 \mathrm{~A}$ & $\mathrm{a}$ & $18,6 \mathrm{~A} \mathrm{a}$ & $19,1 \mathrm{~A} \mathrm{a}$ & $18,7 \mathrm{~A}$ \\
\hline 7,0 & $19,5 \mathrm{~A} \quad \mathrm{a}$ & $19,3 \mathrm{~A} \quad \mathrm{a}$ & $19,0 \mathrm{~A}$ & $\mathrm{a}$ & $19,0 \mathrm{~A} \mathrm{a}$ & $19,3 \mathrm{~A} \mathrm{a}$ & $19,1 \mathrm{~A}$ \\
\hline
\end{tabular}

Médias seguidas por letras diferentes minúsculas na linha, entre horizontes de cada solo e, maiúsculas na coluna, para cada horizonte de cada solo, diferem entre si a $5 \%(p<0,05)$.

A Terra Roxa Estruturada apresentou os maiores valores de cádmio adsorvido em toda faixa de $\mathrm{pH}$ estudada, tanto em superfície como em profundidade (Tabela 10), provavelmente por apresentar PESN inferior aos valores de $\mathrm{pH}$ estudados, apresentando carga elétrica negativa em todo perfil. Devido ao seu estado menos avançado de intemperismo, apresenta minerais do tipo 2:1, identificados pela difração de raios X, como clorita/vermiculita (intrestratificada) e vermiculita no horizonte A na fração argila e ilita e musvovita na fração silte no horizonte B. As cargas desses minerais do tipo 2:1 originam-se por substituíção isomórfica e são permanentes e negativas. A caulinita, que foi o mineral predominante neste solo, embora seja do tipo 1:1, também apresenta baixo PESN, 
aproximadamente igual a 3,0 (Tschapek et al, 1974). Portanto maior seu percentual na fração argila, menor deve ser o PESN do solo, sendo que na faixa de $\mathrm{pH}$ estudada a caulinita desenvolve somente cargas negativas.

Tabela 10. Adsorção de cádmio nos horizontes superficiais (A) e diagnósticos (B) da Terra Roxa Estruturada (TE), Latossolo Roxo ácrico (LR) e Latossolo Una ácrico (LU), após a adição de $2 \mathrm{mg} \mathrm{dm}^{-3} \mathrm{do}$ elemento Análise dentro de cada horizonte.

\begin{tabular}{|c|c|c|c|c|c|c|}
\hline \multirow[t]{2}{*}{$\mathrm{pH}$} & \multicolumn{3}{|c|}{ Horizonte A } & \multicolumn{3}{|c|}{ Horizonte B } \\
\hline & TE & LR & LU & TE & LR & $\mathrm{LU}$ \\
\hline 4,5 & $17,5 \mathrm{a}$ & $15,6 \mathrm{c}$ & $16,5 \mathrm{~b}$ & $14,0 \mathrm{a}$ & $9,6 \mathrm{~b}$ & $9,6 \mathrm{~b}$ \\
\hline 5,0 & $18,7 \mathrm{a}$ & $16,8 \mathrm{c}$ & $17,9 \mathrm{~b}$ & $16,3 \mathrm{a}$ & $12,2 \mathrm{~b}$ & $12,1 \mathrm{~b}$ \\
\hline 5,5 & $19,3 \mathrm{a}$ & $18,0 \mathrm{~b}$ & $18,8 \mathrm{a}$ & $18,6 \mathrm{a}$ & $14,3 \mathrm{~b}$ & $14,6 \mathrm{~b}$ \\
\hline 6,0 & $19,4 \mathrm{a}$ & $18,4 \mathrm{~b}$ & $19,0 \mathrm{ab}$ & $19,1 \mathrm{a}$ & $16,4 \mathrm{~b}$ & $16.8 \mathrm{~b}$ \\
\hline 6,5 & $19,5 \mathrm{a}$ & $18,7 \mathrm{~b}$ & $19,1 \mathrm{ab}$ & $19,2 \mathrm{a}$ & $18,6 \mathrm{~b}$ & $18.7 \mathrm{~b}$ \\
\hline 7,0 & $19,5 \mathrm{a}$ & $19,0 \mathrm{a}$ & $19,3 \mathrm{a}$ & $19,3 \mathrm{a}$ & $19,0 \mathrm{a}$ & $19.1 \mathrm{a}$ \\
\hline
\end{tabular}

Médias seguidas por letras diferentes na linha dentro de cada horizonte, diferem entre si a $5 \%$ $(p<0,05)$.

Nos Latossolos, que apresentaram menores valores de cádmio adsorvido, a magnitude das cargas variou consideravelmente, apresentando hora predomínio de cargas negativas, hora de cargas positivas na faixa de $\mathrm{pH}$ estudada, devido aos elevados valores de PESN. Esses altos valores encontrados nas camadas subsuperficiais dos Latossolos podem ser atribuídos aos baixos teores de matéria orgânica e à presença de grandes quantidades de minerais oxídicos, os quais podem desenvolver cargas positivas ou negativas por meio da protonação (adsorção de $\mathrm{H}^{+}$) ou desprotonação, sendo que o pH é o fator preponderante sobre a origem dessas 
cargas variáveis. Como os valores de PESN destes óxidos são altos (variando de 6,5 a 8,5), quanto maiores suas quantidades, maior a possibilidade de o PESN do solo ser maior que seu $\mathrm{pH}$, atribuindo balanço positivo de carga.

No pH 7,0, que está acima do PESN, o balanço de carga nos solos estudados foi negativo, com marcante aumento na adsorção de cádmio. Neste valor de $\mathrm{pH}$ (Tabela 10), não houve diferenças na adsorção de cádmio entre os solos, sendo que para todos os solos ocorreu quase $100 \%$ de adsorção do cádmio inicialmente adicionado, demostrando a influência marcante do $\mathrm{pH}$ na adsorção de cádmio, superando as diferenças na constituição mineralógica de cada solo, concordando com King (1988); Christensen (1989) e Gray et al.(1999).

Naidu (1994), estudando solos altamente intemperizados, dominados por seisquióxidos, também encontrou $100 \%$ de adsorção quando o pH excedia 6,0 . A elevação do pH da solução do solo para valores entre 6,0 e 7,0 provoca rápido aumento das cargas negativas das superfícies dos minerais, em solos com altos conteúdos de matéria orgânica e óxidos de ferro, aumentando a afinidade pelo íon metálico e a adsorção de cádmio (Garcia-Miragaya \& Page, 1978). Gray et al. (1998) e Filius et al. (1998) relatam que em baixos valores de $\mathrm{pH}$, o cádmio se encontra ligado nos sítios de baixa afinidade. Em contraste, nos valores elevados de $\mathrm{pH}$, ocorre aumento do número de sítios de forte ou alta afinidade ocupados pelo cádmio por adsorção específica, e nesses valores de $\mathrm{pH}$ os sítios não específicos tornam-se menos pronunciados.

Segundo Zachara (1992) em valores de $\mathrm{pH}$ abaixo de 6,5, a magnitude da adsorção é controlada pela capacidade de troca de cátions dos constituintes isolados do solo, que nestes solos são caulinita e minerais 2:1. Confirmando o que foi observado anteriormente com relação a TE apresentar maiores quantidades de cádmio adsorvido em relação aos Latossolos, que são dominados por óxidos, Bolton \& Evans (1996) relatam que a superfície dos óxidos tornam-se importantes adsorventes em valores de $\mathrm{pH}$ acima de 7,0. 
Em profundidade, os Latossolos não diferiram na faixa de $\mathrm{pH}$ estudada ( 4,5 a 7,0 ), sendo que a adsorção passou de $48 \%$ do cádmio adicionado no menor valor de $\mathrm{pH}$ para $97 \%$ de adsorção aos pH 6,5 e 7,0. A Terra Roxa Estruturada neste horizonte apresentou adsorção acima de $90 \%$ a partir do pH 5,5.

Nas camadas superficiais, as diferenças na adsorção de cádmio dos solos não foram tão acentuadas. Verificam-se altos valores de cádmio adsorvido, sendo que a faixa de $\mathrm{pH}$ estudada se encontra acima do PESN de todos os solos (Tabela 5). Nessa camada $(0-0,20 \mathrm{~m})$ o potencial elétrico foi negativo em todas as amostras. A matéria orgânica, que apresenta (PESN $=2,0)$ foi, provavelmente, a principal responsável pelos baixos valores de PESN, conforme apresentado em Alleoni \& Camargo (1994). Siqueira (1985) afirmou que o efeito da matéria orgânica é devido à sua interação com os óxidos e argilas silicatadas do solo, podendo formar complexos coloidais, podendo recobrir os minerais que compõem a fração argila dos solos, bloqueando as cargas positivas e alterando seus atributos eletroquímicos.

Pode-se verificar, também, nesta camada, a influência do $\mathrm{pH}$, embora menos acentuada sobre a adorção de cádmio, a qual em média passou de $80 \%$ a $97 \%$ nos valores de $\mathrm{pH}$ 4,5 e 7,0, respectivamente. Em superficie, o LR sempre apresentou valores de adsorção inferiores aos encontrados no LU, não diferindo somente a partir do pH 6,0 (Tabela 10).

Comparando-se a variação do $\mathrm{pH}$ dentro de cada solo estudado no horizonte A (Tabela 9), verifica-se que o LU, embora contendo menores teores de carbono orgânico (Tabela 3) em relação ao LR e TE, apresentou o mesmo comportamento da TE, não ocorrendo diferenças na adsorção a partir do $\mathrm{pH}$ 5,5, sendo que neste valor de $\mathrm{pH}$ a adsorção de cádmio foi acima de $90 \%$. No LR este nível de adsorção foi atingido ao $\mathrm{pH}$ 6,0. Provavelmente este comportamento pode ser atribuído ao LU apresentar neste horizonte quantidade de caulinita semelhantes à da TE e indícios de mica, que é um mineral 2:1 e apresenta elevada capacidade de adsorção de cádmio. 
As menores quantidades de cádmio adsorvida foram encontradas para todos os solos estudados em valores de $\mathrm{pH}$ inferiores a 5,5, sendo esses valores os mais comumente encontrados em solos de regiões tropicais que normalmente apresentam acidez variando de alta a média. Segundo Raij et al. (1985), solos com valores de $\mathrm{pH}$ entre 4,4 e 5,0 apresentam acidez alta e com valores de $\mathrm{pH}$ entre 5,1 e 5,5 acidez média. Em vista do exposto, em solos de regiões tropicais, nos quais a prática de calagem não é utilizada, espera-se encontrar baixa adsorção de cádmio, permanecendo este elemento na solução do solo disponível para ser absorvido pelas plantas ou lixiviado para o lençol freático.

\subsection{Modelos de adsorção}

\subsubsection{Isotermas de adsorção}

As isotermas de adsorção de cádmio nas amostras de terra ao $\mathrm{pH}$ natural dos solos (testemunha) estão apresentadas nas Figuras 13, 14 e 15. Os resultados que originaram as isotermas de adsorção estão no Apêndice $\mathrm{Al}$ (Tabela A, B e C). Houve boa adequação das equações de Langmuir e de Freundlich aos dados de adsorção de cádmio, com altos coeficientes de correlação $\left(R^{2}\right)$ igual a 0,99 , concordando com ajustes observados em estudos anteriores (Omae, 1984 el986; Pombo, 1995; Lee et al., 1996 e Echeverría et al., 1998).

No presente trabalho, optou-se pelo ajuste não linear das equações de Langmuir e de Freundlich, seguindo a metodologia dos "mínimos quadrados". Este procedimento minimiza a soma de quadrados dos desvios entre os valores estimados pela equação e os observados em laboratório (Shani et al., 1992 e Barrow \& Whelan, 1998). 
HORIZONTE A

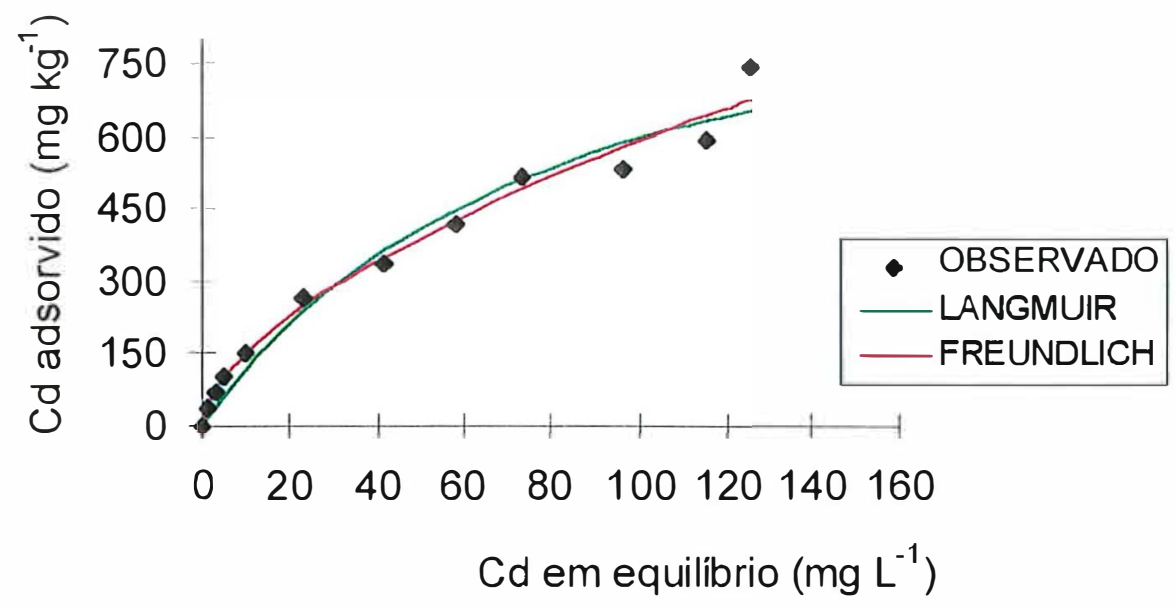

HORIZONTE B

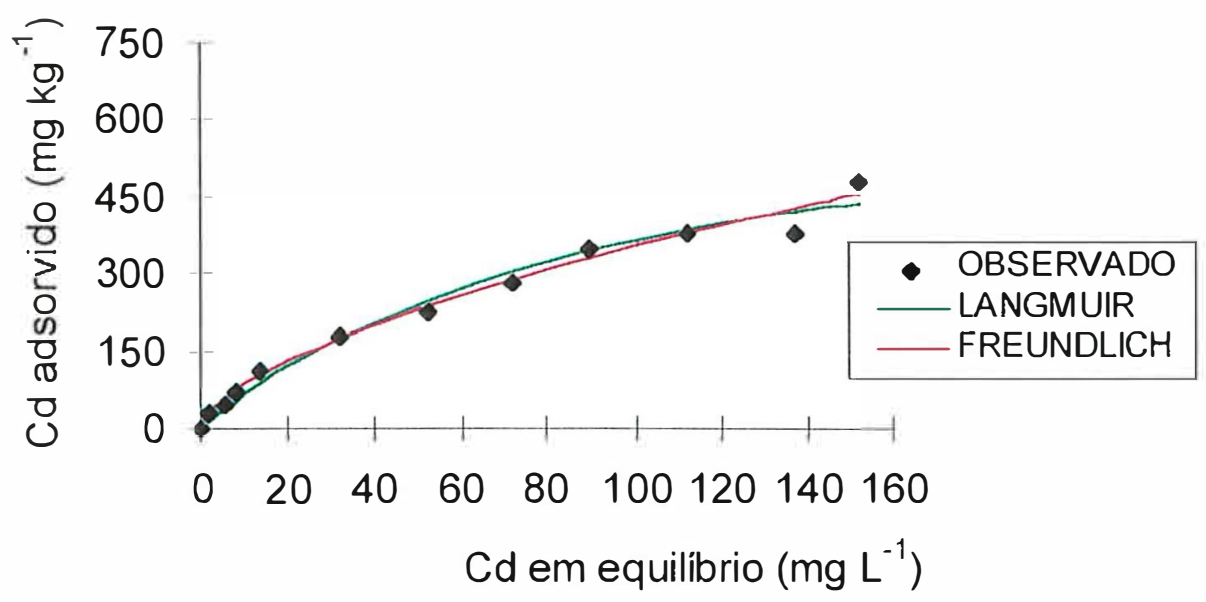

Figura 13 - Curvas de adsorção de cádmio nos horizontes A e B do Latossolo Roxo. 
HORIZONTE A

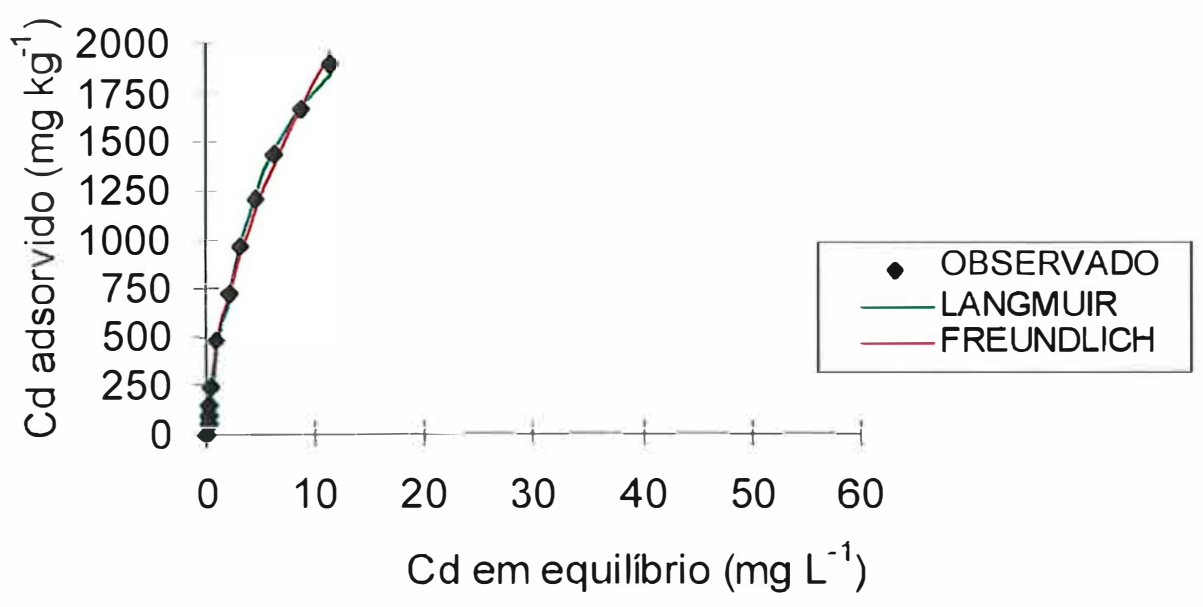

HORIZONTE B

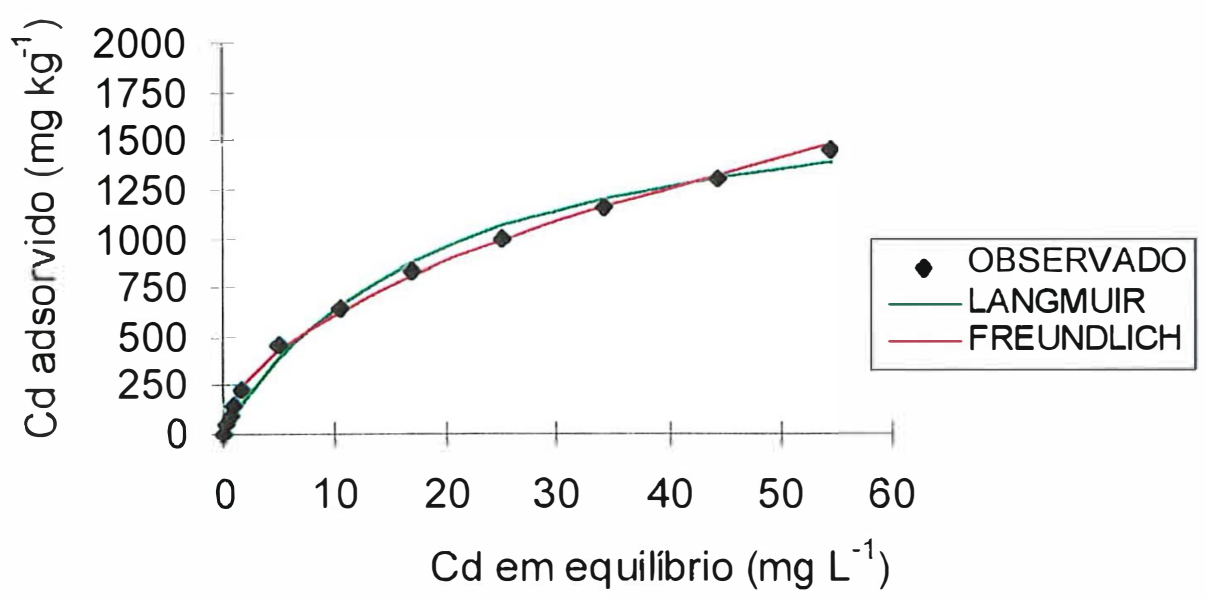

Figura 14 - Curvas de adsorção de cádmio nos horizontes A e B da Terra Roxa Estruturada. 
HORIZONTE A

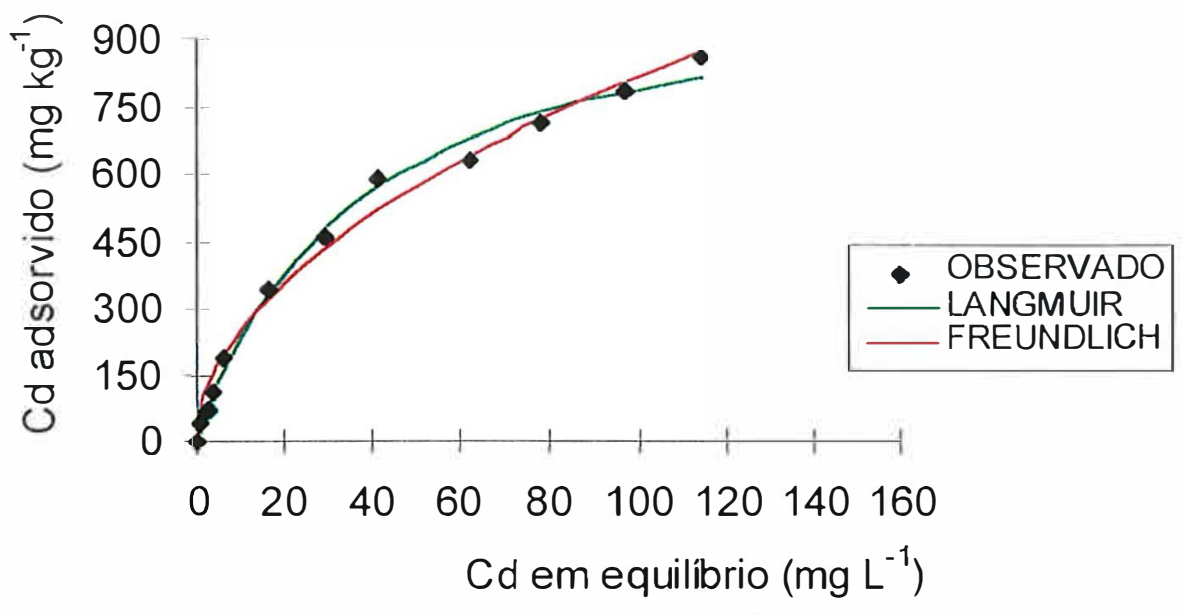

HORIZONTE B

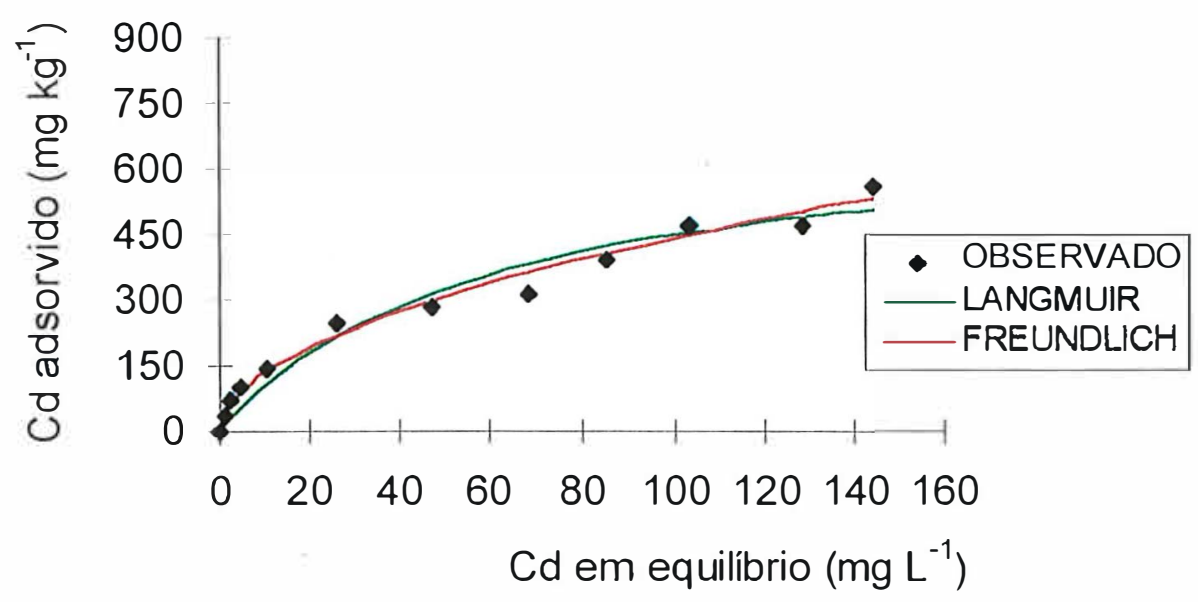

Figura 15 - Curvas de adsorção de cádmio nos horizontes A e B do Latossolo variação Una. 
Este método tem sido recomendado nos últimos anos, porque a linearização das equações induzem a erros na análise de regressão e subseqüente erro na estimativa dos parâmetros dos modelos (Harter, 1984; Persoff \& Thomas, 1988; Houng \& Lee, 1998). Harter (1984) examinou a linearização da equação original e concluiu que a linearização é inadequada, pois reduz a variabilidade e sempre produz um coeficiente de correlação significativo. Observou ainda, que a adsorção máxima estimada pela forma linear pode acarretar um erro de até $50 \%$ ou mais, em estudos envolvendo baixas concentrações do metal.

Observando-se as inclinações das curvas dos Latossolos ácricos, nota-se que o incremento na adsorção de cádmio foi maior nas doses mais baixas e à medida que as doses adicionadas aumentaram, os incrementos foram menos acentuados. Esse incremento pode ser demonstrado pela taxa de adsorção (\%), que é a relação percentual entre a quantidade de cádmio adsorvido e a quantidade adicionada inicialmente. Verificou-se que a maior taxa de adsorção ocorre nas menores doses adicionadas entre 0 e $25 \mathrm{mg} \mathrm{dm}^{-3}$ (Apêndice A1), com média geral de $70 \%$, já a menor taxa de adsorção (30\%) foi encontrada para a dose mais elevada.

A Terra Roxa Estruturada, na camada superficial, apresentou em todas as doses adicionadas taxa de adsorção em torno de 100\%, demonstrando alta afinidade (Figura 14), com curva Tipo H (High) (Sposito, 1984). Este fenômeno usualmente é interpretado como resultado de forte interação específica entre as partículas do solo e o íon cádmio (Neal \& Sposito, 1986). Em profundidade, nas doses mais baixas adsorveu $90 \%$ da quantidade aplicada, chegando a taxa de $70 \%$, na dose mais elevada.

Os maiores valores percentuais de cádmio adsorvido em relação ao adicionado (taxa de adsorção) ocorreram no horizonte A da Terra Roxa Estruturada, com média geral de $97 \%$ e os menores valores ocorreram no 
Latossolo Roxo ácrico na camada subsuperficial, com $36 \%$, em média (Apêndice A1).

Os Latossolos e a Terra Roxa Estruturada na camada subsuperficial apresentaram curva tipo $\mathrm{L}$ ( $\mathrm{L}=$ Langmuir), que é caracterizada por um decréscimo na inclinação da curva, à medida que os sítios disponíveis para a adsorção vão diminuindo, devido ao recobrimento da superfície adsorvedora e indica que, em baixas concentrações, a superficie tem alta afinidade pela substância adsorvida, sendo que esta afinidade diminui em maiores concentrações. Curvas tipo L para adsorção de cádmio são reportadas por Christensen (1984a) e Pombo (1995).

\subsubsection{Os parâmetros de Langmuir e de Freundlich}

Na Tabela 11 estão apresentadas as constantes de Langmuir e Freundlich. A Terra Roxa Estruturada apresentou maiores valores de adsorção máxima (b), obtidos na isoterma de Langmuir e constante de afinidade $(\mathrm{K})$, obtidos pelas equações de Langmuir e de Freundlich, tanto em superfície como em profundidade, provavelmente por possuir PESN inferior ao $\mathrm{pH}$ do solo, conferindo carga líquida negativa em todo perfil $(\Delta \mathrm{pH}=-0,9$ em superfície e $-0,7$ em subsuperfície), provenientes de sua constituição caulinítica e argilominerais 2:1, o que mostra seu menor estado de intemperização $(k i=1,74)$ em relação aos Latossolos (Tabela 3 e 4).

Os menores valores de " $b$ " e " $K$ " encontrados nos horizontes subsuperficiais do Latossolo variação Una ácrico e do Latossolo Roxo ácrico (Tabela 11) podem ser explicados pelo balanço de carga positivo no horizonte B, como resultado do alto grau de intemperismo $(\mathrm{ki}=0,87$ no Latossolo Roxo ácrico e $\mathrm{ki}=0,97$ no Latossolo variação Una ácrico (Tabela 4) e maior participação dos 
óxidos de ferro e de alumínio na definição das cargas. Como os valores de PESN destes óxidos são altos (variando de 6,5 a 8,5), quanto maiores suas quantidades, maior a possibilidade de o PESN dos solos serem maiores que seus valores de pH. Nesse caso, ocorre redução na adsorção do elemento. O fenômeno de reversão de carga ocorre quase sempre em profundidades maiores que $50 \mathrm{~cm}$, pois, nessa condição, a matéria orgânica, cujo $\mathrm{PCZ}$ é bastante baixo $(=2,0)$, praticamente não atua (Tabelas 5 e 6). Estes resultados estão de acordo com os encontrados por Naidu et al. (1994), que utilizaram a equação de Freundlich para descrever a adsorção de cádmio em solos dominados por diferentes constituições mineralógicas e encontraram os menores valores de cádmio adsorvido nos solos altamente intemperizados. Os autores relatam que esta menor adsorção pode ser atribuída à alta superficie de carga positiva e baixa densidade de carga negativa provenientes das mineralogias oxídicas e alofânicas dos solos.

Tabela 11. Constantes de Langmuir e de Freundlich, obtidas a partir dos resultados de adsorção de cádmio para os solos estudados.

\begin{tabular}{llcccc}
\hline Solo & \multicolumn{1}{c}{ Camada } & \multicolumn{2}{c}{ Langmuir } & \multicolumn{2}{c}{ Freundlich } \\
& & $\mathrm{K}$ & $\mathrm{b}$ & $\mathrm{K}$ & $\mathrm{n}$ \\
\hline \multirow{2}{*}{$\mathrm{LR}$} & Superfície & 0,01 & 1086 & 37,55 & 0,60 \\
& Profundidade & 0,01 & 727 & 20,93 & 0,61 \\
& & & & & \\
\multirow{2}{*}{ TE } & Superfície & 0,17 & 2495 & 468,63 & 0,59 \\
& Profundidade & 0,05 & 1877 & 184,07 & 0,52 \\
& & & & & \\
\multirow{2}{*}{ LU } & Superfície & 0,03 & 1073 & 77,36 & 0.51 \\
& Profundidade & 0,02 & 707 & 40.79 & 0,51 \\
\hline
\end{tabular}


Em pH menores que 6,5, a magnitude da adsorção é controlada pela capacidade de troca de cátions isolada de cada constituinte do solo (Zachara et al., 1992). Em vista de todos os solos estudados terem valores de $\mathrm{pH}$ inferiores a 6,5, constata-se esse fato no presente trabalho, sendo que a Terra Roxa Estruturada foi o solo com maior quantidade de caulinita, CTC e com mais de um tipo de mineral 2:1. Como conseqüência, apresentou maiores valores de $\mathrm{K}$ da equação de Freundlich e b da equação de Langmuir.

Os maiores valores de adsorção máxima (b) foram encontrados na camada superficial devido, provavelmente, ao maior teor de carbono orgânico em todos os solos. Maiores valores de " $b$ " da equação de Langmuir e " $K$ " da equação de Freundlich também foram encontrados por Echeverria et al. (1998), em solos com altos conteúdos de matéria orgânica. Os autores relatam que a matéria orgânica favorece a retenção de cádmio. Petruzzelli et al. (1985); Hooda \& Alloway (1994) e Gray et al. (1998) também encontraram altos valores de $\mathrm{K}$ da equação de Freundlich, que também estão relacionados com altos teores de carbono orgânico encontrados nos solos estudados.

A matéria orgânica foi, provavelmente, o principal sítio de adsorção de cádmio, principalmente em seus grupos carboxilicos e fenólicos. Nos solos estudados, com altos teores de óxidos de ferro e de alumínio, a matéria orgânica comandou os mecanismos de retenção iônica, sendo responsável pelos maiores valores de adsorção máxima (b) encontrados na camada superficial em relação à camada subsuperficial dos solos (Tabela 11). Na camada superficial do LU, onde o teor de carbono foi 2,7 vezes mais alto do que no horizonte $\mathrm{B}$, a adsorção máxima de $\mathrm{Cd}$ foi $52 \%$ maior. Já na TE, a diferença também foi alta, em torno de $33 \%$ em favor do horizonte A, sendo que a queda do teor de carbono em profundidade foi de 3,7 vezes. 


\subsubsection{Correlações entre os parâmetros dos modelos de Langmuir e de Freundlich e atributos dos solos.}

Os coeficientes de correlação linear simples entre os parâmetros estimados pelas equações de Langmuir e de Freundlich e os atributos do solo estão apresentados no Apêndice A2.

Foram encontrados coeficientes de correlações simples positivos, significativos a 1\%, entre os parâmetros $\mathrm{K}$ e b de Langmuir e K de Freundlich. Já o parâmetro n de Freundlich não se correlacionou com os outros parâmetros.

Os parâmetros $\mathrm{K}$ e b de Langmuir e $\mathrm{K}$ de Freundlich foram positivamente correlacionados com o carbono orgânico, a capacidade de troca de cátions (CTC), a retenção de cátions (RC), a superfície específica (SE), teor de argila, as cargas negativas variáveis e as cargas negativas permanentes e o índice ki. O carbono orgânico, a RC, a SE, a argila e as cargas negativas permanentes são significativamente correlacionados com a CTC nos solos estudados (Apêndice A3). Assim, um incremento em qualquer um desses atributos corresponderá a um incremento na CTC, com conseqüente aumento da capacidade de adsorção de cádmio. Ziper et al. (1988) encontraram que altas quantidades de cádmio adsorvido estavam relacionados com altas CTC. Estes autores relatam que este fato é esperado, porque o cádmio ocupa sítios de troca nos minerais de argila. Amacher et al. (1996) também encontraram correlação positiva entre pH, matéria orgânica e CTC e as constantes derivadas da isoterma de Langmuir para adsorção de cádmio. Pandeya \& Singh (1998) relatam que altos valores de carbono orgânico, seguidos pela CTC, são fatores dominantes que afetam a adsorção. Esses dois fatores explicaram a variação de $93,6 \%$ na adsorção máxima de cádmio, calculada pela equação de Langmuir. Gray et al. (1999) também observaram que a matéria 
orgânica poderia explicar $24 \%$ da variação do cádmio adsorvido nos solos estudados e que a matéria orgânica, juntamente com o $\mathrm{pH}$ explicaria $75 \%$ da adsorção de cádmio.

As maiores adsorções máximas encontradas na Terra Roxa Estruturada podem ser explicadas pela sua constituição mineralógica. Ziper et al. (1988) relataram que na caulinita somente os sítios das arestas contribuem na CTC, enquanto os minerais 2:1 apresentam sítios de troca entre as camadas, além dos presentes nas arestas. Sendo assim, apresentam capacidade de adsorver maiores quantidades de cádmio. Em superfície, os maiores valores de adsorção máxima podem ser explicadas pela contribuição das cargas negativas da matéria orgânica, que proporcionaram aumento da CTC, com consequente aumento da capacidade de adsorção de cádmio

Não houve correlação significativa entre os parâmetros estimados citados acima e os teores de Ferro $\left(\mathrm{Fe}_{2} \mathrm{O}_{3}, \mathrm{Fe}_{\mathrm{d}}, \mathrm{Fe}_{\mathrm{o}}\right.$ e alumínio total, ocorrendo correlação negativa com gibbisita. Os óxidos do solo (óxido de Fe, Al e Mn) são importantes adsorventes de cádmio (Jarvis \& Jones, 1980 e Backes et al., 1995). King (1988) encontrou que o pH, com matéria orgânica e $\mathrm{Fe}_{\mathrm{o}}$ explicaram 93\% da variação de adsorção de cádmio em 13 amostras de solos coletados na superfície. Pombo (1995); Bolton \& Evans (1996); Wilkens \& Loch (1997) e Gray et al. (1999) não encontraram correlação entre a adsorção de cádmio e os óxidos dos solos. Lee et al. (1996) e Singh et al. (1997) encontraram fraca correlação entre os parâmentros de Langmuir e óxidos de ferro, alumínio e manganês, em amostras de solos de superfície, e relataram que o cádmio está ligado aos sítios de troca presentes na matéria orgânica e em menor grau aos dos óxidos. Bolton \& Evans (1996) sugeriram que as superficies dos óxidos são importantes somente em valores de pH acima de 7,0.

A adsorção máxima (b) estimada pela equação de Langmuir apresentou o maior número de correlações significativas com os atributos dos solos 
(Apêndice A2 ). Além das características discutidas anteriormente, a adsorção máxima (b) foi correlacionada também com os teores caulinita, carga líquida e densidade de carga. Foram encontradas correlações entre a carga líquida e caulinita, e densidade de carga, sendo que a carga líquida se correlacionou com a CTC, demonstrando a importância das cargas nos solos estudados.

Por meio de regressão múltipla foram selecionados os atributos dos solos que tinham maior efeito sobre os parâmetros dos modelos de adsorção. As equações obtidas foram $(\alpha=0,01)$ :

a-) Langmuir

- Adsorção máxima (b): $\mathrm{R}^{2}=0,94$

$\mathrm{b}=5,23924$ (CTC) $+33,81578$ (carga permanente negativa) $+488,29549$

- Constante de afinidade $(\mathrm{K}): \mathrm{R}^{2}=0,98$

$\mathrm{K}=0,00286(\mathrm{CTC})-0,00236(\mathrm{RC})$

b-) Freundlich

- Constante $\mathrm{K}: \mathrm{R}^{2}=0.83$

$\mathrm{K}=2,02257(\mathrm{CTC})+140,95889(\mathrm{ki})-147,37142$

A CTC dos solos, a carga negativa permanente, a retenção de cátion e o índice ki apresentam coeficiente de determinação entre 0,80 e 0,98 , sendo os principais fatores que explicam a adsorção de cádmio. Pela análise conjunta podese confirmar a importância da CTC na adsorção de cádmio dos solos estudados, pois a CTC esteve presente nas três equações com altos coeficientes de determinação. McBride et al. (1981) sugeriram que a quantidade de cádmio adsorvido poderia ser determinada pelo número sítios de cargas da superfĩcie das argilas e da matéria orgânica ocupada pelas bases trocáveis. Omae (1984) estudou a adsorção de cádmio em solos do estado de São Paulo, e demonstrou por meio dos valores de adsorção máxima de cádmio obtidos pela equação de Langmuir, que este 
elemento poderia competir com as bases presentes nos solos pelos mesmos sítios de troca. A baixas concentrações do metal (até $100 \mathrm{mg} \mathrm{dm}^{-3}$ ), a adsorção máxima obtida correspondeu a $58 \%$ da CTC dos solos, e a altas concentrações (até $1000 \mathrm{mgdm}^{-3}$ ) correspondeu a $120 \%$ da CTC, confirmando a importância da CTC na capacidade de adsorção de cádmio pelos solos e justificando as correlações positivas encontradas entre esta e os parâmetros estimados pelas equações de Langmuir e de Freundlich.

Mattiazzo-Prezzotto (1994) sugeriu que, para solos tropicais, a quantidade máxima permissível de metais a ser adicionadas no solo deve ser limitada pelo $\mathrm{pH}$, bem como sua CTC. Pombo (1995) também sugeriu que o conteúdo de argila, matéria orgânica, CTC e pH devem ser considerados no estabelecimento de critérios adequados para o descarte de cádmio nos solos.

No presente trabalho, pode-se confirmar os resultados obtidos em estudos anteriores, mostrando a importância desses atributos no comportamento do cádmio nos solos e principalmente das características eletroquímicas que são consequências diretas da constituição mineralógica e dos teores de carbono orgânico dos solos, principalmente em solos altamente intemperizados, nos quais as cargas são variáveis, podendo se comportar como trocadores de cátions ou de ânions.

\subsection{Energia Livre das reações de cádmio $\left(\Delta \mathbf{G}_{0}\right)$}

Os resultados de $\left(\Delta \mathrm{G}_{0}\right)$ estão apresentados na Figura 16. Os resultados que originaram as curvas encontram-se no Apêndice A4. 
Horizonte A
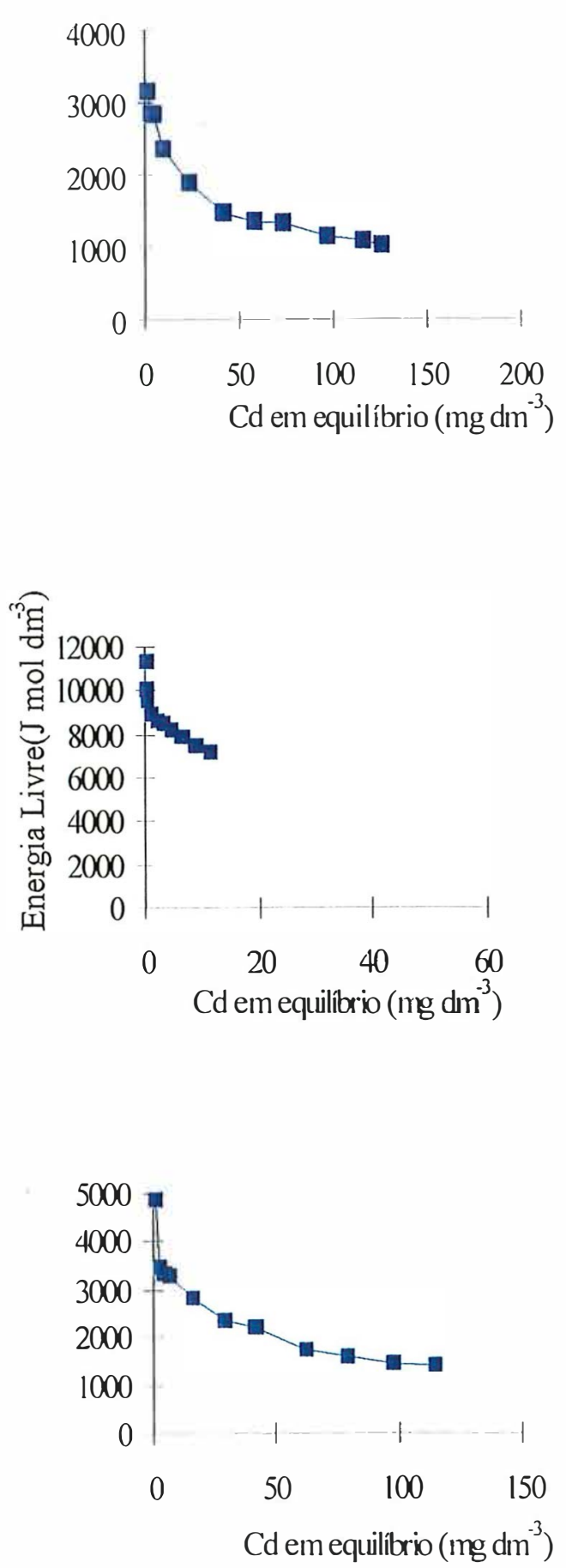

LR

Horizonte B

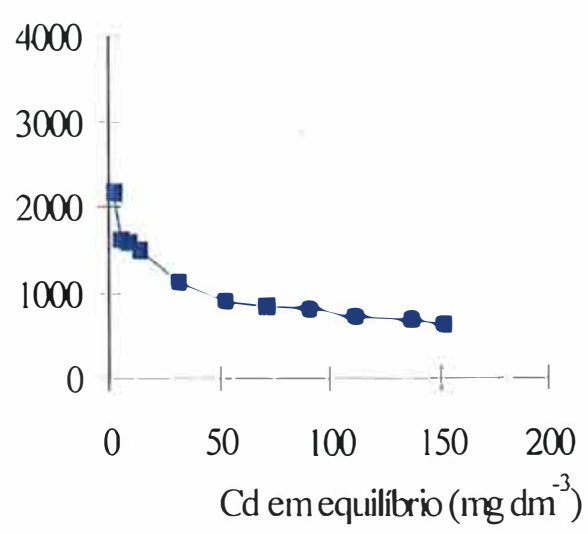

TE

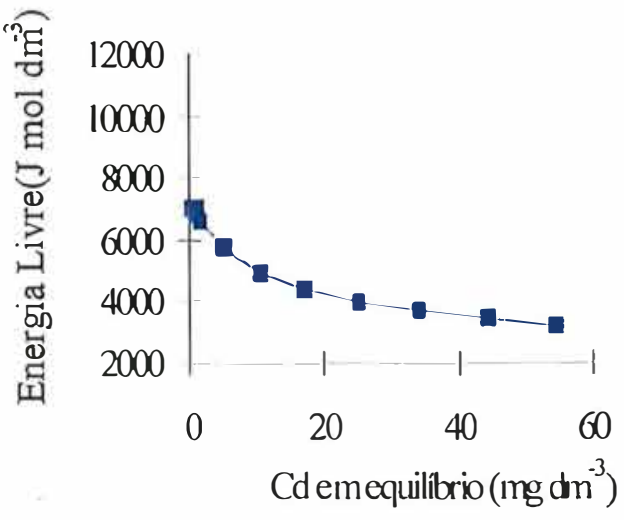

LU

Figura 16 - Valores de Energia Livre ( em módulo) das reações de adsorção de cádmio 
Todos os valores de $\left(\Delta \mathrm{G}_{0}\right)$ foram negativos, mostrando que a quantidade de cádmio em equilíbrio na solução foi sempre inferior ao valor adicionado, ou seja, a reação de adsorção de cádmio foi termodinamicamente espontânea. Os maiores valores médios em módulo foram encontrados em superfície, devido ao maior teor de matéria orgânica na camada superficial em todos os solos. Quanto maior a magnitude do valor da energia livre, maior a força de reação do cádmio pela superficie adsorvente. Esses resultados foram semelhantes aos encontrados por Alleoni \& Camargo (1998) para adsorção de boro e Silveira (1999) para adsorção de cobre.

A Terra Roxa Estruturada, como esperado, apresentou maiores valores de energia livre em relação aos Latossolos, tanto em superfície como em profundidade, provavelmente por apresentar carga elétrica negativa em todo perfil.

Nas doses de cádmio variando entre 5 a $200 \mathrm{mg} \mathrm{dm}^{-3}$, os valores de energia livre na camada superficial da Terra Roxa Estruturada estiveram em torno de $11.000 \mathrm{~J} \mathrm{~mol}^{-1}$ na menor concentração de cádmio adicionado e $7.000 \mathrm{~J} \mathrm{~mol}^{-1}$ na maior dose, em profundidade os valores de energia livre foram em torno de $7000 \mathrm{~J} \mathrm{~mol}^{-1}$ e $3000 \mathrm{~J} \mathrm{~mol}^{-1}$ na menor e na maior dose de cádmio adicionado respectivamente.

Os Latossolos apresentaram valores de energia livre semelhantes, com valores médios na camada superficial em torno de $4.000 \mathrm{~J} \mathrm{~mol}^{-1}$ na menor concentração do metal e próximos de $1000 \mathrm{~J} \mathrm{~mol}^{-1}$ na maior dose. Em profundidade, os valores de energia livre foram inferiores, com valores médios de $2.500 \mathrm{~J} \mathrm{~mol}^{-1}$ e $700 \mathrm{~J} \mathrm{~mol}^{-1}$ na menor dose e na maior dose respectivamente.

Em todas as amostras, a $\left(\Delta \mathrm{G}_{0}\right)$ decresceu com o aumento da concentração de cádmio adicionada inicialmente, indicando que quanto mais concentrada a solução menos fortemente o elemento foi adsorvido. Devido à menor energia de 
adsorção, houve decréscimo na porcentagem de cádmio adsorvido à medida que a concentração do elemento em solução aumentou (Alleoni \& Camargo,1998). 


\section{CONCLUSÕES}

- A adsorção de cádmio foi maior em superfície do que em subsuperfície, em todos os solos, devido ao maior teor de matéria orgânica nas camadas superficiais;

- A Terra Roxa Estruturada adsorveu maiores quantidades de cádmio em relação aos Latossolos, por apresentar cargas negativas em todo o perfil;

- Com a elevação do pH, houve expressivo aumento na adsorção de cádmio em todos os solos, tanto nas camadas superficiais como nas camadas subsuperficiais;

- Os parâmetros K e b de Langmuir e $\mathrm{K}$ de Freundlich foram positivamente correlacionados com carbono orgânico, capacidade de troca de cátions (CTC), Retenção de Cátions (RC), Superfície específica (SE), teor de argila, cargas negativas variáveis e cargas negativas permanentes;

- A CTC foi o atributo do solo selecionado por meio de regressão múltipla que teve maior efeito na adsorção de cádmio.

- A capacidade de troca de cátions (CTC) e o pH mostraram-se fatores preponderantes, no controle da adsorção de cádmio nos solos estudados. 


\section{REFERÊNCIAS BIBLIOGRÁFICAS}

AINSWORTH, C.C.; PILON, L.; GASSMAN, P.L.; SLUYS, W.G.V.D. Cobalt, Cadmium, and Lead Sorption to hydrous iron oxide: Residence Time Effect. Soil Science Society of America Journal, v.58, p.1615-1623, 1994.

ALLEONI, L.R.F.; CAMARGO, O.A. Ponto de efeito salino nulo de Latossolos Ácricos. Revista Brasileira de Ciência do Solo, v.18, p.175-180, 1994.

ALLEONI, L.R.F.; CAMARGO, O. A. Solos ácricos: atributos e manejo. Boletim Informativo da Sociedade Brasileira de Ciência do Solo. v.20, p.9-17, 1995.

ALLEONI, L.R.F.; CAMARGO, O.A. Energia livre das reações de adsorção de boro em solos. Revista de Agricultura, v.73, p.319-330, 1998.

ALLOWAY, B.J. Heavy Metals in Soils. Blackie: B. J. Alloway, 1990. 339p.

AMACHER, M.C.; AMACHER, J.K.; SELIM, H.M.; ISKANDAR. I.K. Retention and release of metals by soils-evaluation of several models. Geoderma, v.38, p.131-154, 1986. 
AMARAL SOBRINHO, N.M.B.; COSTA, L.M.; OLIVEIRA, C.; VELLOSO, A.C.X. Metais pesados em alguns fertilizantes e corretivos. Revista Brasileira de Ciência do Solo, v.16, p.271-276, 1992.

AMARAL SOBRINHO, N.M.B.; VELLOSO, A.C.X.; OLIVEIRA, C.; COSTA, L.M. Riscos de contaminação por metais pesados em solo tratado com resíduo siderúrgico. In: CONGRESSO BRASILEIRO DE CIÊNCIA DO SOLO, 25., Viçosa, 1995. Anais. Viçosa: UFV, SBCS, 1995. p.2321-2322.

AMOOZEGAR-FARD, A.; FULLER, W.H.; WARRICK, A.W. An approach to predicting the movement of selected pollution metals in soils. Journal of Environmental Quality. v.13, p.290-297, 1984.

ANDERSON, B.J.;. JENNE, E.A,; CHAO, T.T. The sorption of silver by poorly crystallized manganese oxides. Geochimica et Cosmochimica Acta v.37, p.611-622, 1973.

ANDERSON, P.R.; CHRISTENSEN, T.H. Distribution coefficients of Cd, Co, $\mathrm{Ni}$, and Zn in soil. Journal of Soil Science. v.39, p.15-22, 1988.

ANDERSON, S.J.; SPOSITO, G. Cesium-adsorption method for measuring acessible strutural surface charge. Soil Science Society of America Journal, v.55, p.1569-1576, 1991. 
BACKES, C.A.; McLAREN, R.G.; RATE, A.W.; SWIFT, R.G. Kinetics of cadmium and cobalt desorption from iron and manganese oxides. Soil Science Society of America Journal v.59, p.778-785, 1995.

BARROW, N.J. The description of phosphate adsorption curves. Journal of Soil Science, v.29, p.447-62, 1978.

BARROW, N.J. Modelling the effects of $\mathrm{pH}$ on phosphate sorption by soils. Journal of Soil Science, v.35, p.283-97, 1984.

BARROW, N.J. Reactions with variable-charge soils. Dordrecht: Martinus Nijhoff Publishers, 1987a. 191p.

BARROW, N.J. The effect of phosphate on zinc sorption by a soil. Journal of Soil Science, v.38, p.453-459, 1987b.

BARROW, N.; WHELAN, J. Comparing the effects of $\mathrm{pH}$ on the sorption of metals by soil and by goethite, and on uptake by plants. European Journal of Soil Science, v.49, p.683-692, 1998.

BEATY, R. D.; KERBER, J. D. Concepts, Instrumentation and Techniques in Atomic Absorption Spectrophotometry. Norwalk: Perkin-Elmer Corporation, 1993. 56p.

BELL, L.C.; GILLMAN, G.P. Surface charge characteristics and soil solution composition of highly weathered soils. In: ANDREW, C.S.; KAMPRATH, E.J. (Ed) Mineral nutricion of legumes in tropical and subtropical soils. Melbourne: CSIRO, 1978. p.37-57. 
BENJAMIN, M. M.; LECKIE, J.O. Multiple-site adsorption of $\mathrm{Cd}$. Cu, $\mathrm{Zn}$ and $\mathrm{Pb}$ on amorphous iron oxyhydroxide. Journal Colloid Interface Science, v.79, p.209-221, 1981.

BLEAM, W.F.; McBRIDE, M.B. The chemistry of adsorbed Cu(II) and Mn(II) in aqueous titanium dioxide suspensions. Journal Colloid Interface Science, v.110, p.335-346, 1986.

BOLTON, K.A.; EVANS, L.J. Cadmium adsorption capacity of selected Ontario soils. Canadian Journal of Soil Science, v.76, p.183-189,1996.

BRADY, N.C. Natureza e propriedades dos solos. 6 ed. Rio de janeiro, Freitas Bastos, 1983.647p.

BRADY, N.C. Natureza e propriedades dos solos. Rio de janeiro, Freitas Bastos, 1989.898p.

BRUEMMER,G.W.; GERTH, J.; TILLER, K.G. Reaction kinetics of the adsorption and desorption of nickel, zinc and cadmium by goethite. I. Adsorption and diffusion of metals. Journal of Soil Science, v.39, p.37-52, 1988.

BURNS, R.G. The uptake of cobalt into ferromanganese nodules, soils. and synthetic manganese (IV) oxides. Geochimica et Cosmochimica Acta, v.40, p.95-102, 1976. 
CAMARGO, O.A.; MONIZ, A.C.; JORGE, J.A.; VALADARES, J.M.A.S. Métodos de análise química, mineralógica e física de solos do Instituto Agronômico de Campinas. Campinas: IAC, 1986. 94 p.

CAVAllARO, N.; McBRIDE, M.B. Copper and cadmium adsorption characteristics of selected acid and calcareous soils. Soil Science Society of America Journal, v.42, p.550-556, 1978.

CHRISTENSEN, T.H. Cadmium soil sorption at low concentrations: I. Effect of time, cadmium load, pH, and calcium. Water Air and Soil Pollution, v. 21, p.105-114, 1984a.

CHRISTENSEN, T.H. Cadmium soil sorption at low concentrations: II. Reversibility, effect of changes in solute composition, and effect of soil againg. Water Air and Soil Pollution, v. 21, p.115-125,1984b.

CHRISTENSEN, T.H. Cadmium soil sorption at low concentrations: VIII. Correlation with soil parameters. Water Air and Soil Pollution, v. 44, p.7182,1989 .

CIHACEK, J.L.; BREMMER, J.M. A simplefied ethylene glycol monoethyl ether procedure for assessment of soil surface area. Soil Science Society of America Journal, v.43, p.21-22, 1979.

COWAN, C.E.; ZACHARA, J.M.; SMITH, S.C.; RESCH, C.T. Individual sorbent contributions to cadmium sorption on Ultisols of mixed mineralogy. Soil Science Society of America Journal, v.56, p.1084-1094,1992. 
DAVIS, J.A.; J.O. LECKIE. Surface ionization at the oxide/water interface: II. Surface properties of amorphous iron oxyhydroxide and adsorption of metal ions. Journal Colloid Interface Science v.67, p.90-107, 1979.

DAVIS, J.A. Complexation of trace metals by adsorbed natural organic matter. Geochimica et Cosmochimica Acta, v.48, p.679-691, 1984.

DONER, H. E. Chloride as a factor in mobilities of $\mathrm{Ni}$ (II), $\mathrm{Cu}$ (II) and Cd (II) in soil. Soil Science Society of America Journal, v.42, p.882-885, 1978.

ECHEVERRIA, J.C.; MORERA, M.T.; MAZKIARAN, C. Competitive sorption of heavy metal by soils. Isotherms and fractional factorial experiments. Environmental Pollution, v,101, p.275-284, 1998

ELLIOT, H.A.; LIBERATI, M.R.; HUANG, C. P. Competitive adsorption of heavy metals by soil. Journal of Environmental Quality, v.15, p.214-219, 1986.

EMBRAPA. Centro Nacional de Pesquisa de Solos. SISTEMA BRASILEIRO DE CLASSIFICAÇÃO DE SOLOS. Brasília: EMBR.APA, 1999. 412p.

FAO. Soil map of the world. Wageningem: ISRIC, 1989. 138p. (FAO.UNESCO. Technical Paper, 20).

FERGUSSON, J.E. The heavy elements: Chemistry, environmental impact and health Effects. Glasgow: Pergamon Press, 1990. 614p. 
FILIUS, A.; STRECK, T.; RICHTER, J. Cadmium sortion and desotion in limited topsoils as influenced by $\mathrm{pH}$ : Isotherms and simulated leaching. Journal of Environmental Quality, v.27, n.1, p.12-18, 1998.

FISCHER, L.; ZUR MUHLEN, E.; BRUEMMER, G.W.; NIEHUS, H. Atomic force microscopy (AFM) investigations of the surface topography of a multidomain porous goethite. European Journal of Soil Science v.47, p.329-334, 1996.

FONTES, M.P.F.; SPOSITO, G. Medição da densidade de carga estrutural acessível em Latossolos Brasileiros com diferentes mineralogias. In: XXV CONGRESSO BRASILEIRO DE CIÊNCIA DO SOLO, Viçosa, 1995. Anais. Viçosa: SBCS, 1995. p.292-294.

FONTES, M. P. F. Caracterização da carga elétrica superficial de partículas do solo (compact disc). In: CONGRESSO LATINO AMERICAO DE CIÊNCIA DO SOLO, 13., Águas de Lindóia, 1996. Solo-suelo 96: trabalhos. Piracicaba: SBCS/SLCS, 1996.

FORBES, E. A.; POSNER, M. A .; QUIRK, J. P. The specific adsortion of divalent $\mathrm{Cd}, \mathrm{Co}, \mathrm{Cu}, \mathrm{Pb}$ and $\mathrm{Zn}$ on goethite. Journal of Soil Science, v.27, p.154-166, 1976.

GADDE, R.R.; LAITINEN, H.A. Studies of heavy metal adsorption by hydrous iron and manganese oxides. Analytical Chemistry, v.46, p.2022-2026, 1974.

GARCIA-MIRAGAYA, J.; PAGE. A.L. Influence of ionic strength and inorganic complex formation on the sorption of trace amounts of $\mathrm{Cd}$ by 
montmorillonite. Soil Science Society of America Journal, v.40, p.658-663, 1976.

GARCIA-MIRAGAYA, J.; PAGE, A.L. Influence of exchangeable cation on the sorption of trace amounts of cadmium by montmorillonite. Soil Science Society of America Journal, v.41, p.718-721, 1977.

GARCIA-MIRAGAYA, J.; PAGE, A.L. Sorption of trace quantities of cadmium by soils with different chemical and mineralogical compositium. Water Air and Soil Pollution, v.9, p.289-99, 1978.

GOLDIN, A.; L.M. LAVKULICH. Effects of historical land clearing on organic matter and nitrogen levels in soils of the Fraser Lowland of British Columbia, Canada and Washington. Canadian Journal Soil Science. v.70, p.583-592, 1990.

GRAY, C.W.; McLAREN, R.G.; ROBERTS, A.H.C.; CONDRON, L..M. Sorption de cadmium from some New Zealand soils: effect of $\mathrm{pH}$ and contact time. Australian Journal of Soil Research, v.36, p. 199-216, 1998.

GRAY, C.W.; McLAREN, R.G.; ROBERTS, A.H.C.; CONDRON, L.M. Solubility, sorption and desortion of native and added cadmium in relation to propertie of soils in New Zealand. European Journal of Soil Science., v.50, n.1, p.127-137, 1999.

HAMON, R.E.; MCLAUGHLIN, M.J.; NAIDU, R.; CORRELL, R. Long-term changes in cadmium bioavailability in soil. Environmental Science Technology, v.32, p.3699-3703, 1998. 
HARTER, R.D. Curve-fit errors in Langmuir adsorption maxima. Soil Science Society of America Journal, v 48, p.749-752, 1984.

HEILMAN, M.D.; CARTER, D.L.; GONZALES, C.L. The ethylene glycol monoethyl ether (EGME) technique for determining soil-surface area. Soil Science, v.100, p.409-413, 1965.

HOGG, D.S.; McLAREN, R.G.; SWIFT, R.S. Desorption of copper from some New Zealand Soils. Soil Science Society of America Journal v,57, p.361366, 1993.

HOODA, P.S.; ALLOWAY, B.J. Effects of time and temperature on the bioavailability of $\mathrm{Cd}$ and $\mathrm{Pb}$ from sludge-amended soils. Journal of Soil Science, v.44, p.97-110, 1994.

HOODA, P.S.; ALLOWAY, B.J. Sorption of $\mathrm{Cd}$ and $\mathrm{Pb}$ by selected temperate and semi-arid soils: effects of sludge application and ageing of sludged soils. Water Air and Soil Pollution v.74, p.235-250, 1997.

HOUNG, K.H.; LEE,Y.D, Comparisons of linear and nonlinear Langmuir end Freundlich curve-fit in the study of $\mathrm{Cu}, \mathrm{Cd}$, and $\mathrm{Pb}$ adsorption on Taiwan Soils. Soil Science. v.163, p.115-121,1998.

JAMES, R.O; HEALY T.W. Adsorption of hydrolyzable metal ions at the oxidewater interface. Journal Colloid Interface Science v.30, p.65-81, 1972. 
JARVIS, S.C.; JONES, L.H.P. The contents and sorption of cadmium in some agricultural soil of England and Wales. Journal of Soil Science, v.31, p.469479,1980 .

JI, G. L.; LI, h., Y. Chemistry of variable charge soils. NewYork, 1997, cap.3, p.64-109: Eletrostatic adsortion of cations.

KABATA, P. A.; PENDIAS, H. Trace elements in solis and plants. Boca Raton, Flórida: CRC Press, 1984. 315p.

KING, L.D. Retention of metals by several soils of the Southeastern United States. Journal of Environmental Quality, v.17, n.2, p.239-246, 1988.

KINNIBURGH, D.G.; JACKSON, M.L.; SYERS, J.K. Adsorption of alkaline earth, transition and heavy metal cations by hydrous oxide gels of iron and aluminium. Soil Science Society of America Journal, v.40, p.796-799, 1976.

KORT, N.E.; SKOPP, J.; FULLER, W.H.; NIEBLA, E.E.; ALESII, B.A. Trace element movement inf soils. Influence of soil physical and chemical properties. Soil Science, v.122, p.350-359, 1976.

KOU, S. Concurrent sorption of phosphate and zinc, cadmium, or calcium by a hydrous ferric oxide. Soil Science Society of America Journal v.50, p.1412$1419,1986$.

LEHMANN, R.G.; HARTER, R.D. Assessment of copper-soil bond strength by desorption kinetics. Soil Science Society of America Journal v.48, p.769$772,1984$. 
LEE, S.Z.; ALLEN, H.E.; HUANG, C.P.; SPARKS, D.L.; SANDERS, P.F.; PEIJNENBURG, W. J.G.M. Predicting soil-water partition coefficients for cadmium. Environmental Science Technology v. 30, p.3418-3424, 1996.

LINDSAY, W. L. Chemical Equilibia in Soils. New York: Wiley, 1979. 449p.

LOTHENBACH, B.; FURRER, G.; SCHULIN, R. Immobilization of heavy metals by polynuclear aluminium and montmorillonite compounds. Environmental Science Technology, v. 31, p.1452-1462, 1997.

LUNE, P. V.; ZWART, K.B. Cadmium uptake by crops from the subsoil. Plant and Soil, v.189, p.231-237, 1997.

MALAVOLTA, E. Fertilizantes e seu impacto ambiental: micronutrientes e metais pesados mitos, mistificação e fatos. São Paulo: Produquímica, 1994. $153 \mathrm{p}$.

MARTIN, H. W.; KAPLAN, D. I. Temporal changes in cadmium, thallium, and vanadium mobility in soil and phytoavailability under field conditions. Water Air and Soil Pollution, v.101, p.399-410, 1998.

MATOS, A.T. Fatores de retardamento e coeficientes de dispersão-difusão do zinco, cádmio, cobre e chumbo em solos do município de Viçosa-MG. Viçosa, 1995. 110 p. Tese (Doutorado) - Universidade Federal de Viçosa/UFV). 
MATTIAZZO-PREZZOTO, M. E. Comportamento de cobre, cádmio, crômio, níquel e zinco adicionados a solos de clima tropical em diferentes valores de pH. Piracicaba, 1994. 197 p. Tese (Livre Docência) - Escola Superior de Agricultura "Luis de Queiroz", Universidade de São Paulo.

MAZUR, N.; VELLOSO, A.C.X.; SANTO, G.A . Efeito do composto de resíduo urbano no pH e alumínio trocável em solo ácido. Revista Brasileira de Ciência do Solo, v.7, p.157-159, 1983.

McBRIDE, M. B.; TYLER, L.D.; HOVDE, D.A. Cadmium adsorption by soils and plants as affected buy soil chemical properties. Soil Science Society America Journal, v. 45, p.739-744, 1981.

McKENZIE, R.M. The sorption of some heavy metals by the tower oxides of manganese. Geoderma, v.8, p.29-35, 1972.

McKENZIE, R.M. The adsorption of lead and other heavy metals on oxides of manganese and iron. Australian Journal of Soil Research v.18, p.6173,1980 .

McLAREN, R.G.; LAWSON, D.M.; SWIFT, R.S. Sorption and desorption of cobalt by soils and soil components, Journal of Soil Science, v.37, p.413$426,1986$.

MORTVEDT, J.J. Plant uptake of heavy metals in zinc fertilizers made from industria; by products. Journal of Environmental Quality, v. 14, p.424-427, 1985. 
MORTVEDT, J.J. Cadmium levels in soils and plants from some long term soil fertility experiments in the United States of America. Journal of Environmental Quality, v. 16, p.137-142, 1987.

MULLA, D.J.; PAGE, A..L.; GANJE, T. J. Cadmium accumulations and bioavailability in soils from long term phosphorus fertilization. Journal of Environmental Quality, v. 9, p.408-414, 1980.

NAIDU, R.; BOLAN, N.S.; KOOKANA, R.S.; TILLER, K.G. Ionic-strength and $\mathrm{pH}$ effects on the sorption of cadmium and the surface charge of soils. European Journal of Soil Science, v.45, p.419-429, 1994.

NAIDU, R.; KOOKANA, R.S.; SUMNER, M.E.; HARTER, R. D.; TILLER, K.G. Cadmium sorption and transport in variable charge soils: A review. Journal of Environmental Quality, v.26, p.602-617, 1997.

NAIDU, R.; HARTER, R.D. Effect of different organic ligands on cadmium sorption by and extractability from soils. Soil Science Society America Journal, v. 62, p.644-650, 1998.

NEAL, R. H.; SPOSITO, G. Effects of soluble organic matter and sewage sludge amendments on cadmium sorption by soils at low cadmium concentration. Journal of Environmental Quality, v.142, p.164-172, 1986.

NRIAGU, J.O.; PACYNA, J.P. Quantitative assessment of wordwide contamination of air, water and soils by trace metals. Nature, v.333, p.134-139,1988. 
OLIVEIRA, J.B.; MENK, J.R.F. Latossolos roxos do Estado de São Paulo. Campinas: IAC, 1984. 135 p.

OLIVEIRA, J.B.; PRADO, H. Levantamento pedológico semi-detalhado do Estado de São Paulo: quadrícula de Ribeirão Preto. Campinas: IAC, 1987.

OLIVEIRA, J.B.; PRADO, H. do. Carta pedológica semi-detalhada do Estado de São Paulo: Guaíra; projeto cartográfico IGC. Campinas: IAC, 1991. Escala 1:100.000.

OLSEN, S.R.; WATANABE, F.S. A method to determine a phosphorus adsorption maximum of soils as measured by the Langmuir isoltherm. Soil Science Society of America Journal, v.21, p.144-9, 1957.

OMAE, S. Adsorção de cádmio em solo podzólico vermelho amarelo-orto, glei húmico da região do vale do Ribeira-SP e terra roxa estruturada do município de Piracicaba-SP. Piracicaba, 1984. 4 1 p. Dissertação (M.S.) - Escola Superior de Agricultura "Luís de Queiroz", Universidade de São Paulo.

OMAE, S. Adsorção e deslocamento dos metais pesados, cromo, chumbo e cádmio em alguns solos do estado de São Paulo. Piracicaba, 1986. 184 p. Tese (Doutorado) - Escola Superior de Agricultura "Luís de Queiroz", Universidade de São Paulo.

ORIGIN. Data Analysis and Techinical Graphics. Programa Origin 6.0: Data Analysis and Techinical Graphics (software). Northampton: Micronal software incorporation, 1999. 
PADMANABHAM, M. Adsorption-desorption behaviour of copper (II) at the goethite solution interface. Australian Journal of Soil Research, v.21, p.309-320, 1983.

PANDEYA, S.B. Thermodynamics of adsorption of iron-fulvic acid complexes on soils. Journal Indian Society Soil Science and Plant Analysis. v.38, p.650-657, 1991.

PARDO, M.T.; GUADALIX, M.E. Cadmium sorption by two acid soils as affected by clearing and cultivation. Communications in Soil Science and Plant Analysis, v.26, p.289-302, 1995.

PEIXOTO, R.T. dos G. Surface Chemical properties of oxisols derived from Paraná basalt (Brazil). Ohio, 1995. 188p. Dissertation (Ph. D.) - Ohio State University.

PERSOFF, P.; THOMAS, E. Estimating Langmuir costantes by weighted nonlinar least squares. Soil Science Society of America Journal, v. 52, p.886-889, 1988.

PETRUZZELLI, G.; GUIDI, G.; LUBRANO, L. Ionic strength effect on heavy metal adsorption by soil. Communications in Soil Science and Plant Analysis, v.16, n.9, p.971-86, 1985.

POMBO, L.C.A. Adsorção de cádmio em solos do Estado do Rio Grande do Sul. Revista Brasileira de Ciência do Solo, v.19, n.1, p.19-24, 1995. 
RAIJ, B. V.; PEECH, M. Eletrochemical properties of Some Oxisols and alfisols of the tropics. Soil Science Society of America Proceedings, v.36, p.587593, 1972.

RAIJ, B. V.; SILVA, N.M.; BATAGLIA, O.C.; QUAGgIO, J.A.; HIROCE, R.;CANTARELLA, H.; BELINAZZI Jr., R.; DECHEN, A.R.; TRANI, P.E. Recomendações de adubação e calagem para o Estado de São Paulo. Campinas: IAC, 1985. 107p.

RAIJ, B. V. Propriedades eletroquímicas de solos. In: SIMPÓSIO AVANÇADO DE QUÍMICA E FERTILIDADE DO SOLO, 1, Piracicaba., 1986. Anais. Campinas: Fundação Cargill, 1986, p.9-39.

RATNER-ZOHAR, Y.; BANIN, A.; CHEN, Y. Oven drying as a pretreatment for surface-area determinations of soils and clays. Soil Science Society of America Journal, v.47, p.1056-1059, 1983.

REZENDE, M.; SANTANA, D. P. Uso das relações ki e kr na estimativa da mineralogia para a classificação dos latossolos. In: REUNIÃO DE CLASSIFICAÇÃO, CORRELAÇÃO DE SOLOS E INTERPRETAÇÃO DE APTIDÃO AGRÍCOLA, 3, Rio de janeiro, 1988. Anais. Rio de Janeiro: EMBRAPA, SNLCS, 1988. p.225-232. (EMBRAPA, SNLCS. Documentos, 12).

SAS INSTITUTE. SAS user's guide: release 6.03. Cary, 1988. 1028p. 
SHANI, U.; DUDLEY, L.M.; HANKS, R.J. Model of boron movement in soils. Soil Science Society of America Journal, v.56, p.1365-1370, 1992.

SILVEIRA, M. L. A Adsorção de cobre em latossolos ácricos paulista. Piracicaba, 1999. 91p. Dissertação (M.S.) - Escola Superior de Agricultura "Luiz de Queiroz", Universidade de São Paulo.

SIQUEIRA, C. Eletroquímica dos solos tropicais de carga variável: Efeito da matéria orgânica. Itaguai, 1985. 113 p. Tese (Doutorado) - Universidade Federal Rural do Rio de Janeiro- UFRRJ.

SINGH, M. Retention of added copper by two soils as affected by organic matter, $\mathrm{CaCO}_{3}$ and exchangeable íons. Geoderma, v.5, p.219-227, 1971.

SINGH, S. S. Sorption and release of cadmium in some canadian soils. Canadian Journal of Soil Science, v.59, p.119-30, 1979.

SINGH, D.; McLAREN, R. J.; CAMERON, K.C. Desorption of native and added zinc from a range of New Zealand soil in relation to soil properties. Australian Journal of Soil Research, v.35, p.1253-1266, 1997.

SINGH, A .K.; PANDEYA, S.B. Sorption and release of cadmium-fulvic acid complexes in sludge treated soils. Bioresource Technology, v.66, p.119-127, 1998.

SKOOG, D. A .; LEARY, J. J. Principles of instrumental analysis. Harcourt: Brace College Publishers, $1992.700 p$. 
SMITH, B.H.; EMERSON, W.W. exchangeable aluminium in kaolinite. Australian Journal of soil Research. v.14, p.45-53, 1976.

SPARKS, D.L. Environmental soil chemistry. San Diego: California, 1995.cap.5, p.99-139: Sorption phenomena on soils.

SPOSITO, G. The operational definition of the zero point of the charge in soils. Soil Science Society of America Journal, v.45, p.292-297, 1981.

SPOSITO, G. The Surface Chemistry of Soils. New York: Oxford University Press, 1984. p. 234.

STAHL, R.S.; JAMES, B.R. Zinc sorption by B horizon soils as a function of $\mathrm{pH}$. Soil Science Society of America Journal v.55, p.1592-1597, 1991.

TILLER, K.G.; NAYYAR, V. K.; CLAYTON, P.M. Specific and non-specific sorption of cadmium by soil clays as influenced by zinc and calcium. Australian Journal of Soil Research, v.17, p.17-28, 1979.

TILLER, K.G.; GERTH, J.; BRUEMMER, G. The sorption of Cd, Zn and Ni by soil clay fractions: procedures for partition of bound forms and their interpretation, Geoderma, v.34, p.1-16, 1984a.

TILLER, K.G.; GERTH, J.; BRUMMER, G. The relative affinities of Cd, Ni and $\mathrm{Zn}$, for different soil clay fractions and goethite. Geoderma, v.34, p17-35, 1984b. 
TILLER, K. G. Heavy metal in soils and their environmetal significance. Advances in Soil Science, v. 9, p.113-142, 1989.

TSCHAPEK, M.; TCHEICHVILI, L.; WASOWSKI, C. The point of zero charge (pzc) of kaulinite and $\mathrm{SiO}_{2}+\mathrm{Al}_{2} \mathrm{O}_{3}$ mixtures. Clay Minerals, v.10, p.219229, 1974.

UEHARA, G. Acric properties and their significance to soil classification. In: INTERNATIONAL SOIL CLASSIFICATION WORKSHOP, 8., Rio de Janeiro, 1986. Proceedings. Rio de Janeiro: Embrapa,SNLCS, 1988. p.19-22.

WILKENS, B.J.; LOCK, J.P.G. Acucumulation of cadmium and zinc from diffuse immission on acid sandy soils, as a function of soil composition. Water Air and Soil Pollution, v.48, p.337-346, 1997

YUAN, G.; LAVKULICH, L.M. Sorption behavior of copper, zinc, and cadmium in response to simulated changes in soil properties. Communications in Soil Science and Plant Analysis, v.28, p.571-587, 1997.

ZACHARA, J. M.; SMITH, S.C.; RESCH, C.T.; COWAN, C.E. Cadmium sorption to soil separates containing layer silicates and iron and aluminium oxides. Soil Science Society of America Journal, v. 56, p.1974-1084, 1992.

ZACHARA, J.M.; SMITH, S.C. Edge complexation reactions of cadmium on specimen and soil-derived smectite. Soil Science Society of America Journal, v.58, p.762-764, 1994. 
ZIPER, C.; KOMARNENI, S.; BAKER, D.E. Specific cadmium sorption in relation to the crystal chemistry of clay minerals. Soil Science Society of America Journal, v. 52, p.49-53, 1988. 
APÊNDICE 


\section{A1:Resultados de cádmio adsorvido e estimado pelas equações de Langmuir} e de Freundlich, que originaram as isotermas de adsorção.

Tabela A. Quantidades de Cádmio adicionadas em equilíbrio, adsorvidas e estimadas pelas equações de Langmuir e Freundlich, para amostras do Latossolo Roxo, ao pH natural, coletadas em superficie e em profundidade.

\begin{tabular}{|c|c|c|c|c|c|}
\hline Camada & $\begin{array}{c}\text { Cd } \\
\text { Adicionado }\end{array}$ & $\begin{array}{c}\text { Cd } \\
\text { em equilíbrio } \\
\text { (CE) }\end{array}$ & $\begin{array}{c}\text { Cd } \\
\text { Adsorvido }\end{array}$ & Langmuir & Freundlich \\
\hline & $=\mathrm{m}_{\xi}$ & $\mathrm{dm}^{-3}$ & & $\mathrm{mg} \mathrm{kg}^{-1}$ & \\
\hline \multirow{12}{*}{ Superfície } & 0 & 0,0 & 0,00 & 0,00 & 0,00 \\
\hline & 5 & 1,40 & 35,97 & 18,17 & 45,96 \\
\hline & 10 & 3,19 & 68,10 & 40,55 & 75,20 \\
\hline & 15 & 4,78 & 102,25 & 59.50 & 95,70 \\
\hline & 25 & 9,69 & 153,07 & 114,26 & 146,16 \\
\hline & 50 & 23,42 & 265,83 & 240.21 & 247,80 \\
\hline & 75 & 41,41 & 335,89 & 363,14 & 348,67 \\
\hline & 100 & 57,91 & 420,88 & 448,09 & 426,15 \\
\hline & 125 & 73,05 & 519,50 & 510.18 & 489,70 \\
\hline & 150 & 96,50 & 535,00 & 585.59 & 578,53 \\
\hline & 175 & 115,60 & 594,00 & 633,81 & 644,58 \\
\hline & 200 & 125,60 & 744,00 & 655,55 & 677,40 \\
\hline \multirow{12}{*}{ Profundidade } & 0 & 0,0 & 0,00 & 0,00 & 0,00 \\
\hline & 5 & 2,1 & 29,09 & 14,64 & 32,88 \\
\hline & 10 & 5,3 & 47,00 & 35.88 & 58,03 \\
\hline & 15 & 7,9 & 71,00 & 52.26 & 74,11 \\
\hline & 25 & 13,8 & 111,90 & 86,70 & 104,28 \\
\hline & 50 & 31,9 & 181,00 & 173,16 & 173,99 \\
\hline & 75 & 52,3 & 226.64 & 246.42 & 235,47 \\
\hline & 100 & 71,7 & 282,77 & 300,03 & 285,53 \\
\hline & 125 & 90,1 & 349,00 & 340,71 & 328,10 \\
\hline & 150 & 112,0 & 380,00 & 380.36 & 375,01 \\
\hline & 175 & 137,1 & 379,00 & 416,72 & 424,35 \\
\hline & 200 & 152.0 & 480,00 & 434.92 & 452.01 \\
\hline
\end{tabular}


Tabela B. Quantidades de Cádmio adicionadas, em equilíbrio, adsorvidas e estimadas pelas equações de Langmuir e Freundlich, para amostras da Terra Roxa Estruturada, ao pH natural coletadas em superfície e em profundidade.

\begin{tabular}{|c|c|c|c|c|c|}
\hline Camada & $\begin{array}{c}\text { Cd } \\
\text { Adicionado }\end{array}$ & $\begin{array}{c}\text { Cd } \\
\text { em equilíbrio } \\
\text { (CE) }\end{array}$ & $\begin{array}{c}\text { Cd } \\
\text { Adsorvido }\end{array}$ & Langmuir & Freundlich \\
\hline \multirow{13}{*}{ Superfície } & mg & $\mathrm{dm}^{-3}-$ & $\longrightarrow$ & $\mathrm{mg} \mathrm{kg}^{-1}$ & 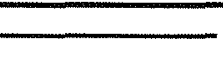 \\
\hline & 0 & 0,0 & 0,00 & 0,00 & 0,00 \\
\hline & 5 & 0,2 & 48,48 & 71,22 & 154,24 \\
\hline & 10 & 0,2 & 98,25 & 81,49 & 168,20 \\
\hline & 15 & 0,2 & 148,45 & 72,43 & 156,86 \\
\hline & 25 & 0,4 & 245,76 & 189,79 & 283,43 \\
\hline & 50 & 1,1 & 489,50 & 425,95 & 480,99 \\
\hline & 75 & 2,1 & 729,23 & 733,99 & 719,44 \\
\hline & 100 & 3,2 & 967,84 & 992,16 & 928,88 \\
\hline & 125 & 4,6 & 1203,80 & 1235,75 & 1151,95 \\
\hline & 150 & 6,4 & 1436,48 & 1457,16 & 1388,52 \\
\hline & 175 & 8,8 & 1662,50 & 1674,79 & 1672,40 \\
\hline & 200 & 11,4 & 1886,34 & 1837,10 & 1940,69 \\
\hline \multirow{12}{*}{ Profundidade } & 0 & 0,0 & 0,00 & 0,00 & 0,00 \\
\hline & 5 & 0,3 & 47,03 & 28,43 & 97,90 \\
\hline & 10 & 0,7 & 93,10 & 64,89 & 151,76 \\
\hline & 15 & 0,9 & 141,25 & 81,36 & 171,74 \\
\hline & 25 & 1,6 & 233,97 & 143,52 & 235,14 \\
\hline & 50 & 5,0 & 450,14 & 384,95 & 424.58 \\
\hline & 75 & 10,5 & 645,48 & 657,38 & 623,19 \\
\hline & 100 & 17,0 & 830,43 & 875,60 & 801,59 \\
\hline & 125 & 25,1 & 999,00 & 1059,43 & 984.04 \\
\hline & 150 & 34,2 & 1158,27 & 1197,80 & 1154,84 \\
\hline & 175 & 44,2 & 1308,50 & 1304,11 & 1320,08 \\
\hline & 200 & 54,6 & 1454,39 & 1384,90 & 1473,19 \\
\hline
\end{tabular}


Tabela C. Quantidades de Cádmio adicionadas, em equilíbrio, adsorvidas e estimadas pelas equações de Langmuir e Freundlich, para amostras do Latossolo Variação Una ácrico, ao pH natural coletadas em superfície e em profundidade.

\begin{tabular}{|c|c|c|c|c|c|}
\hline Camada & $\begin{array}{c}\text { Cd } \\
\text { Adicionado }\end{array}$ & $\begin{array}{c}\text { Cd } \\
\text { em equilíbrio } \\
\text { (CE) }\end{array}$ & $\begin{array}{c}\text { Cd } \\
\text { Adsorvido }\end{array}$ & Langmuir & Freundlich \\
\hline \multirow{13}{*}{ Superfície } & \multicolumn{2}{|c|}{$\mathrm{mg} \mathrm{dm^{-3 }}$} & \multicolumn{3}{|c|}{$\mathrm{mg} \mathrm{kg}^{-1}$} \\
\hline & 0 & 0,0 & 0,00 & 0,00 & 0,00 \\
\hline & 5 & 0,7 & 42,95 & 20,31 & 64,57 \\
\hline & 10 & 2,7 & 73,25 & 73,53 & 127,91 \\
\hline & 15 & 3,9 & 110,90 & 104,14 & 155.30 \\
\hline & 25 & 6,2 & 187,96 & 156,12 & 196,67 \\
\hline & 50 & 16,1 & 339,42 & 328,07 & 319,80 \\
\hline & 75 & 29,0 & 460,44 & 474,83 & 432,31 \\
\hline & 100 & 41,2 & 588,41 & 568,77 & 517,50 \\
\hline & 125 & 62,0 & 630,00 & 675,40 & 638,09 \\
\hline & 150 & 78,5 & 714,69 & 732,39 & 720,07 \\
\hline & 175 & 97,0 & 780,00 & 778,79 & 801,84 \\
\hline & 200 & 114,0 & 859,76 & 812,67 & 871,40 \\
\hline \multirow{12}{*}{ Profundidade } & 0 & 0 & 0 & 0,000 & 0 \\
\hline & 5 & 1,36 & 36,4 & 15,976 & 47,785 \\
\hline & 10 & 2,62 & 73,8 & 30,147 & 66,953 \\
\hline & 15 & 4,61 & 103,9 & 51,381 & 89,537 \\
\hline & 25 & 10,736 & 142,64 & 109,120 & 138,313 \\
\hline & 50 & 25,554 & 244,46 & 214,117 & 216,069 \\
\hline & 75 & 46,617 & 283,83 & 312,576 & 294,371 \\
\hline & 100 & 68,614 & 313,86 & 380,658 & 359,126 \\
\hline & 125 & 85,8 & 392 & 419,438 & 402,886 \\
\hline & 150 & 103 & 466 & 450,003 & 442,588 \\
\hline & 175 & 128,4 & 470 & 484,869 & 495,727 \\
\hline & 200 & 144 & 560 & 501,954 & 525,845 \\
\hline
\end{tabular}




\section{A2: Coeficientes de correlação simples entre os parâmetros das equações de} Langmuir e de Freundlich e os atributos dos solos.

Coeficientes de correlação simples entre os parâmetros estimados pelas equações de Langmuir ( $\mathrm{K} \mathrm{e} \mathrm{b}$ ) e Freundlich (K ).

\begin{tabular}{|c|c|c|c|}
\hline \multirow{3}{*}{ Atributo } & \multicolumn{3}{|c|}{ Coeficiente de Correlação } \\
\hline & \multicolumn{2}{|c|}{ Langmuir } & \multirow{2}{*}{$\begin{array}{c}\text { Freundlich } \\
\text { K }\end{array}$} \\
\hline & $\mathrm{K}$ & $\mathrm{b}$ & \\
\hline Carbono & $0,66^{*}$ & $0,58^{*}$ & $0,64^{*}$ \\
\hline СTC & $0,86^{* * *}$ & $0,88 * * *$ & $0,88^{* * *}$ \\
\hline $\mathrm{RC}$ & $0,71 * *$ & $0,79 * *$ & $0,73 * *$ \\
\hline SE & $0,68^{*}$ & $0,85 * * *$ & $0,75^{* *}$ \\
\hline ki & $0,68^{*}$ & $0,85 * * *$ & $0,75^{* *}$ \\
\hline $\mathrm{kr}$ & NS & $0,70^{*}$ & NS \\
\hline Gibbisita & $-0,69 *$ & $-0,72 * *$ & $-0,73^{* *}$ \\
\hline Argila & $0,67^{*}$ & $0,71^{* *}$ & $0,70^{*}$ \\
\hline$\Delta \mathrm{pH}$ & NS & $-0,69 *$ & NS \\
\hline PESN & NS & $-0.60 *$ & NS \\
\hline Caulinita & NS & $0,61^{*}$ & NS \\
\hline Potencial elétrico & $-0,63 *$ & NS & NS \\
\hline Carga líquida & NS & $0,82 * *$ & $0,64^{*}$ \\
\hline Densidade de carga & NS & $0,62^{*}$ & NS \\
\hline $\mathrm{Fe}_{2} \mathrm{O}_{3}$ (total) & NS & NS & NS \\
\hline $\mathrm{Fe}_{\mathrm{d}}$ (livre) & NS & NS & NS \\
\hline $\mathrm{Fe}_{0}$ (amorfo) & NS & NS & NS \\
\hline $\mathrm{Al}_{2} \mathrm{O}_{3}$ (total) & NS & NS & NS \\
\hline Carga variável & $0,86^{* * *}$ & $0,87 * * *$ & $0,87^{* * *}$ \\
\hline Carga permanente & $0,76^{* *}$ & $0,92 * * *$ & $0,83^{* * *}$ \\
\hline
\end{tabular}




\section{A3: Coeficientes de correlação simples entre os atributos dos solos e a CTCt}

\begin{tabular}{lc}
\hline Atributos do solo & Coeficiente de Correlação \\
& CTC \\
\hline Carbono & $0,83^{* * *}$ \\
$\mathrm{RC}$ & $0,97^{* * *}$ \\
$\mathrm{SE}$ & $0,66^{* *}$ \\
Argila & $0,73^{* *}$ \\
Carga permanente & $0,98^{* * *}$ \\
Carga líquida & $0,73^{* *}$ \\
\hline * $\mathrm{P}<0,05^{* * *} \mathrm{P}<0,01 * * * * \mathrm{P}<0,001$ & \\
\hline
\end{tabular}




\section{A4: Energia livre das reações de adsorção de cádmio $\left(\mathrm{J} \mathrm{mol}^{-1}\right)$}

\begin{tabular}{|c|c|c|c|c|c|c|}
\hline Cádmio & \multicolumn{2}{|c|}{ TE } & \multicolumn{2}{|c|}{ LR } & \multicolumn{2}{|c|}{$\overline{\mathrm{LU}}$} \\
\hline & Sup. & Prof. & Sup. & Prof. & Sup. & Prof. \\
\hline $\mathrm{mg} \mathrm{kg}^{-1}$ & & & $(\mathrm{~J} \mathrm{n}$ & 11) & & \\
\hline 5 & $-11309,33$ & $-7028,37$ & $-3142,38$ & $-2155,71$ & $-4845,38$ & $-3312,90$ \\
\hline 10 & $-10080,88$ & $-6983,55$ & $-2831,19$ & $-1585,91$ & $-3446,93$ & $-3220,25$ \\
\hline 15 & $-10006,27$ & $-6794,43$ & $-2826,02$ & $-1570,31$ & $-3325,52$ & $-2918,17$ \\
\hline 25 & $-9555,32$ & $-6613,00$ & $-2343,35$ & $-1467,83$ & $-3261,51$ & $-2090,70$ \\
\hline 50 & $-8871,01$ & $-5702,15$ & $-1876,22$ & $-1111,55$ & $-2809,33$ & $-1660,22$ \\
\hline 75 & $-8632,24$ & $-4874,32$ & $-1469,06$ & $-889,94$ & $-2353,92$ & $-1176,16$ \\
\hline 100 & $-8501,15$ & $-4389,02$ & $-1351,08$ & $-822,06$ & $-2195,68$ & $-931,66$ \\
\hline 125 & $-8157,07$ & $-3970,91$ & $-1328,64$ & $-809,78$ & $-1734,30$ & $-930,73$ \\
\hline 150 & $-7820,56$ & $-3658,65$ & $-1150,66$ & $-722,57$ & $-1600,62$ & $-929,77$ \\
\hline 175 & $-7409,64$ & $-3406,35$ & $-1091,00$ & $-678,79$ & $-1459,49$ & $-812,52$ \\
\hline 200 & $-7092,84$ & $-3212,92$ & $-1025,60$ & $-603,70$ & $-1389,81$ & $-765,85$ \\
\hline
\end{tabular}

$\mathrm{TE}=$ Terra Roxa Estruturada; $\mathrm{LR}=$ Latossolo Roxo e LU = Latossolo variação Una. 
A5: Quadro de análise de varância com aplicação do Teste $F$, obtido no estudo de Adsorção de cádmio.

\begin{tabular}{lccccc}
\hline Causas da variação & G.L. & S.Q. & Q.M. & F & $\alpha$ \\
Solo (S) & 2 & 101,81 & 52,42 & 472,32 & 0,00001 \\
Profundidade (Prof) & 1 & 235,95 & 235,95 & 2126,05 & 0,00001 \\
pH (pH) & 5 & 479,81 & 95,96 & 864,67 & 0,00001 \\
S*Prof & 2 & 36,95 & 18,48 & 166,49 & 0,00001 \\
S*pH $^{*}$ & 10 & 31,54 & 3,15 & 28,42 & 0,00001 \\
Prof*pH & 5 & 145,14 & 29,03 & 261,56 & 0,00001 \\
S*Prof*pH & 10 & 16,18 & 1,62 & 14,58 & 0,00001 \\
Resíduo & 108 & 11,99 & 0,11 & & \\
\hline Total & 143 & 1062,42 & & & \\
\hline
\end{tabular}

